\title{
Mimicking Hydrogenases: from Biomimetics to Artificial Enzymes
}

Trevor R Simmons, ${ }^{1 \#}$ Gustav Berggren, ${ }^{1,2 \#}$ Marine Bacchi, ${ }^{1}$ Marc Fontecave, ${ }^{1,3}$ and Vincent Artero ${ }^{1 *}$

${ }^{1}$ Laboratoire de Chimie et Biologie des Métaux (CEA / Université Grenoble 1 / CNRS), 17 rue des Martyrs, F38054 Grenoble cedex 9, France

${ }^{2}$ Department of Biochemistry and Biophysics, Stockholm University, Svante Arrhenius väg 16, SE-106 91 Stockholm, Sweden.

${ }^{3}$ Collège de France, 11 place Marcelin-Berthelot, F-75231 Paris cedex 5, France.

\# These two authors have equally contributed to the work

*Corresponding author; vincent.artero@cea.fr

Keywords : hydrogenase, biomimetic chemistry, bioinspired chemistry, artificial enzyme, biohybrids, photocatalysis

\begin{abstract}
Over the last 15 years, a plethora of research has provided major insights into the structure and function of hydrogenase enzymes. This has led to the important development of chemical models that mimic the inorganic enzymatic co-factors, which in turn has further contributed to the understanding of the specific molecular features of these natural systems that facilitate such large and robust enzyme activities. More recently, efforts have been made to generate guest-host models and artificial hydrogenases, through the incorporation of transition metal-catalysts (guests) into various hosts. This adds a new layer of complexity to hydrogenase-like catalytic systems that allows for better tuning of their activity through manipulation of both the first (the guest) and the second (the host) coordination sphere. Herein we review the aforementioned advances achieved during the last 15 years, in the field of inorganic biomimetic hydrogenase chemistry. After a brief presentation of the enzymes themselves,
\end{abstract}


as well as the early bioinspired catalysts, we review the more recent systems constructed as models for the hydrogenase enzymes, with a specific focus on the various strategies employed for incorporating of synthetic models into supramolecular frameworks and polypeptidic/protein scaffolds, and critically discuss the advantages of such an elaborate approach, with regard to the catalytic performances.

\section{Introduction}

Hydrogenases, one of the rare families of organometallic biomolecules, are unique catalysts for both the production of hydrogen from water and its oxidation back to water [1]. While hydrogen is often referred to as one of the post-oil fuels [2], most technological solutions developed so far, such as photoelectrochemical cells or proton-exchange-membrane fuel-cells and electrolyzers, are based on the powerful catalytic properties of platinum metal. Interestingly, hydrogenases have been shown to rival platinum, working at the thermodynamic equilibrium and with high catalytic rates, whilst only employing first row transition metals, nickel and/or iron, as the metal centers of their active sites [3]. As a consequence their use as substitutes for platinum in future technological devices, holds promise for the development of a sustainable and economically viable $\mathrm{H}_{2}$ economy [4]. Unfortunately these enzymes are in general, highly sensitive to oxygen, which represents a major obstacle for their incorporation into technological devices. Intense research is currently devoted to the understanding of the mechanism of enzyme inactivation by $\mathrm{O}_{2}[5,6]$ and to the detailed characterization of the few $\mathrm{O}_{2}$-tolerant hydrogenases, which interestingly catalyze hydrogen cycling in the presence of oxygen [7, 8], thanks to specific iron-sulfur clusters [9] shuttling electrons between the surface and the active site. This aspect is not discussed is this review article, but it is important to note that irreversible oxidative degradation of hydrogenase, is not due to the intrinsic oxygen sensitivity of their dinuclear active site itself. The design of active site analogues, through the biomimetic approach, is thus relevant for the preparation of stable and noble-metal free catalysts for $\mathrm{H}_{2}$ evolution and uptake. In this review article we will first describe how mimics of the active sites of hydrogenases have been developed and progressively refined during the last fifteen years. We will then discuss the various approaches followed to improve the activity of these mimics, through a precise control of their immediate environment by means of supramolecular chemistry, as well as the alternative biosynthetic approach which has recently produced bio-hybrid systems consisting of synthetic mimics of hydrogenase active sites associated with peptides or accommodated within protein cavities. Not only has this opened up new avenues for the development of $\mathrm{H}_{2^{-}}$ 
evolving systems with enhanced activity, it has also recently provided a novel and exciting route for the direct and facile activation of native [FeFe] hydrogenases [10, 11].

\section{Hydrogenases}

Characterization of certain living organisms, such as archaea, bacteria, cyanobacteria and algae, has led to the exciting discovery that hydrogen can be either produced or utilised as a source of low-potential electrons within living cells participating in a global $\mathrm{H}_{2}$ cycle [12]. Bacteria such as Ralstonia eutropha (a facultative chemolithoautotrophic organism) provide a good example of this as they are able to use hydrogen as their sole source of energy [13]. Another example comes from micro-algaea such as Chlamydomonas reinhardtii, which under certain conditions is able to use sunlight to transiently drive the reverse reaction, i.e. extracting electrons from water and using them to reduce protons into hydrogen [14]. Finally, methanogens such as Methanobacterium thermoautotrophicum are able to exploit the reducing power of $\mathrm{H}_{2}$ to produce $\mathrm{CH}_{4}$ from $\mathrm{CO}_{2}$ [15].

This chemical activity is made possible through the expression of fascinating metalloenzymes called hydrogenases $[13,16,17]$. There are two classes of hydrogenmetabolizing enzymes, the $[\mathrm{NiFe}]-$ and $[\mathrm{FeFe}]$-hydrogenases, which catalyse these reactions without any overpotential [18] and at very high rates (one molecule of hydrogenase produces between 1500 to 20000 molecules of $\mathrm{H}_{2}$ per second at $\mathrm{pH} 7$ and $37{ }^{\circ} \mathrm{C}$ in water) $[3,19,20]$. A third class, $[\mathrm{Fe}]$-hydrogenase or Hmd (Hydrogen-forming methylene-tetrahydromethanopterin dehydrogenase), is only found in archaea methanogens and requires the use of a hydride acceptor/donor substrate to react with or produce $\mathrm{H}_{2}$.

\subsection{Structure and activity of [FeFe]-hydrogenases}

Detailed information regarding the structure of this class of enzymes is available from the X-ray structures of the [FeFe]-hydrogenases, in particular from Clostridium pasteurianum and Desulfovibrio desulfuricans originally solved at $1.8 \AA$ and $1.6 \AA$ resolution, respectively $[21,22]$. In all $[\mathrm{FeFe}]-h y d r o g e n a s e s$ the dinuclear Fe centre ([FeFe]) shares a cysteine ligand 
with a standard [4Fe-4S] cluster, thus forming the buried so-called H-cluster, shown in Figure 1. The cysteine bridging the $[4 \mathrm{Fe}-4 \mathrm{~S}]$ and the di-iron sub-clusters is the only protein ligated to the second sub-cluster. A combination of X-ray crystallographic [21, 22] and infrared spectroscopic investigations $[23,24]$ has established that each Fe centre features one $\mathrm{CN}^{-}$and one CO ligand, both in a terminal binding mode, with an additional CO in a bridging mode between both $\mathrm{Fe}$ atoms, in the oxidized $\mathrm{H}_{\mathrm{ox}}$ redox state of the $\mathrm{H}$-cluster (Figure 2). These diatomic molecules are strong $\pi$-acid ligands to $\mathrm{Fe}$, which undergo metal-to-ligand back bonding that stabilizes the low $\mathrm{Fe}$ oxidation states. Accordingly, the $\mathrm{H}_{\mathrm{ox}}$ state can be described as a low spin $\mathrm{S}=1 / 2$ state with a $\mathrm{Fe}(\mathrm{II}) / \mathrm{Fe}(\mathrm{I})$ pair $[25,26]$ and a cubane cluster in the oxidized and diamagnetic $[4 \mathrm{Fe}-4 \mathrm{~S}]^{2+}$ state [27]. Several $\mathrm{H}$-bonds to the $\mathrm{CN}^{-}$ligands are important, as they stabilize a specific orientation of the di-iron subcluster in the active site.
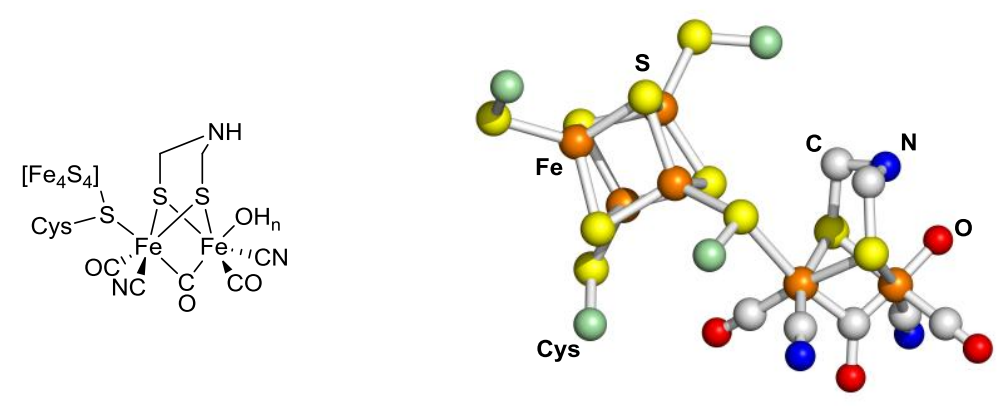

Figure 1. Schematic representation (left) and X-ray crystal structure (right) of the 'H-cluster' in the $H_{o x}$ state, found in [FeFe]-hydrogenase, (PDB code 3C8Y with modification of the bridgehead atom from oxygen to nitrogen).

The coordination sphere is completed by a dithiolate ligand, whose composition has been a matter of debate. It has been proposed, on the basis of the electron density from X-ray crystallographic data, to be ${ }^{-} \mathrm{SCH}_{2} \mathrm{XCH}_{2} \mathrm{~S}^{-}$(xdt), with $\mathrm{X}$ being either nitrogen (an $\mathrm{NH}$ group, adt) oxygen or carbon (an ether or methylene group in odt and pdt, respectively). Because of the potential role of an amine group in proton trafficking, the first alternative was considered as the most likely [28]. Further support for this hypothesis was provided by analysis of ${ }^{14} \mathrm{~N}$ nuclear quadrupole and hyperfine interactions of the H-cluster determined by advanced EPR spectroscopy [29-31]. However, this conundrum was finally solved by Berggren et al.[10], 
who showed that upon maturation of apo-HydA with complexes bearing the 3 alternative bridgeheads, only the $\mathrm{NH}$ bridged hybrid enzyme gave spectroscopic data and catalytic activity in line with the naturally occurring [FeFe]-hydrogenase.

In $[\mathrm{FeFe}]-h y d r o g e n a s e s$ from green-algae including Chlamydomonas reinhardtii, Scenedesmus obliquus and Chlorella fusca, the protein only contains the catalytic H-cluster. These enzymes thus represent the simplest forms of $[\mathrm{FeFe}]$-hydrogenases yet identified. However, $[\mathrm{FeFe}]$-hydrogenases more generally contain accessory [4Fe-4S] and [2Fe-2S] ferredoxin-like clusters that function as electron-transfer centres, electronically connecting the active site to the protein surface. These redox partners can either provide electrons for hydrogen generation or capture them for use as reducing power by the cell.

Combination of crystallographic and spectroscopic data has provided a rather clear view of the enzymatic mechanism (Figure 2). In the $\mathrm{H}_{\mathrm{ox}}$ state, the distal $\mathrm{Fe}$ is in an octahedral coordination environment, with two thiolates from the bridging ligand, two CO ligands (one terminal and one bridging), a terminal $\mathrm{CN}^{-}$ligand and what is thought to be an exchangeable $\mathrm{OH}_{n}$ ligand $(n=1,2)[13,32]$. Upon one-electron reduction, the $\mathrm{H}_{\mathrm{red}}$ state is generated, with the cubane subcluster still in the oxidized state, the di-iron subcluster in the $\mathrm{Fe}(\mathrm{I}) / \mathrm{Fe}(\mathrm{I})$ state, with the distal iron in a square pyramidal geometry bearing a free coordination site [33]. The formation of $\mathrm{H}_{\text {red }}$ from $\mathrm{H}_{\mathrm{ox}}$ is a proton-coupled electron transfer process but the location of the proton is still not identified. Very recently a third paramagnetic redox state, $\mathrm{H}_{\text {sred }}$ ('superreduced') has been experimentally observed and characterized by EPR and FTIR spectroscopy [34]. $\mathrm{H}_{\text {sred }}$ contains one more electron than $\mathrm{H}_{\mathrm{red}}$, which is located on the [4Fe$4 \mathrm{~S}]$ cluster, and is characterized by a $\mathrm{Fe}(\mathrm{I}) / \mathrm{Fe}(\mathrm{I}) /[4 \mathrm{Fe}-4 \mathrm{~S}]^{+}$configuration. It is suggested that $\mathrm{H}_{\text {sred }}$ forms part of the catalytic cycle as an additional intermediate [34, 35]. 


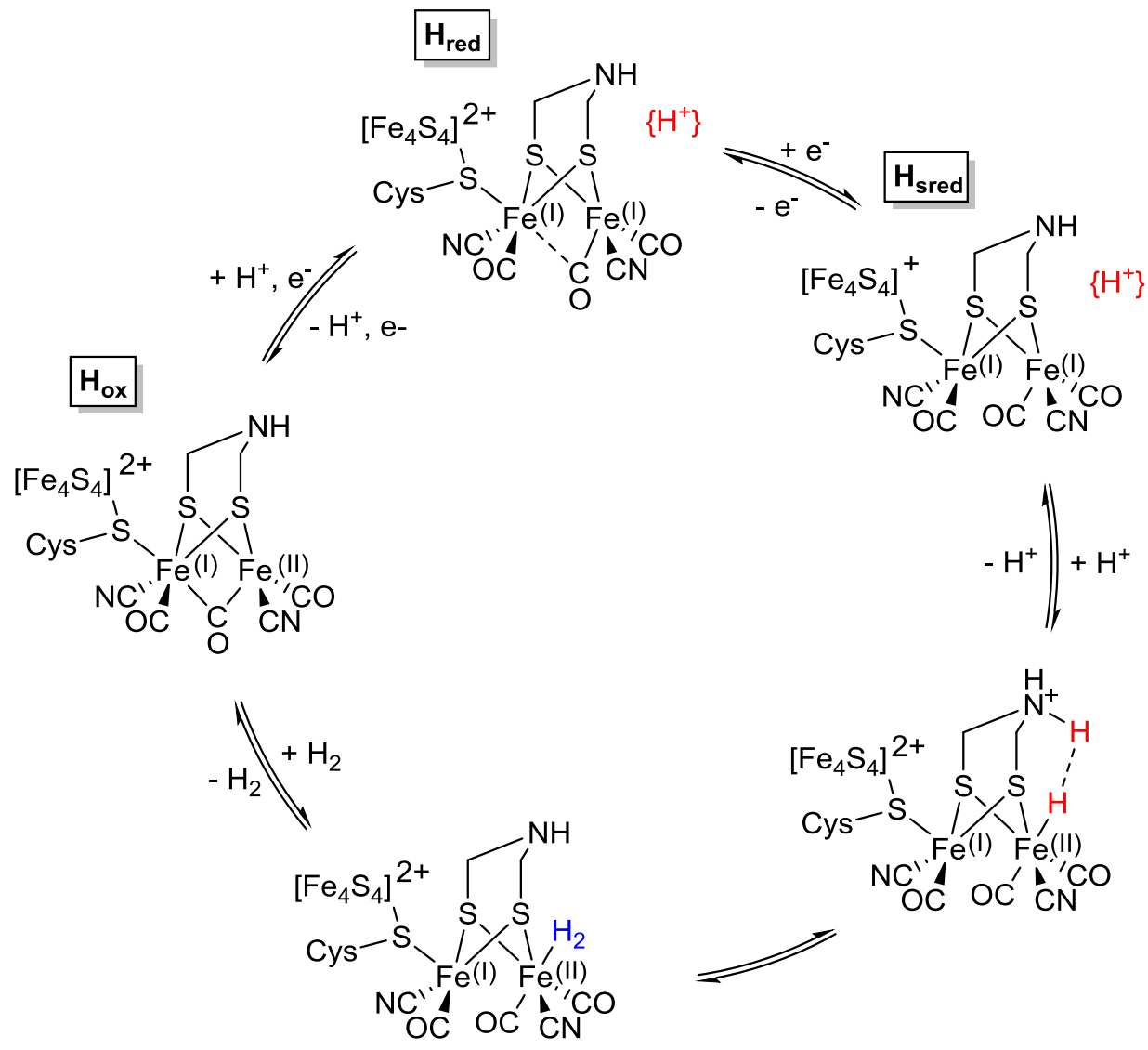

Figure 2. Postulated catalytic mechanism for reversible $\mathrm{H}^{+}$reduction by [FeFe]hydrogenases, including the recently characterised $H_{\text {sred }}$ state. The location of the proton in the $H_{\text {red }}$ and $H_{\text {sred }}$ state is undetermined. Adapted from ref [34].

It was thus proposed, on this basis, that $\mathrm{H}_{2}$ oxidation, catalysed by [Fe-Fe]hydrogenases, proceeds via initial binding of $\mathrm{H}_{2}$ to the exchangeable/free coordination site of $\mathrm{H}_{\mathrm{ox}}$, followed by heterolytic cleavage of the $\mathrm{H}-\mathrm{H}$ bond assisted by the bridgehead amine function, and finally transfer of two individual electrons from the Fe-bound hydride to the [4Fe-4S] cluster and the distal $\mathrm{Fe}$ of the $[\mathrm{FeFe}]$ subsite. Ejection of the protons and the electrons from $\mathrm{H}_{\text {sred }}$ regenerates $\mathrm{H}_{\mathrm{ox}}$ to complete the catalytic cycle. Each step is reversible, and as such proton reduction to $\mathrm{H}_{2}$ is proposed to use the same catalytic steps and intermediates, but in the opposite direction. 


\subsection{Structure and activity of [NiFe]-hydrogenases}

Structural characterisation of $[\mathrm{NiFe}]-h y d r o g e n a s e s$ from Desulfovibrio gigas, $D$. fructosovorans, D. vulgaris and D. desulfuricans, revealed that these enzymes consist of two subunits (Figure 3) [36, 37], The small unit contains three aligned iron-sulphur clusters, a [4Fe-4S] cluster located $13 \AA$ away from the active site, a distal [4Fe-4S] cluster close to the surface of the protein, and a [3Fe-4S] cluster half-way between the two [4Fe-4S] units. Together they form part of an electron transfer pathway between a redox protein partner at the surface and the hetero-bimetallic $\mathrm{Ni}-\mathrm{Fe}$ active centre, which lies buried within the large subunit. In the as-isolated oxidized, and thus inactive form, the $\mathrm{Ni}$ (III) ion features a strongly distorted square pyramidal geometry. The four thiolate ligands are provided by cysteinate residues, two of which are terminal and two that are bridging between the nickel and iron centres. The Fe(II) ion is further ligated by two cyanide ions and one carbon monoxide ligand, as confirmed by FTIR spectroscopic studies. The CO ligand is situated in a hydrophobic pocket while the $\mathrm{CN}^{-}$ligands interact with the protein through hydrogen bonds. In the oxidized forms such as the $\mathrm{Ni}-\mathrm{A}$ and $\mathrm{Ni}-\mathrm{B}$ states, an oxygenated ligand (peroxide or hydroxide respectively) forms a third bridge between nickel and iron [38]. These inactive states can be converted into the active species Ni-SI (vide infra), upon a one-electron reduction.
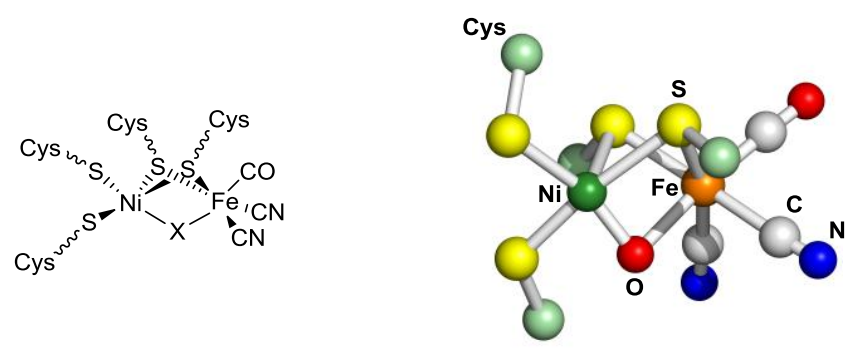

Figure 3. Schematic representation (left) and X-ray crystal structure (right) of the [NiFe]hydrogenase $(P D B$ code $1 \mathrm{WUJ})$ active site in the inactive $\mathrm{Ni}-\mathrm{A}\left(\mathrm{O}=\mathrm{X}=\mathrm{HOO}^{-}\right)$and $\mathrm{Ni}-\mathrm{B}(\mathrm{O}$ $\left.=X=H O^{-}\right)$state. 
Several $\mathrm{H}_{2}$ uptake mechanisms have been proposed for [NiFe] hydrogenases but a consensus has yet to be reached [39]. One possible mechanism (Figure 4) involves an initial so-called Ni-SI form, containing a $\mathrm{Ni}$ (II) species with only two cysteinate bridges. $\mathrm{H}_{2}$ reacts with Ni-SI to produce an EPR-silent form called Ni-R. Three possible structures have been proposed for the Ni-R state. The first two involve $\mathrm{H}_{2}$ binding to nickel or iron, with a preference for the former based on the following considerations: (i) the $\mathrm{H}_{2}$ transport channel is directly connected to the nickel centre rather than to iron [40]; (ii) exogenous $\mathrm{CO}$, a competitive inhibitor of $\mathrm{H}_{2}$, has been shown to bind to nickel [41-43] and (iii) long-elusive $\mathrm{H}_{2}$ binding to $\mathrm{Ni}^{\mathrm{II}}$ centres has recently been documented [44]. It is also possible that heterolytic cleavage of $\mathrm{H}_{2}$ via proton abstraction, presumably by a terminal cysteinate ligand of Ni [45] occurs at the Ni-R stage [46]. Subsequent one-electron oxidation generates the paramagnetic $\mathrm{Ni}-\mathrm{C}$ state [47]. As shown by ENDOR and HYSCORE spectroscopy [48-51], the Ni-C state contains a bridging hydride between nickel and iron. A second one-electron oxidation is followed by release of the former hydride ligand as a proton, regenerating the Ni-SI form and thus closing the catalytic cycle. Throughout this cycle the iron centre remains in the low-spin $\mathrm{Fe}(\mathrm{II})$ configuration, a state favoured by the high-field $\mathrm{CO}$ and $\mathrm{CN}^{-}$ligands, whilst the nickel centre switches between the Ni(III) (in Ni-C) and $\mathrm{Ni}$ (II) (in Ni-SI and Ni-R) oxidation states. As with the $[\mathrm{FeFe}]$-hydrogenase, it is assumed that $\mathrm{H}_{2}$ production occurs through the same pathways in the reverse direction. 


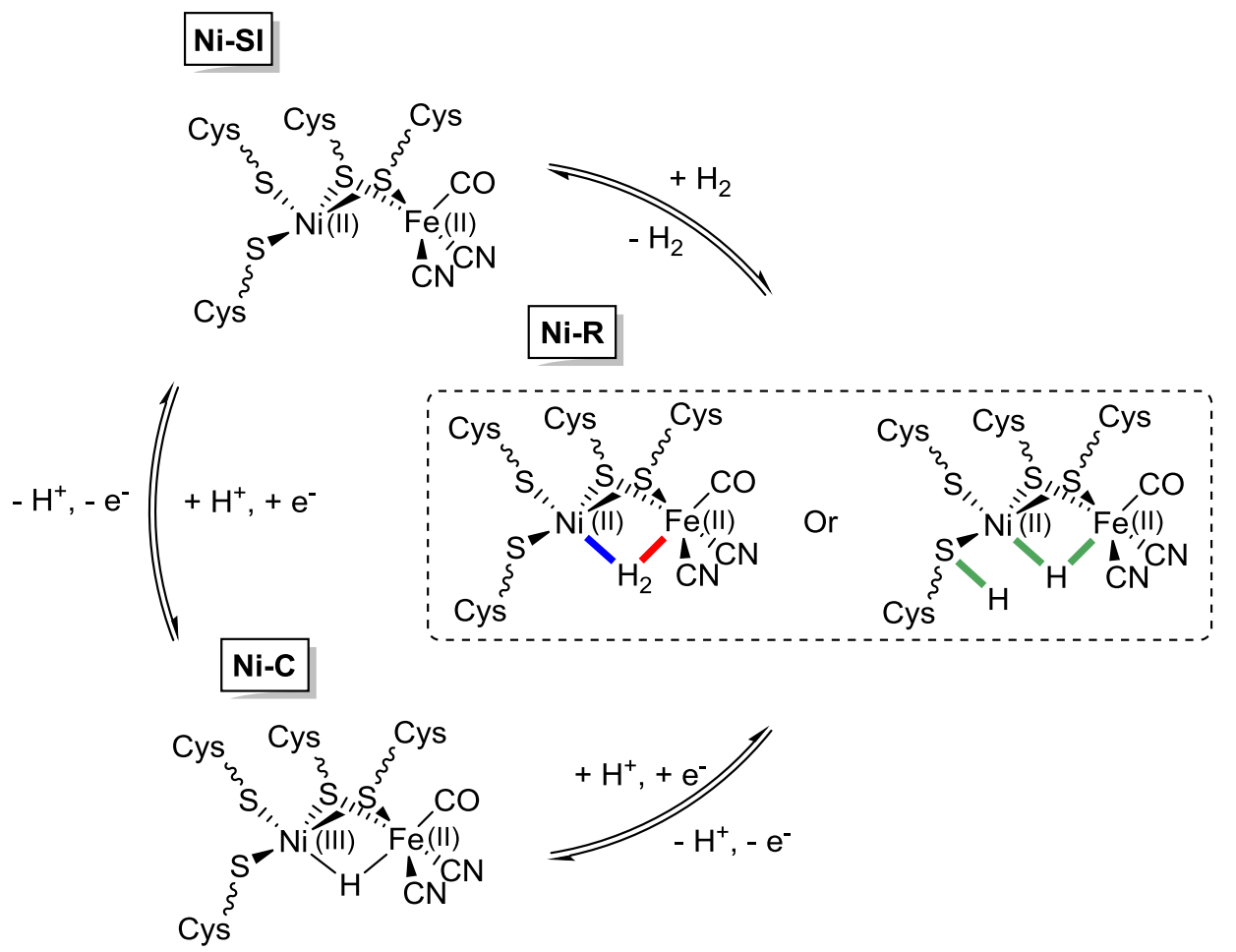

Figure 4. Postulated catalytic mechanism for reversible $\mathrm{H}_{2}$ oxidation by [NiFe]hydrogenases, with the three proposed structures for structurally uncharacterised Ni-R state including two possible modes of $\mathrm{H}_{2}$ binding shown in red $\left(\mathrm{Ni}-\mathrm{H}_{2}\right)$ and blue $\left(\mathrm{Fe}-\mathrm{H}_{2}\right)$ (dashed box). Adapted from ref [52].

\subsection{Structure and activity of [Fe]-hydrogenases}

Hydrogenases from the third class, which are only found in methanogens, had long been thought to be purely bio-organic catalysts, and as such were initially called metal-free hydrogenases [15]. It is now well known that these enzymes in fact contain an organometallic mono-iron active site, and as a consequence are now referred to as either [Fe]-hydrogenase (not to be mistaken with $\mathrm{Fe}$-only hydrogenase, the previous name for [FeFe]-hydrogenase), iron-sulphur cluster-free hydrogenase or Hmd for Hydrogen-forming methylenetetrahydromethanopterin dehydrogenase. This last denomination correctly accounts for the activity of this class of hydrogenases that heterolytically split $\mathrm{H}_{2}$ into a hydride $\left(\mathrm{H}^{-}\right)$and a proton, with the hydride transferred to the carbocation containing substrate, methenyltetrahydromethanopterin (methenyl- $\mathrm{H}_{4} \mathrm{MPT}^{+}$), (Figure 5), yielding methylenetetrahydromethanopterin (methylene- $\left.\mathrm{H}_{4} \mathrm{MPT}\right)$. In contrast to $[\mathrm{FeFe}]-$ and $[\mathrm{NiFe}]-$ 
hydrogenases, to which they are not phylogeneticaly related, [Fe]-hydrogenases do not catalyse the splitting of $\mathrm{H}_{2}$ into protons and electrons. In addition, they do not catalyse a H/D exchange reaction at a significant rate unless methylene- $\mathrm{H}_{4} \mathrm{MPT}$ or methenyl- $\mathrm{H}_{4} \mathrm{MPT}^{+}$is present [53].

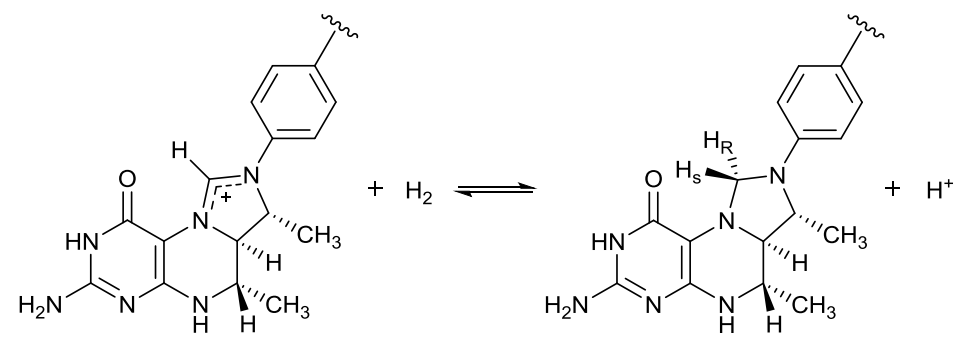

Figure 5. Schematic of the reversible heterolytic splitting of $\mathrm{H}_{2}$ by $\mathrm{Hmd}$, showing a hydride stereospecifically transferred into the pro- $R$ site of methenyl- $\mathrm{H}_{4} M P T^{+}$to yield methylene$H_{4} M P T$ plus a proton.

Structural determination of the active site has been achieved in three successive steps by the group of Shima and Thauer. First, a low molecular mass cofactor could be isolated and was shown to be associated with one tightly bound iron ion [54]. Both the enzyme and the isolated cofactor were found to be light-sensitive. The structure of the light-inactivated cofactor was shown in 2004 , to be a 2-pyridone derivative bearing a pendant carboxylate function [55]. In a second step, IR spectroscopy revealed that an iron dicarbonyl moiety was bound to the cofactor in its active state [56]. Third, a crystal structure could be obtained showing that iron was bound to the nitrogen atom of the 2-pyridone cofactor [57]. Coordination of a thiolate function of the C176 cysteine residue was later confirmed [58] along with the cis-coordination of two carbonyl ligands. A fuller picture of the iron coordination sphere was eventually achieved with the crystal structure of the C176A mutated $[\mathrm{Fe}]$-hydrogenase (Figure 6). In the crystal structure exogenous dithiothreitol was found to act as a bidentate ligand towards the iron centre, replacing both the thiolate function (C176 in the native enzyme) and a labile coordination site, where $\mathrm{H}_{2}$ is likely activated. The coordination sphere of $\mathrm{Fe}$ is completed by an acyl $(-\mathrm{C}(=\mathrm{O})-\mathrm{R})$ ligand, a reduced form of the carboxylate residue found in the light-inactivated cofactor [59]. The site for $\mathrm{H}_{2}$ binding has 
recently been identified through the crystal structure determination of an isocyanide-inhibited form of the [Fe]-hydrogenase, since kinetic studies have suggested that $\mathrm{H}_{2}$ and isocyanide bind to the same ligation site [60]. The structure showed that this site is located trans to the acyl ligand [61]. In addition, the strong interaction observed between the bound isocyanide molecule and the pyridinol hydroxylate group (deprotonated form) in the crystal structure, suggests that this group also affects the chemistry of $\mathrm{Fe}$-bound $\mathrm{H}_{2}$, perhaps acting as a "pendant" base, as discussed earlier for adt ${ }^{2-}$ and terminal cysteine ligands in the enzymatic mechanism of $[\mathrm{FeFe}]$ and $[\mathrm{NiFe}]$-hydrogenases.
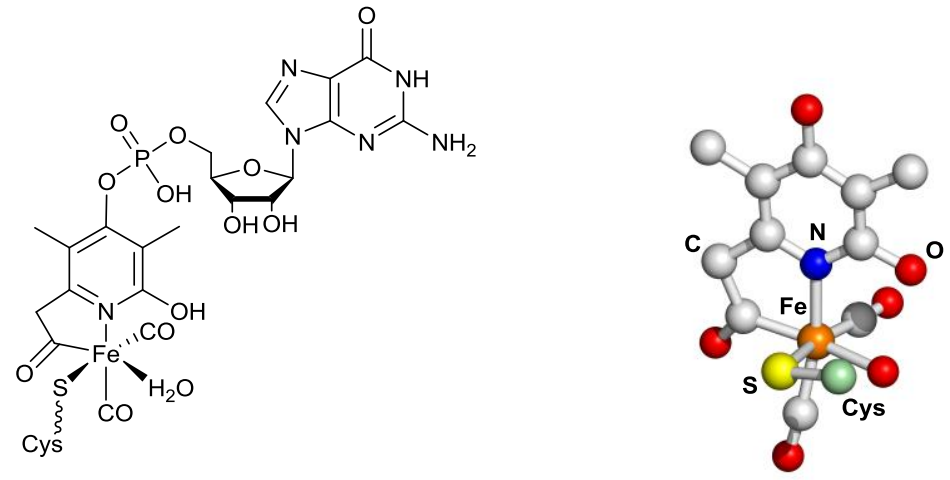

Figure 6. Schematic representation (left) of the [Fe]-hydrogenase active site with the Hmd cofactor, and the X-ray crystal structure (right) of the mono-iron complex obtained from the cysteine 176 mutant (PDB code 3H65).

The iron centre remains EPR-silent throughout the enzymatic cycle and is now thought to be a low spin $\mathrm{Fe}$ (II) centre acting as a Lewis base for $\mathrm{H}_{2}$ coordination and activation. The general catalytic mechanism is now understood as follows: first, methenyl- $\mathrm{H}_{4} \mathrm{MPT}^{+}$binds to the enzyme, which induces a conformational change from an open to a closed form of the enzyme. In this latter form, the carbocationic site of the substrate is located close to the iron atom. Hydrogen then binds to the iron atom of the active site trans to the acyl ligand. Heterolytic cleavage of the $\mathrm{H}_{2}$ molecule likely occurs at this point, and whilst the intimate mechanism of this step remains unclear, it is believed that the coordinated thiolate ligand acts 
as a base in the process, a hypothesis made by comparison with heterolytic $\mathrm{H}_{2}$ cleavage at the active site of [NiFe]-hydrogenase [62]. The oxygen atom of 2-pyridone, which exhibits phenolate character in one of its mesomeric forms, is another possible proton acceptor site during $\mathrm{H}_{2}$ cleavage [63]. The substrate is the final acceptor of the hydride ligand while the proton is rapidly exchanged with bulk water.

\section{Biomimetic catalysts}

\subsection{Models of the active site of [FeFe]-hydrogenases}

\subsection{1. $\quad$ First generation of $[\mathrm{FeFe}]-m i m i c s$}

Long before the structural elements of [FeFe]-hydrogenases' active subsite were known, the preparation of analogous dithiolate-bridged hexacarbonyl diiron complexes was reported by Reihlen et al., describing the synthesis of $\left[(\mu-\mathrm{SEt})_{2} \mathrm{Fe}_{2}(\mathrm{CO})_{6}\right](\mathbf{1})$ as early as 1929 [64].

Upon structural elucidation of the H-cluster in 1998-1999 [21, 22], the striking similarity of the $2 \mathrm{Fe}$ subsite to the propanedithiolate (pdt) bridged diiron complex $[(\mu-$ pdt) $\left.\mathrm{Fe}_{2}(\mathrm{CO})_{6}\right]$ (2) previously reported by Seyferth [65], no doubt inspired the three independent groups of Pickett, Rauchfuss and Darensbourg, to replace two CO with two cyanide ligands to give the water-soluble dianion, $\left[(\mu-\mathrm{pdt}) \mathrm{Fe}_{2}(\mathrm{CO})_{4}(\mathrm{CN})_{2}\right]^{2-}$ (3) (Figure 7) [66-68].

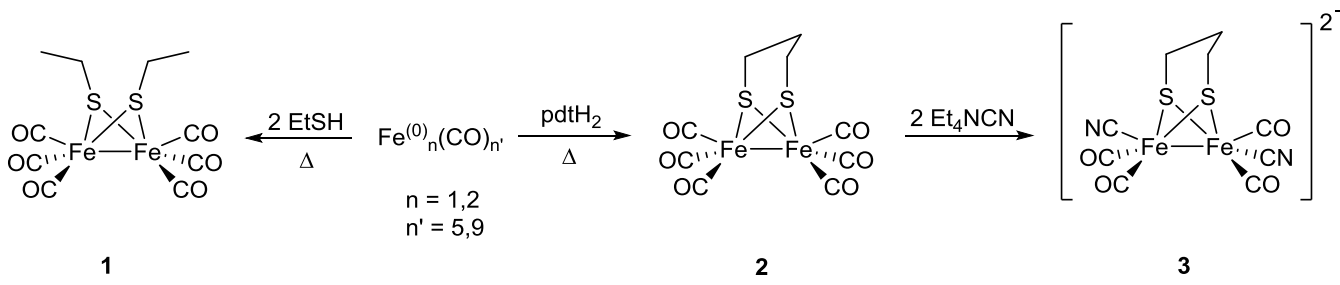

Figure 7. Synthetic scheme for the preparation of $\left[(\mu-\mathrm{SEt})_{2} \mathrm{Fe}_{2}(\mathrm{CO})_{6}\right](1)$ [64], and the precursor diiron hexacarbonyl complex (2) utilised en-route to the first true [FeFe]-model, $\left[(\mu-p d t) \mathrm{Fe}_{2}(\mathrm{CO})_{4}(\mathrm{CN})_{2}\right]^{2-}(3)$ [66-68]. 
Although the identity of the bridgehead atom of the natural subsite has now been confirmed as a secondary amine [10], the ambiguity of its identity at that time led to the preparation of related $[2 \mathrm{Fe}]$-units bearing adt (azadithiolate $\left.=\left[\left(\mathrm{SCH}_{2}\right)_{2} \mathrm{NR}\right]^{2-}\right)(\mathbf{5 - 6})[69]$ and odt $\left(\right.$ oxodithiolate $\left.=\left[\left(\mathrm{SCH}_{2}\right)_{2} \mathrm{O}\right]^{2-}\right)($ 7-8) $[69-71]$ derivatives of the pdt bridge (Figure 8).

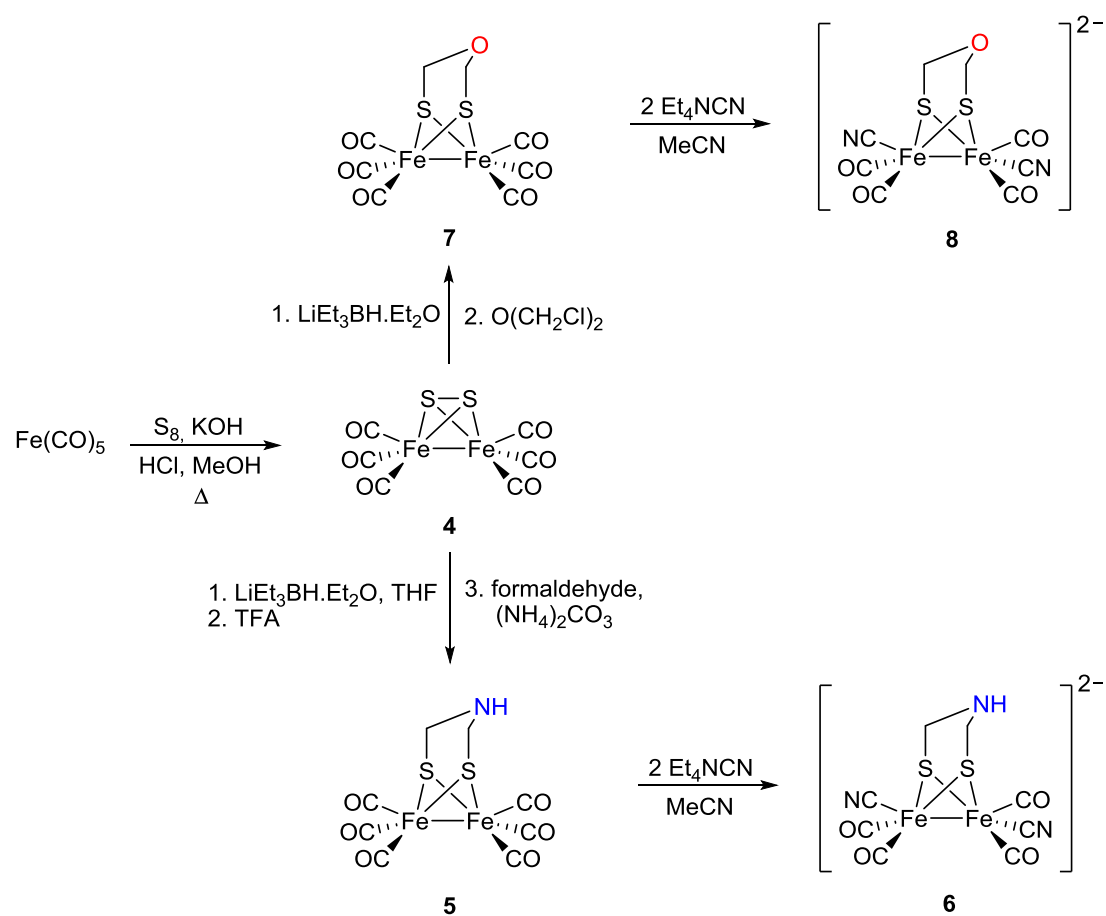

Figure 8. Scheme for the preparation of [FeFe]-subsite analogues bearing naturally relevant adt (5-6) and alternative odt (7-8) bridging groups, with their alternate bridgeheads highlighted in blue and red respectively.

These early models appear to have had a profound effect on the chemical community, as over the last two decades a plethora of wide ranging [FeFe]-hydrogenase mimics have been reported, with over 300 novel systems described [33, 72].

Much of this work has focused on preparing subsites that mimic the natural enzyme's key features such as a bridging $\mathrm{CO}$ [73-77], formation of mixed valent $\mathrm{Fe}(\mathrm{II})-\mathrm{Fe}(\mathrm{I})$ systems reproducing the 'rotated state' of the enzyme [78-85], isolation of stable, biologically relevant terminal hydride species [86-88] and attachment to a synthetic $\mathrm{Fe}_{4} \mathrm{~S}_{4}$ cubane, to give a full $\mathrm{H}$ - 
cluster model (28, Figure 18) [89]. However, many of the compounds that are closest to resembling the natural subsite in terms of valency and oxidation state of the iron metal centre, make use of abiological phosphine or carbene ligands. Furthermore they tend to electrocatalytically reduce protons at large overpotentials, cycling through the $\mathrm{Fe}(\mathrm{I})-\mathrm{Fe}(\mathrm{I}) /$ $\mathrm{Fe}(\mathrm{I})-\mathrm{Fe}(0)$ levels as opposed to the natural $\mathrm{Fe}(\mathrm{II})-\mathrm{Fe}(\mathrm{I})[33,72]$.

\subsubsection{Second generation models: modification of the bridging group}

Whilst the interest in [FeFe]-model systems continues unabated, with close to 100 new papers in the last 5 years alone, the vast majority of this work focuses on exploratory alteration of the bridging group, with limited success in overcoming key issues, such as large overpotential requirements for $\mathrm{H}^{+}$reduction, intrinsic for many [FeFe]-mimics. Nonetheless, interesting systems bearing novel features have been developed, which may benefit the design of any future catalytic systems.

The catalogue of bridgehead groups has been extended by recent work to include Se [90, 91] and $\mathrm{Si}$ [92-94] bridgeheads, whilst the bridging sulphur atoms have been replaced with $\mathrm{Te}$ in isolation [95-97] or combination with other chalcogens [98].

The effect of using higher group chalcogens to replace the bridging dithiolates has recently been explored by groups including Hou and Weigand, which demonstrate contrasting effects of this modification on electrocatalytic $\mathrm{H}^{+}$reduction. Hou et al. describe the synthesis of an $[\mathrm{FeFe}]-m i m i c$ containing a phenyl amine, diselenolate bridge $[(\mu$ $\left.\left(\mathrm{SeCH}_{2}\right)_{2} \mathrm{NC}_{6} \mathrm{H}_{4} \mathrm{CH}_{3}\right) \mathrm{Fe}_{2}(\mathrm{CO})_{6}$ ] which is an active catalyst for $\mathrm{H}^{+}$reduction using $p$ toluenesulfonic acid (HOTs) [99]. When compared to its dithiolate bridge derivative, the reduction potentials for the $\mathrm{Fe}(\mathrm{I})-\mathrm{Fe}(\mathrm{I})$ to $\mathrm{Fe}(\mathrm{I})-\mathrm{Fe}(0)$ process are almost identical at $-1.50 \mathrm{~V}$ vs. $\mathrm{Ag} / \mathrm{AgCl}$, yet the diselenolate bridged species shows a slightly larger increase in current, indicative of higher catalytic activity. Contrastingly, when Weigand and co-workers carried out a comparative study of water soluble dithiolate and diselenolate bridged species $[(\mu$ $\left.\left.\left(\mathrm{ECH}_{2}\right)_{2} \mathrm{CH}_{2} \mathrm{R}\right) \mathrm{Fe}_{2}(\mathrm{CO})_{6}\right](\mathrm{R}=$ tetra- $O$-acetyl- $\beta$-D-glucopyranoside, $\mathrm{E}=\mathrm{S} / \mathrm{Se})$ in acetic acid and water, the diselenolate species shows lower catalytic activity towards $\mathrm{H}_{2}$ evolution than 
its the dithiolate equivalent, although it does exhibit improved robustness in water under reductive conditions, relative to its dithiolate derivative.

One strategy for designing diiron model systems with redox properties closer to the thermodynamic potential for $\mathrm{H}^{+}$reduction is inclusion of a suitably substituted aromatic dithiolato bridgehead, as highlighted by a recent study by Felton and co-workers [100]. The $\left[(\mu\right.$-bdt $\left.) \mathrm{Fe}_{2}(\mathrm{CO})_{6}\right]\left(\mathrm{bdt}=\right.$ benzenedithiolate, $\left.\left[(\mathrm{S})_{2} \mathrm{C}_{6} \mathrm{H}_{4}\right]^{2-}\right)$ type diiron system, bearing benzene rings highly substituted with electron withdrawing groups such as chloride were prepared, analogous to earlier work from the Ott group [101]. The catalytic potentials and efficiencies of these and related systems were compared and it appeared that increasing the number of electron-withdrawing groups lowers the potential for catalysis (up to $150 \mathrm{mV}$ ) but compromises the catalytic efficiency in terms of turnover frequency.

\subsubsection{Variation of ligands: from cyanide to abiological phosphines and/or carbenes}

Whilst the first generation of cyanide containing [FeFe]-mimics fulfilled a structural requisite, it soon became apparent that use of cyanide outside of the protective protein environment presented difficulties, somewhat highlighted by the fact that new reports of cyanide ligated systems are in very short supply. Single substitution of a CO from 2 with cyanide gives an electron rich diiron complex that can be protonated, although the preferred site is the $\mathrm{CN}^{-}$ligand itself [102]. Disubstitution gives the highly reactive dianion 3 which upon protonation results in sub-stoichiometric $\mathrm{H}_{2}$ evolution with subsequent decomposition of the compound $[102,103]$.

Since this early work, much use has been made of surrogate ligands, which are said to approach the electron donating properties of cyanide, but without the inherent complications, including biologically relevant thioether groups, isocyanides, and to a larger extent more abiological ligands such as carbenes, amines, and phosphines [33]. Importantly, the use of these alternative ligands has allowed for key aspects of the natural subsite to be replicated, such as isolation of a terminal hydride species, discussed in section 3.1.6.

Another important feature of the natural enzyme diiron site is the $\mathrm{H}_{2} \mathrm{O}$ molecule or hydroxide ion, coordinated to the $\mathrm{Fe}$ distal to the $[4 \mathrm{Fe}-4 \mathrm{~S}]$ cubane, which is believed to play an 
important protective role in the $\mathrm{H}_{\mathrm{ox}}{ }^{\text {air }}$ state of the enzyme [13, 32]. Surprisingly, this feature has only very recently been replicated by Liu and co-workers by addition of a phenol functionality connected to the bridge group of a diiron hexacarbonyl system to give [ $(\mu$ $\left.\left.\mathrm{SCH}_{2}\right)_{2} \mathrm{CMe}\left(\mathrm{CH}_{2}-o-\mathrm{C}_{6} \mathrm{H}_{4} \mathrm{OH}\right) \mathrm{Fe}_{2}(\mathrm{CO})_{6}\right]$ (9) [104, 105]. Upon deprotonation of the phenol group of 9 with $\mathrm{NaH}$, the phenolate oxygen coordinates to an iron centre with release of a $\mathrm{CO}$ ligand to give the pentacarbonyl species $\left[\left(\mu-\mathrm{SCH}_{2}\right)_{2} \mathrm{CMe}\left(\mathrm{CH}_{2}-O-\mathrm{C}_{6} \mathrm{H}_{4} \mathrm{O}\right) \mathrm{Fe}_{2}(\mathrm{CO})_{5}\right]^{-}$(10, Figure 9).

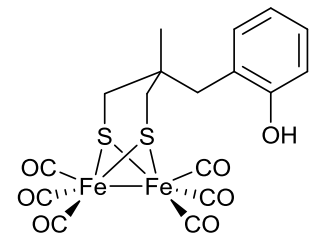

9
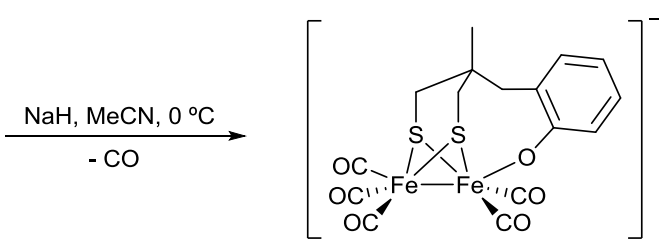

10

Figure 9. Scheme for the intra-molecular coordination of the deprotonated phenol group of 9 to give $\left[\left(\mu-\mathrm{SCH}_{2}\right)_{2} \mathrm{CMe}\left(\mathrm{CH}_{2}-\mathrm{O}-\mathrm{C}_{6} \mathrm{H}_{4} \mathrm{O}\right) \mathrm{Fe}_{2}(\mathrm{CO})_{5}\right]^{-}(\mathrm{10})$, as a structural model for the $\mathrm{H}_{\text {ox }}{ }^{\text {air }}$ and $\mathrm{H}_{\text {ox }}$ states of the [FeFe]-hydrogenase.

\subsubsection{Bridging $\mathrm{CO}$, mixed valence state and rotated structures}

To date, there is still only one example of a diiron complex with bridging $\mathrm{CO}$, solely supported by cyanide ligation [73]. This species slowly converts back to an all terminal CO system.

The first examples of isolated stable complexes containing a bridging $\mathrm{CO}$ ligand were achieved utilising electron rich (relative to $\mathrm{CO}$ ) isocyanides $(\mathrm{MeCN})$, or phosphine/phosphite in isolation or combination with $\mathrm{CN}$, in diferrous systems [33]. More recent examples of similar systems include work by Talarmin and co-workers, in which $\mathbf{2}$ is coordinated by a chelating dicarbene substrate to give $\left[(\mu\right.$-pdt $\left.) \mathrm{Fe}_{2}(\mathrm{CO})_{4}\left(\kappa 2-\mathrm{IMe}_{-} \mathrm{CH}_{2}-\mathrm{IMe}\right)\right](\mathrm{IMe}=1$ methylimidazol-2-ylidene) [77]. The effect of this ligand on the ability of the complex to bind varying substrates $\left(\mathrm{CO}, \mathrm{MeCN}, \mathrm{P}(\mathrm{OMe})_{3}\right)$ was probed under electrochemical oxidation conditions. In the presence of $\mathrm{P}(\mathrm{OMe})_{3}$ the diferrous, bridging $\mathrm{CO},[(\mu$-pdt $)(\mu$ $\left.\mathrm{CO}) \mathrm{Fe}_{2}(\mathrm{CO})_{2}\left(\mathrm{P}(\mathrm{OMe})_{3}\right)_{2}\left(\kappa 2-\mathrm{IMe}-\mathrm{CH}_{2}-\mathrm{IMe}\right)\right]^{2+}$ compound is produced. 
Mixed valence models have relied upon ligation with phosphines and/or carbenes to give compounds that stabilize oxidised Fe(II)-Fe(I) systems in non-coordinating solvents, through a combination of enhanced electron density at Fe, and steric effects imparted by the bulky ligands [33]. This has allowed for the fabrication of model systems with a 'rotated state' in which an Fe centre assumes a square-pyramidal geometry, with a free coordination site for substrate binding, which neatly mimics the $\mathrm{H}_{\mathrm{ox}} / \mathrm{H}_{\mathrm{ox}}-\mathrm{CO}$ states of the natural enzyme.

Ott and co-workers have recently demonstrated that substitution of two CO ligands of $\mathbf{2}$ for a chelating diphosphine ligand with an electron deficient carborane bridgehead, gives the diiron unit $\left[(\mu\right.$-pdt $\left.) \mathrm{Fe}_{2}(\mathrm{CO})_{4}(\mathrm{BC})\right]$ (BC = 1,2-bisdiphenylphosphine-1,2-o-carborane) (11, Figure 10), which has sufficient electron density to stabilise the $\mathrm{Fe}(\mathrm{II})-\mathrm{Fe}(\mathrm{I})$ state. This mixed valent species was formed through electrochemical oxidation and was found to be stable on a minutes timescale, resulting in a reversible oxidation process in the $\mathrm{CV}$, and allowing for its spectroscopic characterization via EPR and HYSCORE [106].

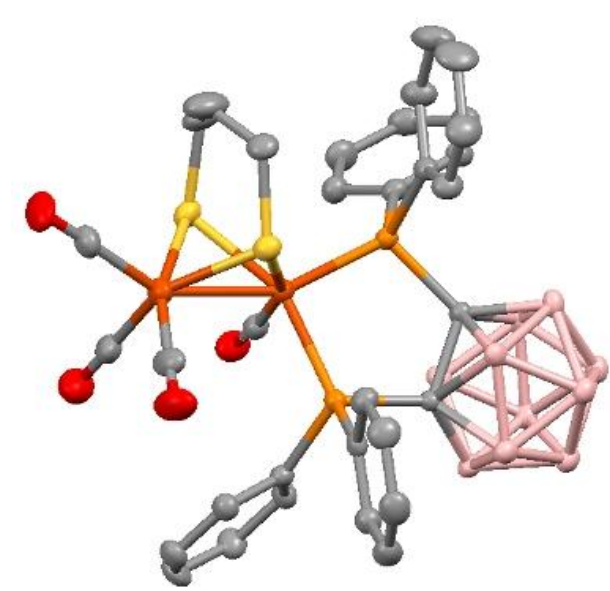

$[\mathrm{A}]$

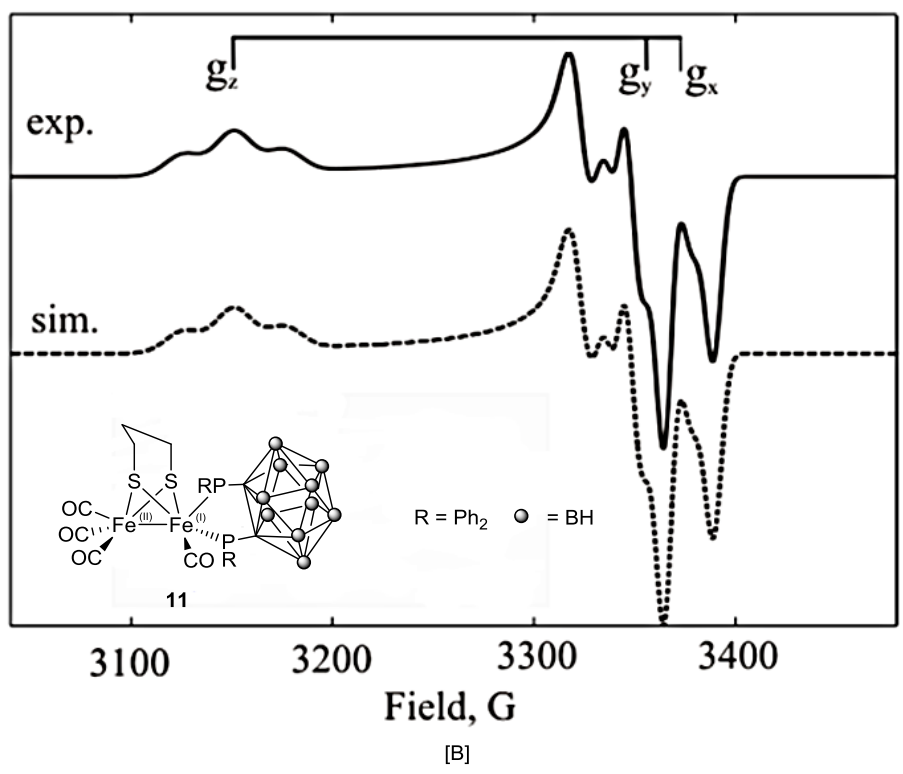

[B]

Figure 10. X-ray crystal structure [A] of the [FeFe]-model (11) that features a chelating diphosphine borane ligand, and the EPR spectrum of the Fe(II)Fe(I) species [B] formed through electrochemical oxidation. Reproduced with permission from reference [106].

\subsubsection{Proton relays}


Protonation of the [FeFe]-subsite is generally believed to occur at the free coordination site of the distal $\mathrm{Fe}$ in the $\mathrm{H}_{\mathrm{ox}}$ state of the enzyme, however other possible sites for protonation have been suggested [88, 107-109], such as the Fe-Fe bond, the amino bridge, the cyanide ligands and the dithiolate bridges, all with precedents in the literature [33, 110]. Indeed, in a very recent report by Liu et al. [111] the novel diiron mimic $\left[\left(\mu, \kappa^{2}-b d t\right)\left(\mu-\mathrm{PPh}_{2}\right) \mathrm{Fe}_{2}(\mathrm{CO})_{5}\right]^{-}$is prepared, which features a bridging phosphine ligand. Protonation with an excess of trifluoromethanesulfonic acid (HOTf) produces a doubly protonated species, bearing a $\mu$ hydride and a protonated thiolate, characterized by X-ray crystallography.

Similar results were reported by Ott and co-workers, showing that inclusion of ligands bearing varying amine functionalities (12-14), allows for the directional control of the initial protonation site (Figure 11), with generation of either an ammonium salt (15) or $\mu$-H species (16), depending on the nature of the amine group, or formation of a $\mathrm{SH}^{+}$species (17) when the basic amine group is omitted from the chelating diphosphine ligand [107].

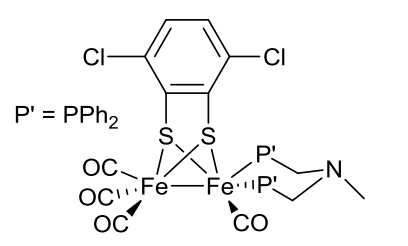

12

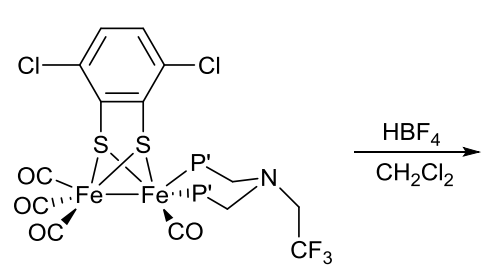

13

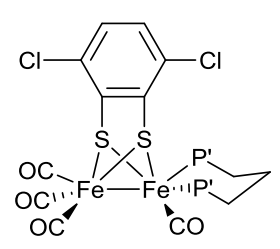

14

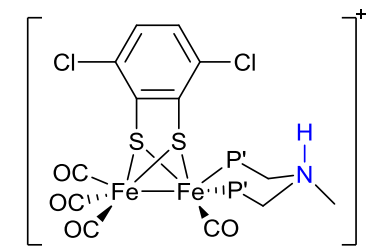

15

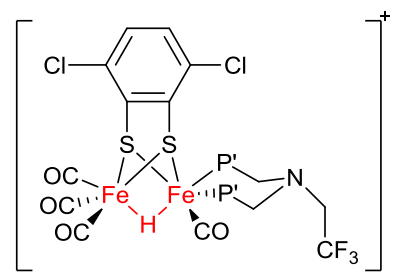

16

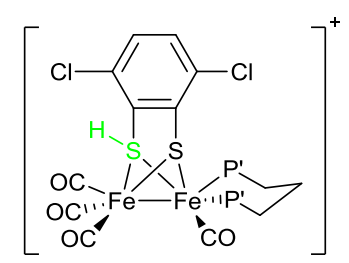

17

Figure 11. A series of [FeFe]-models bearing chelating diphosphine ligands with varying bridgeheads groups (12-14), and the protonated products (15-17) all featuring unique sites of protonation, coloured for clarity. 
A comparable observation is reported by Åkermark and co-workers, upon inclusion of aryl and alkyl carboxylic acid groups to the dithiolate bridge of a diiron unit [112]. They showed that in the presence of strong HOTf acid the aryl-COOH groups direct protonation to the amine bridgehead first, whilst the initial site of protonation for the diiron units bearing alkyl$\mathrm{COOH}(\mathbf{1 8})$ is the metal-metal bond (Figure 12). Interestingly, the alkyl-COOH functionalized diiron units are electrocatalytically active in fully aqueous medium, with the carboxylic acid group believed to play a role in the transportation of $\mathrm{H}_{3} \mathrm{O}^{+}$protons to the amino bridge.

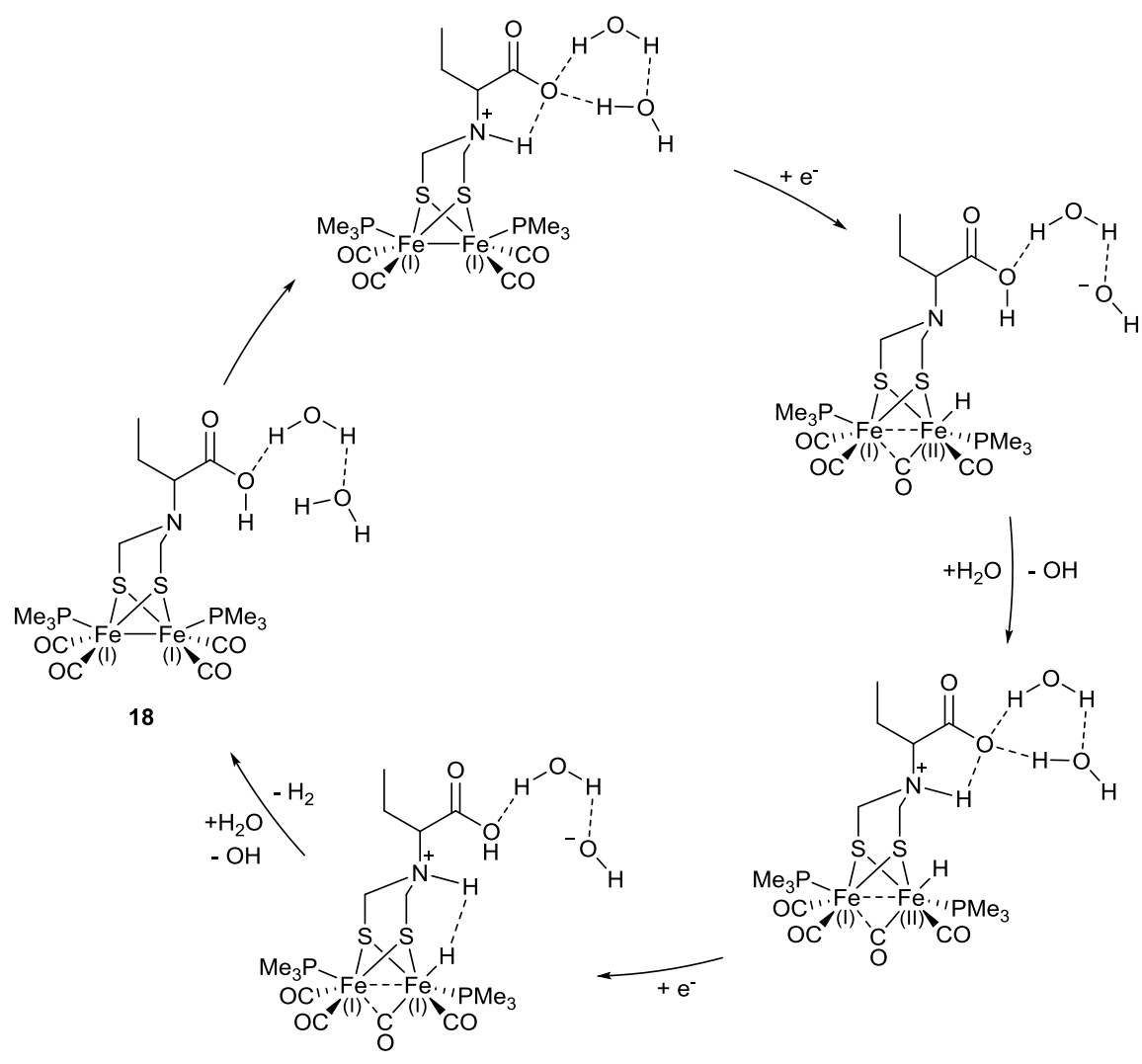

Figure 12. Proposed catalytic mechanism for the electrocatalytic reduction of $H^{+}$from 18 in aqueous media, illustrating the mooted role of the carboxylate group as a proton transfer relay.

Many systems bearing protonated amine bridges have been previously described, with their spectroscopic characteristics described in detail in a recent review [110]. Recent work from the groups of Schollhammer [113], Liu [114] and Sun [115] describe protonation of a pendant 
basic functionality incorporated into phosphine ligands, with their potential as proton shuttles discussed. A good example of such proton transfer behaviour is the description of an unsymmetrically substituted diphosphine diiron unit by Talarmin and co-workers [113], in which two CO ligands from $\mathbf{2}$ are substituted with a chelating di-phosphine ligand, bearing a $\mathrm{NMe}$ bridgehead to give $\left[(\mu-\mathrm{pdt}) \mathrm{Fe}_{2}(\mathrm{CO})_{4}\left(\left\{\mathrm{PPh}_{2} \mathrm{CH}_{2}\right\} \mathrm{NMe}\right)\right](\mathbf{1 9})$. Protonation with an excess of $\mathrm{HBF}_{4} \mathrm{Et}_{2} \mathrm{O}$ in acetone leads to protonation of the NMe group in axial position (20). However, upon dissolving the protonated species in $\mathrm{CH}_{2} \mathrm{Cl}_{2}$, the compound isomerizes, altering the arrangement of the phosphine ligand from basal-apical to the basal-basal form whilst concomitantly forming the bridging hydride species 21 (Figure 13). Although the method of proton delivery is not discussed in detail, it could be suggested that rotation about the chelating ligand allows the protonated NMe group within close enough proximity of the metal-metal bond to form the thermodynamically favoured product via proton transfer.

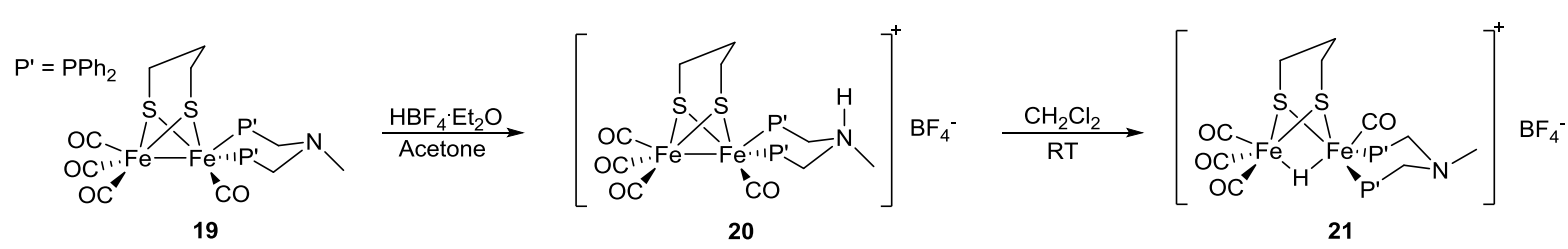

Figure 13. Scheme for the protonation of 19 to yield the ammonium salt 20, and its subsequent isomerization that results in delivery of the proton to the metal-metal bond, to form the bridging hydride 21.

Of course the natural system functions reversibly and thus a proton relay would be required not only for delivery of a proton but also for its dispatch following $\mathrm{H}_{2}$ oxidation, activity which can been probed by catalytic exchange of H/D. Whilst there are reports of catalytic exchange of H/D from $\mu$-hydride diiron mimics void of pendant base functionality, these generally required pre-treatment, via photolysis, to open a coordination site of an Fe centre $[103,116,117]$ yielding slow rates of exchange.

A recent study by Sun and co-workers clearly demonstrates the importance of the basic functionality for catalytic H/D exchange [118]. Complex 2 is treated with a chelating diphosphine containing an $\mathrm{N}-n \mathrm{Pr}$ bridgehead $\left(n \mathrm{Pr}=\mathrm{CH}_{2} \mathrm{CH}_{2} \mathrm{CH}_{3}\right)$ to give, amongst other products, the unsymmetrically substituted complex $\left[(\mu\right.$-pdt $\left.) \mathrm{Fe}_{2}(\mathrm{CO})_{4}\left(\left\{\mathrm{PPh}_{2} \mathrm{CH}_{2}\right\}_{2} \mathrm{~N}-n \mathrm{Pr}\right)\right]$. 
Upon treatment with two equivalents of $\mathrm{HBF}_{4} \mathrm{Et}_{2} \mathrm{O}$ in $\mathrm{CH}_{2} \mathrm{Cl}_{2}$, the $\mu$-hydride, ammonium salt species $\left[(\mu-\mathrm{H})(\mu \text {-pdt }) \mathrm{Fe}_{2}(\mathrm{CO})_{4}\left(\left\{\mathrm{PPh}_{2} \mathrm{CH}_{2}\right\}_{2} \mathrm{NH}-n \mathrm{Pr}\right)\right]^{2+}$ (22) is quantitatively formed. When this hydride species was treated with 10 equivalents of $\mathrm{CH}_{3} \mathrm{COOD}$ in $\mathrm{CH}_{2} \mathrm{Cl}_{2}$, the ${ }^{1} \mathrm{H} \mathrm{NMR}$ signal for the $\mu$-hydride at $\delta-13.0 \mathrm{ppm}$ was rapidly lost, whilst a new high field signal attributed to the $\mu$-deuteride was observed in the ${ }^{2} \mathrm{H}$ NMR. Contrastingly, when the same experiment was carried out on the equivalent diiron unit that lacks a basic bridgehead ([ $\mu$ $\mathrm{H})(\mu$-pdt $\left.\left.) \mathrm{Fe}_{2}(\mathrm{CO})_{4}\left(\left\{\mathrm{PPh}_{2} \mathrm{CH}_{2}\right\}_{2} \mathrm{CH}_{2}\right)\right]\right)$, the $\mu$-hydride signal at $\delta-12.8 \mathrm{ppm}$ remained unaltered. Additionally, the latter compound could not be deprotonated even with 20 equivalents of aniline base, yet the hydride from 22 could be removed by $\mathrm{H}_{2} \mathrm{O}$ alone. A mechanism for H/D exchange by this system has been discussed, with a schematic representation shown in Figure 14.

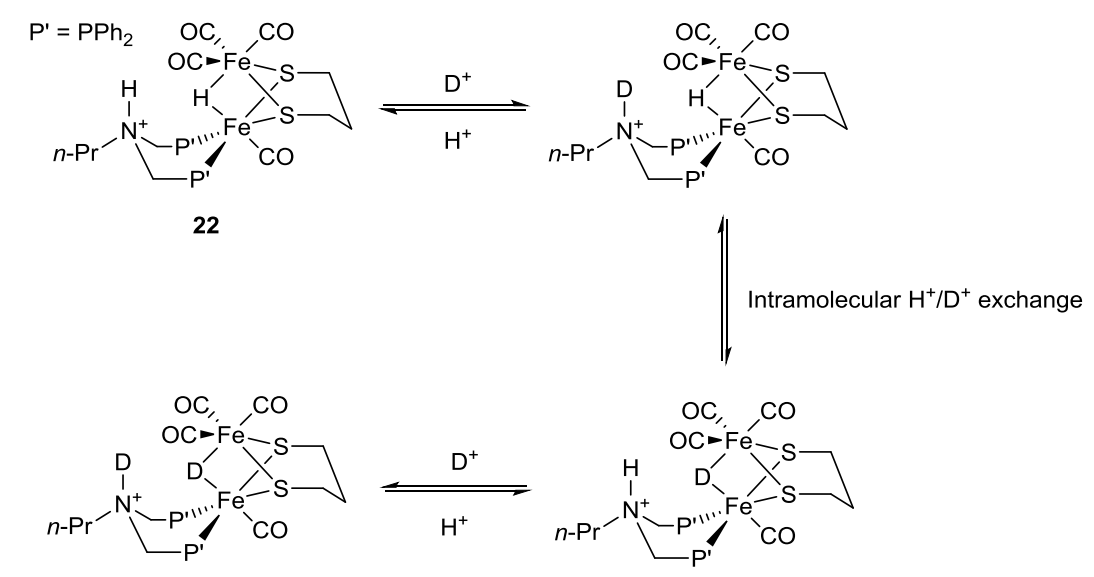

Figure 14. Scheme for the reversible exchange of protons and deuterons in 22, facilitated by the basic amine bridgehead of the diphosphine ligand.

If it appears logical that the pendant amine group of the H-cluster functions as a proton relay, perhaps less obvious is its possible role in the protection of an uncoordinated site of the diiron unit. Rauchfuss and co-workers have recently shown that the inclusion of an amino bridgehead helps to stabilise the two electron oxidized state of the triphosphine substituted diiron unit $\left[\left(\mu-\left(\mathrm{SCH}_{2}\right)_{2} \mathrm{NBn}\right) \mathrm{Fe}_{2}(\mathrm{CO})_{3}(\mathrm{dppv})\left(\mathrm{PMe}_{3}\right)\right](\mathbf{2 3})\left(\mathrm{Bn}=\mathrm{Benzyl}, \mathrm{C}_{6} \mathrm{H}_{5} \mathrm{CH}_{2}\right.$, dppv = diphenylphosphine vinyl, $\left.\mathrm{P}\left(\mathrm{Ph}_{2}\right)_{2} \mathrm{CHCHP}\left(\mathrm{Ph}_{2}\right)_{2}\right)$ [119]. Electrochemical oxidation of this $[\mathrm{FeFe}]$-mimic occurs at mild potential, relative to the pdt-bridged equivalent, whilst also showing good reversibility on the cyclic voltammetry timescale. The stabilisation of this $32 \mathrm{e}^{-}$ complex is due to the coordination, following rotation about the chelating diphosphine ligand, 
of the NBn bridgehead group to the coordinatively unsaturated iron centre to give $\mathbf{2 4}$, characterized by X-ray crystallography (Figure 15). This result suggests that the bridging amine unit could also function as a protective ligand in the natural enzyme, in a similar vein to the role of the $\mathrm{H}_{2} \mathrm{O} / \mathrm{OH}^{-}$ligand in the $\mathrm{H}_{\mathrm{ox}}$ state.
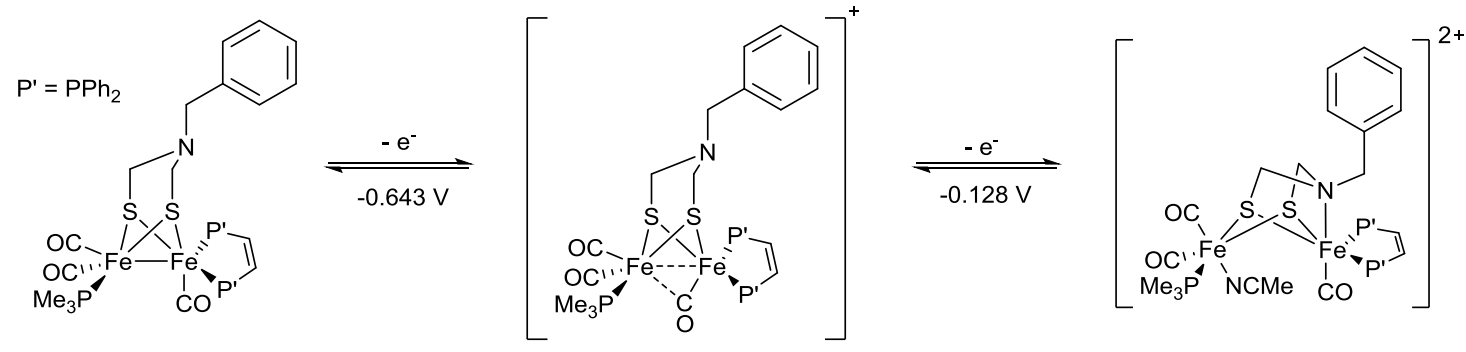

23

24

Figure 15. Scheme for the reversible two electron oxidation of $\mathbf{2 3}$, resulting in the breaking of the metal-metal bond, stabilised by the coordination of a solvent molecule to one Fe centre and coordination of the nitrogen atom of the bridgehead to the second to yield $\mathbf{2 4}$.

Another interesting finding from this work is that the ammonium equivalent of this compound, $\left[\left(\mu-\left(\mathrm{SCH}_{2}\right)_{2} \mathrm{NHBn}\right) \mathrm{Fe}_{2}(\mathrm{CO})_{3}(\mathrm{dppv})\left(\mathrm{PMe}_{3}\right)\right]^{+}$, can function as an efficient hydrogen atom donor in the presence of the H-atom abstracting agent TEMPO $(2,2,6,6-$ tetramethylpiperidin-1-oxyl), to yield the mixed valent $\mathrm{Fe}(\mathrm{II})-\mathrm{Fe}(\mathrm{I})$ species, suggesting that these types of mimics, and by extension the natural system, may function through a PCET mechanism.

\subsubsection{Hydrides: bridging vs. terminal binding modes}

Hydride derivatives of dithiolate-bridged diiron clusters pre-date the crystal structure determination of the natural subsite of [FeFe]-hydrogenase by over 20 years, when Poilblanc and co-workers reported the protonation of symmetrically substituted diphosphine $[(\mu-\mathrm{H})(\mu-$ $\left.\mathrm{SMe})_{2} \mathrm{Fe}_{2}(\mathrm{CO})_{4}(\mathrm{PPhMe} 2)_{2}\right]^{+}$to yield a bridging hydride species [120]. Whilst the majority of hydride models are bridging in nature [33], and active electrocatalysts for $\mathrm{H}^{+}$reduction, comparative catalytic studies on terminal hydride derivatives are needed if we are to better understand the bias, if any, the natural system has towards a particular mode (bridging versus terminal) of metal hydride, and the specific reasons for such a preference. 
A crystal structure of a diiron unit bearing a terminal hydride was first reported by Rauchfuss and co-workers in 2005 [86], although this was achieved by addition of a hydride ligand from $\mathrm{LiAlH}_{4} / \mathrm{NaBH}_{4}$ to a tetraphosphine ligated diferrous complex (25) to give $[(\mu$-edt $)(\mu$ $\left.\mathrm{CO}) \mathrm{HFe}_{2}(\mathrm{CO})\left(\mathrm{PMe}_{3}\right)_{4}(\mathrm{NCMe})\right]^{2+}\left(\mathbf{2 6}\right.$, Figure 16) $\left(\mathrm{edt}^{2-}=\right.$ ethanedithiolate $)$.

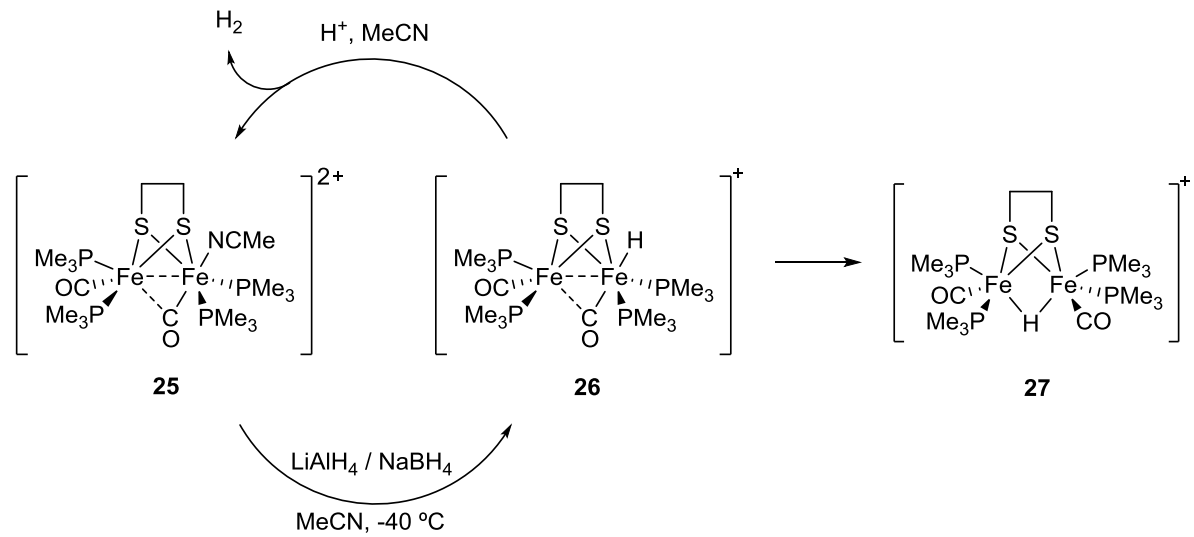

Figure 16. Scheme for the formation of the first isolated diiron unit to bear a terminal hydride (26), through hydride addition to the tetraphosphine species 25, and the thermodynamically stable bridging hydride equivalent 27.

This work was followed by the groups of Schollhammer [121], Rauchfuss [122] and Hogarth [123], who reported that upon protonation of phosphine substituted [FeFe]-mimics, at low temperatures, it was possible to detect ${ }^{1} \mathrm{H}-\mathrm{NMR}$ signals characteristic of terminally bound hydride ligands. The isolation and characterisation of a stable terminal hydride diiron unit via protonation was finally achieved by Rauchfuss and co-workers in 2012 with the low temperature synthesis and isolation of the doubly protonated diiron unit $[(\mu-$ adtH) $\left.\mathrm{Fe}_{2} \mathrm{H}(\mathrm{CO})_{2}(\mathrm{dppv})_{2}\right]^{2+}$ (Figure 17) [87]. The crystal structure replicates the naturally relevant bridging $\mathrm{CO}$. It also demonstrates a strikingly short distance between the terminal hydride and equatorial amino proton of $1.88(7) \AA$, indicating significant dihydrogen bonding. It should be noted that, upon warming the reaction solution to room temperature, the terminal hydride species isomerizes to give the bridging derivative, as confirmed by ${ }^{1} \mathrm{H}$ NMR. 


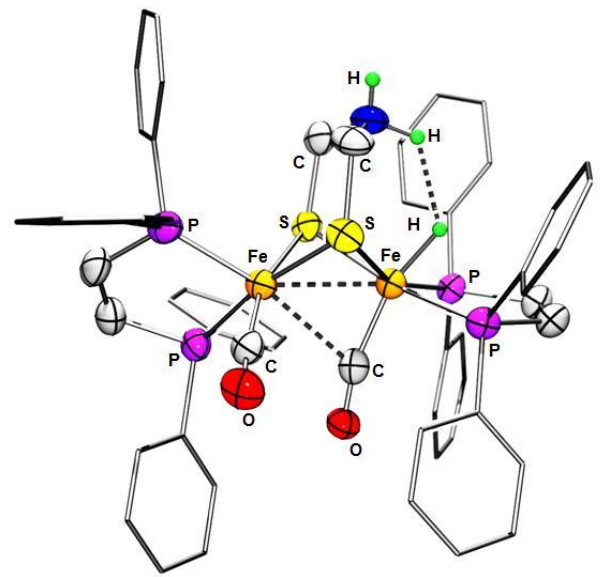

Figure 17: ORTEP representation of $\left[(\mu-a d t H) \mathrm{Fe}_{2} \mathrm{H}(\mathrm{CO})_{2}(\mathrm{dppv})_{2}\right]^{2+}$ with thermal ellipsoids drawn at $50 \%$ probability. Phenyl hydrogen atoms, counter-ions and solvent of crystallization omitted for clarity. Reproduced with permission from reference [87].

It has previously been suggested that the presence of a pendant base group such as the adt bridge would kinetically favour terminal hydride species [124] and that the overpotential would be smaller in comparison to bridging hydride species. This notion is given credence by the reduction potential recorded for $\left[\left(\mu \text {-adtH)Fe }{ }_{2} \mathrm{H}(\mathrm{CO})_{2}(\mathrm{dppv})_{2}\right]^{2+}\right.$, which is anodically shifted by $150 \mathrm{mV}$, relative to its bridging hydride derivative. The advantages of a terminal hydride are further evidenced by the relatively large TOF $\left(5000 \mathrm{~s}^{-1}\right)$ calculated for the singly protonated terminal hydride species $\left[(\mu \text {-adt }) \mathrm{Fe}_{2} \mathrm{H}(\mathrm{CO})_{2}(\mathrm{dppv})_{2}\right]^{2+}$ during electrochemical reduction in the presence of trifluoroacetic acid in $\mathrm{CH}_{2} \mathrm{Cl}_{2}$, again compared to the bridging hydride derivative $\left(20 \mathrm{~s}^{-1}\right)$.

When considering the advantages of a terminal hydride species over a bridging hydride, such as their milder reduction potentials and their proximity to the mooted proton transfer group, it is tempting to suggest that the natural enzyme would likely favour such a catalytic intermediate [125].

\subsubsection{H-cluster models: towards the complete catalytic package}

The first attempts to introduce an electron transfer relay, a key component of the natural enzyme (see 2.1 above), were achieved by Tard et al. by inclusion of a biologically relevant cubane $\left[\mathrm{Fe}_{4} \mathrm{~S}_{4}\right]$-cluster, bridged to a $[2 \mathrm{Fe} 3 \mathrm{~S}]$-model via a sulphur ligand to yield the $\mathrm{H}$-cluster model system depicted in Figure 18 [89]. Whilst this system is functional as an 
electrocatalyst for proton reduction, it is at the cost of large overpotentials, whilst also lacking the ability to perform the reverse process.

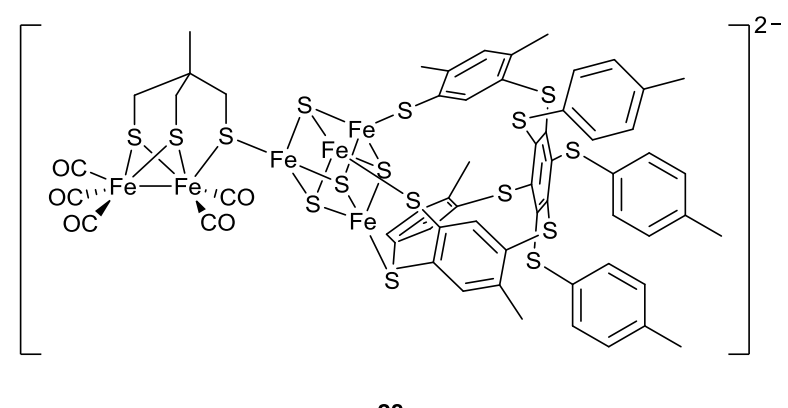

28

Figure 18. Schematic representation of the H-cluster model 28 synthesized by Tard et al. [89].

When considering the amount of work that has been published on $[\mathrm{FeFe}]$-mimics it is somewhat surprising that very little attention has been given to the introduction of an electron transfer relay, to replicate $[4 \mathrm{Fe}-4 \mathrm{~S}]$ cluster function, particularly as understanding the cluster's role in enabling catalysis may be key to achieving truly functional model systems. The recent detection and characterisation of the $\mathrm{H}_{\text {sred }}$ oxidation state (Figure 2) by the groups of Lubitz and King will likely inspire many groups in the field to pursue this endeavour $[34,35]$.

There are a handful of reports of diiron units bearing additional redox active moieties, however almost all of the reported systems show no significant overpotential decrease or catalytic efficiency increase. Models include the attachment of pendant ferrocene (Fc) groups [126-129], a diphosphine functionalised fullerene [130], non-innocent 2,3bis(diphenylphosphine) maleic anhydride (BMA) [131], and bipy ligands (bipy = 2,2'bipyridine) [132]. Unfortunately, only the fullerene model exhibits any electronic communication between the second and first redox coordination spheres, with the only other functionality observed being that of an electrochemical internal standard [126-128].

In fact, the only example of an $[\mathrm{FeFe}]-$ mimic that bears a functional electron transfer relay is the complex $\left[\mu-\left\{\left(\mathrm{SCH}_{2}\right)_{2} \mathrm{NBn}\right\} \mathrm{Fe}_{2}(\mathrm{CO})_{3}(\mathrm{FcP} *)(\mathrm{dppv})\right](\mathbf{2 9})\left(\mathrm{FcP}^{*}=\mathrm{Cp} * \mathrm{Fe}\left(\mathrm{C}_{5} \mathrm{Me}_{4} \mathrm{CH}_{2} \mathrm{PEt}_{2}\right)\right)$ (Figure 19) recently reported by Camara and Rauchfuss [133]. This is also the first example of a model $[\mathrm{FeFe}]$-system that performs catalytic $\mathrm{H}_{2}$ oxidation. 


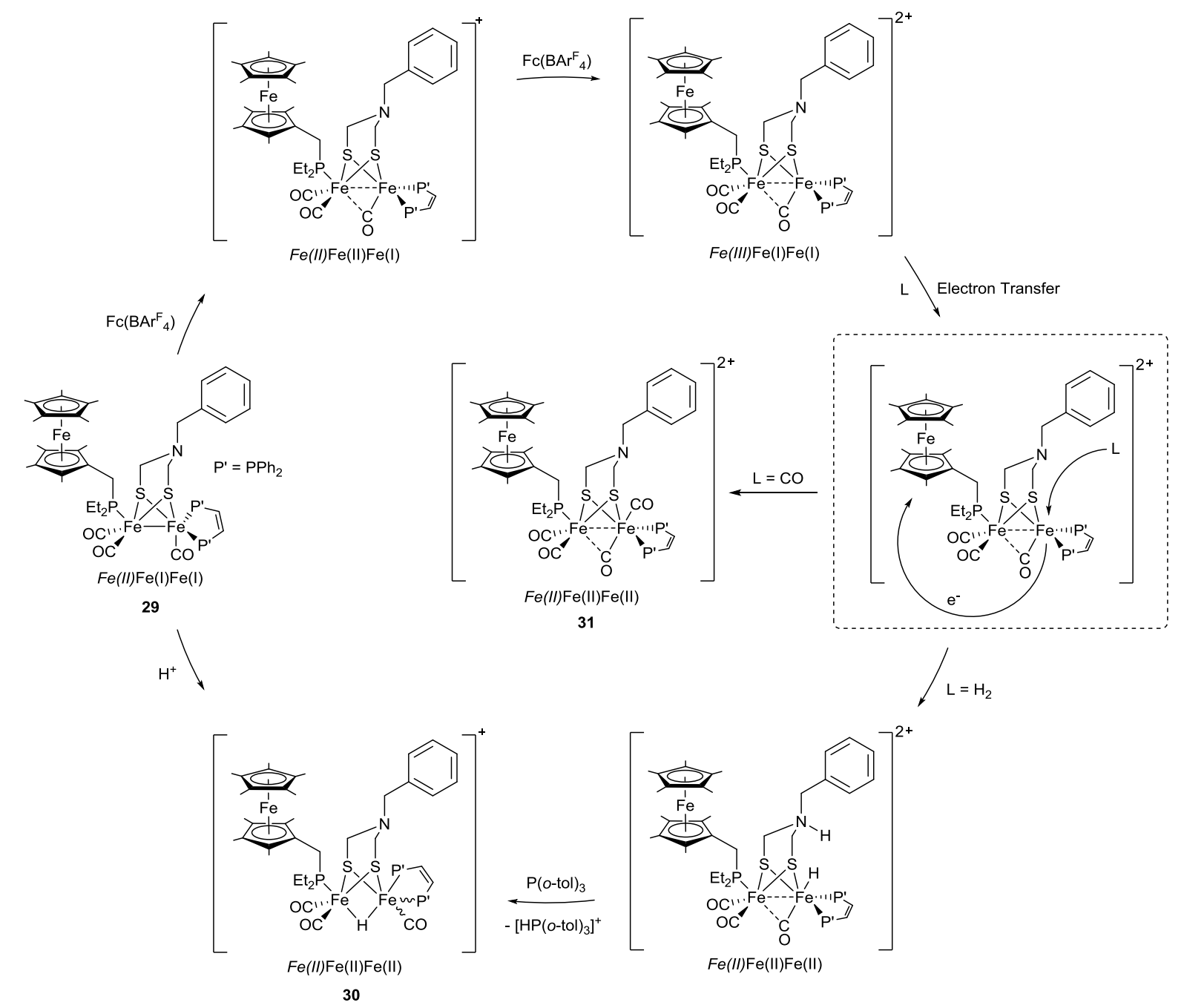

Figure 19. Scheme for the catalytic oxidation of hydrogen by 29, facilitated by the electron acceptor capability of a ferrocenyl group in the secondary coordination sphere. The isolated bridging hydride catalytic intermediate 30, and the CO inhibited form 31 are also shown.

This complete $\mathrm{H}$-cluster model incorporates not only a functional electron transfer relay, in the form of a phosphine functionalized ferrocene group ( $\mathrm{FcP} *)$, but an N-benzyl group that reportedly functions as a proton relay unit. Upon chemical oxidation with one equivalent of the oxidant $\mathrm{Fc}\left(\mathrm{BAr}_{4}^{\mathrm{F}}\right)$ in $\mathrm{CH}_{2} \mathrm{Cl}_{2}$, a $60 \mathrm{~cm}^{-1}$ shift in the FTIR suggests that the mixed valence state (for the diiron catalytic unit) $\mathrm{Fe}(\mathrm{II})-\mathrm{Fe}(\mathrm{I})$ is achieved. Upon titration of a second equivalent of oxidant only a small shift of $4 \mathrm{~cm}^{-1}$ is observed, indicative of a redox process in the secondary coordination sphere. The resulting product is the triply mixed valent state $\mathrm{Fe}(\mathrm{III})-\mathrm{Fe}(\mathrm{II})-\mathrm{Fe}(\mathrm{I})$, with the $\mathrm{CO}$ of the distal iron in a partially bridging mode, leaving a free 
coordination site in the apical position. Bubbling of $\mathrm{H}_{2}$ through a $\mathrm{CH}_{2} \mathrm{Cl}_{2}$ solution of the complex in the presence of 6 equivalents of base $\left(\mathrm{P}(o \text {-tolyl })_{3}\right)$ and excess of oxidant (4 equiv. of $\left.\mathrm{Fc}\left(\mathrm{BAr}_{4}{ }_{4}\right)\right)$ led to 4 turnovers of $\mathrm{H}_{2}$ oxidation over a 5 hour period.

It is important to note that unlike previous doubly oxidized diiron systems, the diferrous state for the catalytic subunit is not achieved. Instead the second oxidation step likely results in the loss of an electron from the ferrocene electron relay to yield a ferrocenium moiety. It has previously been shown that the binding of a $\mathrm{H}^{-}$ligand to [FeFe]-model systems can be energetically biased towards a diferrous system [119], although there is no evidence for an unsaturated diferrous state in the enzyme. It is suggested rather that nature would proceed with activation of $\mathrm{H}_{2}$ via a proton coupled electron transfer (PCET) mechanism, with the [4Fe-4S] cubane providing the oxidative power required (Figure 2). Indeed, these results suggest that $\mathrm{H}_{2}$ binding, its heterolytic cleavage and transfer of an electron to the pendant ferrocenium occur concomitantly, as strengthened by a recent DFT study on the same system [134].Although at first glance, the inclusion of an electron transfer relay would appear intrinsic to this model systems ability to catalytically oxidize $\mathrm{H}_{2}$, Sun and coworkers [135] have subsequently shown that under similar experimental conditions, their previously reported model system bearing only a proton transfer relay (22 Figure 14) is also active for catalytic $\mathrm{H}_{2}$ oxidation, and at a slightly increased rate.

Whilst these systems no doubt represent a dramatic breakthrough in modelling the bidirectional functionality of the $[\mathrm{FeFe}]$-hydrogenase enzyme, their catalytic rates for $\mathrm{H}_{2}$ oxidation of $10^{-4} \mathrm{~s}^{-1}$ are several orders of magnitude lower than the $28000 \mathrm{~s}^{-1}$ of the natural system [1]. It is vital that these types of challenges are overcome if we are to develop efficient catalytic systems, which are adequate for incorporation into future practical technological devices [136].

\subsection{Models of the active site of [NiFe]-hydrogenases}


Although several mimics of the active site of $[\mathrm{NiFe}]$-hydrogenase were reported shortly after the structure of the natural subsite had been determined (32-33, Figure 20) [137], construction of models with greater structural relevance, that also replicate the active site's functionality, has long been a challenge for chemists, due in no small part to its complexity. Up to 2009, a large number of mimics had been reported [33, 39, 138], some of them featuring the all-sulphur coordination sphere around nickel, the $\left\{\mathrm{Ni}(\mu-\mathrm{SR})_{2} \mathrm{Fe}\right\}$ core, and $\mathrm{CN}^{-}$ /CO ligands bound to Fe (34-37). However, none of these structural mimics were shown to be catalytically active.

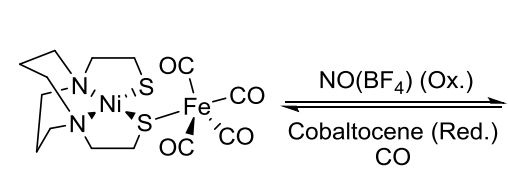

32

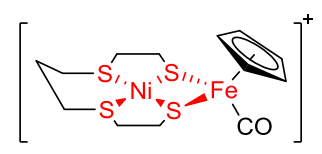

34

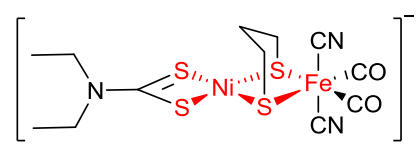

36

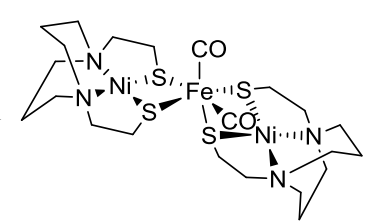

33

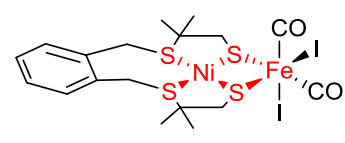

35

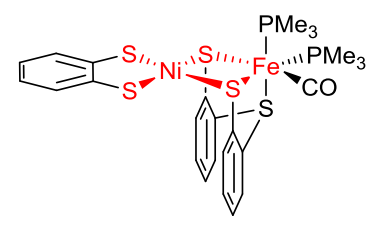

37

Figure 20. Selected early [NiFe]-models, with compounds 34-37 featuring the biologically relevant $\left\{\mathrm{Ni}(\mu-\mathrm{SR})_{2} \mathrm{Fe}\right\}$ core, coloured in red.

\subsubsection{Nickel-ruthenium mimics}

The use of organometallic ruthenium moieties as surrogates for the $\left\{\mathrm{Fe}(\mathrm{II})(\mathrm{CN})_{2}(\mathrm{CO})\right\}$ fragment is justified by the lack of redox change at the low-spin Fe(II) centre of native enzymes during catalysis, suggesting that the role of the carbonyl and cyanide ligands found at the active site may be restricted to the modulation of the electronics of the iron centre and/ 
or the stabilization of intermediates such as hydride or dihydrogen derivatives. In respect to this latter described role, ruthenium complexes are widely used as catalysts for hydrogenation or hydrogen-transfer reactions [139] and $\mathrm{Ru}(\mathrm{II})$ can easily accommodate both hard and soft ligands including dihydrogen or a hydride, a required property for a metal to replicate the $\mathrm{Fe}$ function during catalysis by NiFe hydrogenases. This approach allowed Oudart and coworkers from our group to prepare active [NiRu] catalysts for $\mathrm{H}_{2}$ evolution, through combination of the weakly active $\mathrm{Ni}$ complex, $[\mathrm{Ni}(\mathrm{xbsms})][140,141]$ with $\left\{\mathrm{Ru}(\mathrm{CO})_{2} \mathrm{Cl}_{2}\right\}$ (38-39), $\left\{\mathrm{Ru}(\mathrm{CO})_{3} \mathrm{Cl}\right\}^{+}(\mathbf{4 0})$ and $\left\{\operatorname{RuCl}(p \text {-cymene })_{2}\right\}^{+}$(41-42) moieties (Figure 21) [142144]. It also made it possible to derive a structure-function relationship that resulted in significant improvement of nickel-ruthenium $\mathrm{H}_{2}$-evolving catalyst performance: using the infrared $\bar{v}_{\mathrm{CO}}$ frequency as a probe for the electron density on the metal centres, the same authors concluded that the more electron-rich the metal centre, the better the catalyst, as far as overpotential requirement is concerned. Canaguier and co-workers from our group followed this trend, with substitution of $\{\mathrm{Ru}(\text { arene })\}^{2+}$ or $\left\{\mathrm{Ru}(\mathrm{CO})_{2} \mathrm{Cl}\right\}^{+}$for more electron-rich organometallic moieties such as $\{\mathrm{RuCp}\}^{+}(\mathbf{4 3 - 4 5})\left(\mathrm{Cp}^{-}=\right.$cyclopentadienyl anion) fragments (Figure 21). This approach was successful as it was possible to gain $200 \mathrm{mV}$ under the same assay conditions using $[\mathrm{Ni}(\mathrm{xbsms}) \mathrm{RuCp}]$ compounds, relative to the former $[\mathrm{NiRu}]$-catalysts [141]. The introduction of the electron-enriched $\left\{\mathrm{RuCp}^{*}\right\}^{+}$moiety $(46-48)\left(\mathrm{Cp}^{*^{-}}=\right.$ pentametylcyclopentadienyl anion) finally yielded the most active catalyst in the series (46) with both a relatively low overpotential requirement $(620 \mathrm{mV})$ and a high turnover frequency [145]. In addition, the steric protection provided by the bulky $\mathrm{Cp}^{*^{-}}$ligand resulted in an increased stability upon cycling. The group of S. Ogo in Japan used a similar strategy to produce a dinuclear nickel-ruthenium compound (49, Figure 21) bearing a hexamethylbenzene ligand capable of catalytically oxidizing $\mathrm{H}_{2}$ in the presence of $\mathrm{Cu}(\mathrm{II})$ ions as the oxidizing agents [146]. It was shown that the activation of $\mathrm{H}_{2}$ by the dinuclear catalyst involves the formation of an intermediate containing a hydride ligand $\left(\mathrm{H}^{-}\right)$bridging the two metal centres [147], a geometry very similar to that found in the catalytically competent Ni-C state of NiFe hydrogenases [48]. Similar bridging hydride intermediates have also been proposed through DFT calculations for the reverse process, i.e. hydrogen evolution [141, 148]. In a recent study, our group revisited the mechanism for $\mathrm{H}_{2}$ evolution catalyzed by this series of compounds, and highlighted the possibility that $\mathrm{H}_{2}$ is produced via a PCET mechanism from just such a bridging hydride ligand [149]. 


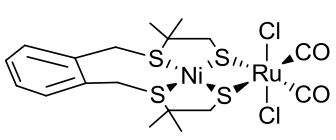

38

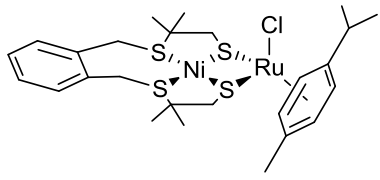

41

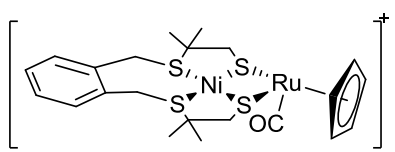

44

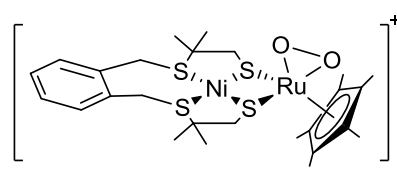

47

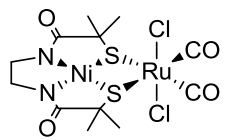

39

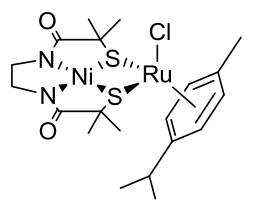

42

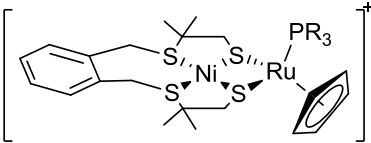

45

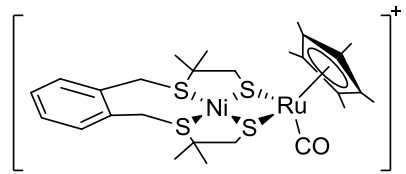

48

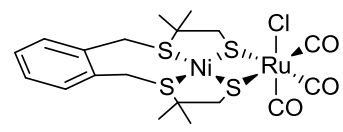

40

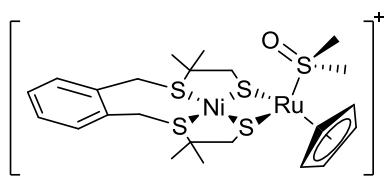

43

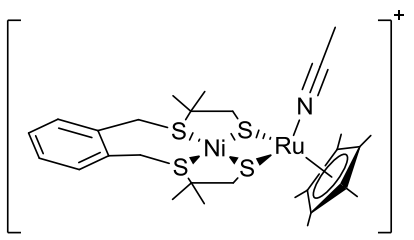

46

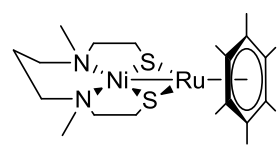

49

Figure 21. Selected [NiRu] complexes as functional models of the [NiFe]-hydrogenase.

\subsubsection{Nickel-iron functional mimics}

The next milestone was the design of functional models only containing first-row transition metals. Seven such systems (compounds 50-55 and 57, Figure 22) were reported as exhibiting catalytic activity, albeit restricted to $\mathrm{H}_{2}$ evolution [150-153], once again with a bridging hydride species as the active intermediate.

In 2009 Rauchfuss and coworkers prepared a dinuclear Ni-Fe hydride compound through the apparently facile protonation of $\left[(\mathrm{dppe}) \mathrm{Ni}(\mu\right.$-pdt $\left.) \mathrm{Fe}(\mathrm{CO})_{3}\right]$, initially reported by Schröder [154], with $\mathrm{HBF}_{4}$ to yield $\left[(\mathrm{dppe}) \mathrm{Ni}(\mu-\mathrm{H})(\mu-\mathrm{pdt}) \mathrm{Fe}(\mathrm{CO})_{3}\right]^{+}(\mathbf{5 0})$ [150]. Other derivatives 
could be obtained through the substitution of two CO ligands with phosphites (51), phosphines (52-53) [151] or diphosphines [150], requiring photochemical activation in the latter case. All of these dinuclear bridging hydride derivatives proved electrocatalytically competent for hydrogen evolution from trifluoroacetic acid (TFA) in a $\mathrm{CH}_{2} \mathrm{Cl}_{2}$ solution. The absence of any thermodynamical data for acid-base constants in this solvent makes the determination of the overpotential requirement quite difficult. A $1 \mathrm{~V}$ estimation for the overpotential requirement for $\mathrm{H}_{2}$ evolution from TFA catalysed by $\mathbf{5 0}$ could be obtained from comparison of $\mathrm{H}_{2}$ evolution in $\mathrm{CH}_{2} \mathrm{Cl}_{2}$ and $\mathrm{DMF}$ at a platinum electrode [152]. Measurements were further made from freshly prepared $\mathrm{CH}_{3} \mathrm{CN}$ solutions of phosphine derivatives (51-53), despite their low stability in this solvent, and yielded lower overpotential values in the $260-430 \mathrm{mV}$ range [151].

Canaguier and coworkers from our group reported another functional Ni-Fe mimic in 2010 (54), by coordination of [Ni(xbsms)] to a cyclopentadienyl Fe(II) moiety, originated from the $\left[\mathrm{CpFe}(\mathrm{CO})_{2}(\mathrm{thf})\right]^{+}$precursor. The two thiolate ligands of the $\mathrm{xbsms}^{2-}$ ligand bridge the nickel and the iron centres and the Fe coordination sphere is completed by a single CO ligand. Complex 54 was shown to catalyse $\mathrm{H}_{2}$ evolution from TFA in DMF with a $730 \mathrm{mV}$ overpotential requirement, with subsequent DFT calculations proposing that possible formation of a bridging hydride could occur through protonation at the $\mathrm{CO}$ ligand in the oneelectron reduced state, followed by rearrangement and elimination of the CO ligand. 


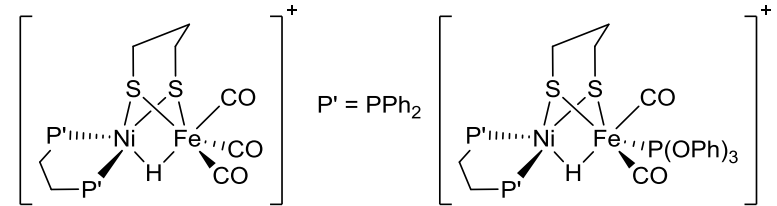

50

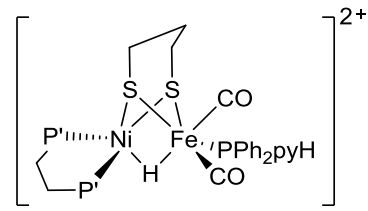

53

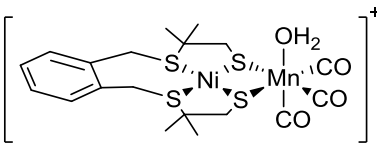

56
51

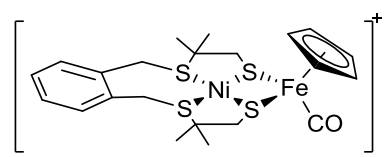

54

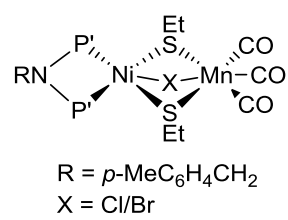

57

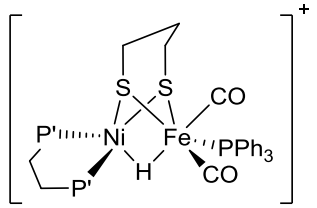

52

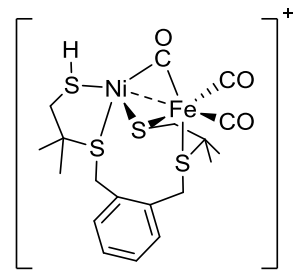

55

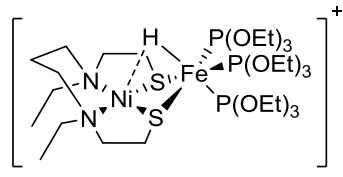

58

Figure 22. Schematic representation of the majority of structurally relevant [NiFe]-mimics, active for electrocatalytic proton reduction (50-55), and for the bidirectional conversion of protons and electrons into dihydrogen (58). Also shown are the only known [NiMn] systems $(56,57)$, also active for electrocatalytic proton reduction.

A similar approach allowed for the synthesis of a Ni-Mn compound (56,), with a similar structure and requiring an overpotential of $860 \mathrm{mV}$ to evolve $\mathrm{H}_{2}$ from TFA in DMF [155, 156]. A second series of Ni-Mn compounds has been reported by L.-C. Song, two of which (57) proved active for $\mathrm{H}_{2}$ evolution from acetic acid in $\mathrm{CH}_{3} \mathrm{CN}$ [157] with low catalytic current enhancement but reduced overpotential requirement $(\sim 480 \mathrm{mV})$.

Using an analogous strategy, Weber and coworkers from the Lubitz group reacted the $[\mathrm{Ni}(\mathrm{xbsms})]$ complex with $\left[\mathrm{Fe}(\mathrm{CO})_{3}(\mathrm{bda})\right]$ (bda = benzylidene acetone) to obtain 55; a $[\mathrm{NiFe}]-$ model with only three sulphur ligands on the $\mathrm{Ni}$ centre, and a thioether group coordinated to the Fe atom. In this highly structurally distorted compound, a CO ligand was found to bridge between both metals. Interestingly, in the presence of $\mathrm{HBF}_{4}$, protonation occurred at the terminal thiolate ligand of the nickel centre, a feature reminiscent of the active 
site of NiFe hydrogenases. Both un-protonated and protonated compounds proved active for $\mathrm{H}_{2}$ evolution from TFA in $\mathrm{CH}_{3} \mathrm{CN}$ with overpotential requirements of 540-570 mV [153].

Recently, Ogo and co-workers have described a nickel-iron mimic able to mediate both hydrogen evolution and oxidation, thus reproducing for the first time at a binuclear core the bidirectional activity of the [NiFe]-hydrogenases [158]. The novelty of this mimic, which is likely responsible for its functionality, is the use of three triethylphosphite $\left(\mathrm{P}(\mathrm{OEt})_{3}\right)$ ligands to modulate the electronic properties of the iron centre, so as to promote coordination of $\mathrm{H}_{2}$ as a first step towards its activation. Heterolytic splitting of $\mathrm{H}_{2}$ is promoted in the presence of methanolate, a strong base that captures a proton whilst a hydride ligand remains coordinated to the iron centre, in a terminal binding mode (Figure 22, 58). This hydride species can be oxidized by methylviologen $\left(\mathrm{MV}^{2+}\right)$, thus at a mild potential. Release of a proton regenerates the starting compound, completing the catalytic cycle. The net reaction is the two-electron oxidation of molecular hydrogen with formation of two protons. It is however important to note that the nickel-iron compound reported by Ogo and co-workers achieves only a single turn-over with a $12 \%$ yield, although a better yield (45\%) could be measured when using a stronger oxidant such as the ferrocenium ion. The system also operates at energies far from the thermodynamic equilibrium, as evidenced by the requirement of a strong base to activate $\mathrm{H}_{2}$, while the natural process operates in water at neutral $\mathrm{pH}$. Similarly, a strong acid is required to produce $\mathrm{H}_{2}$ from the hydride species. So whilst this system shows promise as a catalyst for hydrogen evolution, this will be at the expense of quite large overpotentials as noted with other Ni-Fe mimics [150, 152, 153]. Comparison of two Ni-Fe and Ni-Ru compounds with the same set of ligands [152] neatly highlights the benefit of $\mathrm{Ru}$ over $\mathrm{Fe}$ in terms of overpotential requirement for catalysis $[156,159]$, consistent with the fact that noble metals are currently preferred as catalysts in technological devices. Nonetheless, this novel nickel-iron compound performs a single turnover reaction both for hydrogen oxidation and evolution, behaviour so far restricted to a single series of mononuclear nickel catalysts [160162] that have been the subject of a previous detailed review [163].

Structural similarity of these systems with the active site of [NiFe] hydrogenases is obvious. Nevertheless, comparison to the enzyme should be made with caution, with regard to the elucidation of the natural catalytic mechanism. An issue of particular concern is the 
binding mode of the hydride intermediate, i.e. bridging $v s$. terminal, with the latter option providing the additional question as to which metal site accommodates the hydride. While a terminal hydride ligand bound to a mononuclear iron centre has been recently reported as an active catalyst for $\mathrm{H}_{2}$ oxidation [164], most characterised [147, 150, 151] or computed [141, $148,152,165]$ dinuclear hydride derivatives, based on a $\left\{\mathrm{Ni}(\mathrm{II})(\mu-\mathrm{SR})_{2} \mathrm{M}\right\}$ core with $\mathrm{M}$ a low-spin $\mathrm{d}^{6}$ metal centre, feature a bridging structure in contrast to the terminally bound hydride recently described by Ogo, rendering any association between terminal/bridging binding modes and $\mathrm{H}_{2}$ evolution/activation futile. Even if a terminally $\mathrm{Fe}$-bound hydride is associated with $\mathrm{H}_{2}$ activation, it is not in accordance with the observation of a bridging hydride in the Ni-C state of the enzyme [48]. That being said, the production of a bridging hydride derivative that does replicate the $\mathrm{Ni}(\mathrm{III})-\mathrm{Fe}(\mathrm{II})$ electronic structure of the Ni-C state remains elusive. It could thus be argued that the $\mathrm{Ni}(\mathrm{II})-\mathrm{Fe}(\mathrm{II})$ centres of Ogo's hydride derivative (58) would better reproduce the structure of the Ni-R state of the enzyme, but no definitive data exists as to the nature of the additional ligand $\left(\mathrm{H}_{2}, \mathrm{H}^{-} \ldots\right)$ nor to its binding mode to the $\left\{\mathrm{Ni}(\mathrm{II})(\mu-\mathrm{SR})_{2} \mathrm{Fe}\right\}$ core in this particular state.

Very recent work by Manor and Rauchfuss describes the synthesis of two [(dxpe)Ni( $\mu$ pdt $\left.) \mathrm{Fe}(\mathrm{CO})_{\mathrm{n}}\left(\mathrm{CNBAr}_{3}\right)_{2}\right]^{-}$compounds, 59 and $\mathbf{6 0}\left(\mathrm{x}=\right.$ phenyl or cyclohexenyl, and $\mathrm{BAr}_{3}^{\mathrm{F}}=$ $\left.\mathrm{B}\left(\mathrm{C}_{6} \mathrm{~F}_{5}\right)_{3}\right)$ (Figure 23) [166], which represent the closest models of biomimetic ligation at the Fe centres. This was made possible by utilising isocyanides ligands $\mathrm{CNBAr}_{3}{ }_{3}$, which not only protect the Fe centre from chemical attack through steric bulk but also provide the anionic character of the subsite found in the natural enzyme. Furthermore, compounds $\mathbf{5 9}$ and $\mathbf{6 0}$ are capable of heterolytically splitting $\mathrm{H}_{2}$ to yield the bridging hydride species 61 and 62 respectively, both of which show hydridic character, evidenced through ${ }^{1} \mathrm{H}$ NMR and FTIR spectroscopy. In line with the recent work of Ogo [158], $\left[\mathrm{Et}_{4} \mathrm{~N}\right][(\mathrm{dppe}) \mathrm{Ni}(\mu$-pdt $)(\mu-$ $\left.\mathrm{H}) \mathrm{Fe}(\mathrm{CO})\left(\mathrm{CNBAr}_{3}\right)_{2}\right](\mathbf{6 1})$ exhibits bidirectional behaviour, capable of electrocatalytic $\mathrm{H}_{2}$ oxidation in the presence of the strong base DBU (diazabicycloundecene) and $\mathrm{H}_{2}$ evolution in the presence of $\mathrm{HCl}$, although this latter process only occurs on a stoichiometric level.

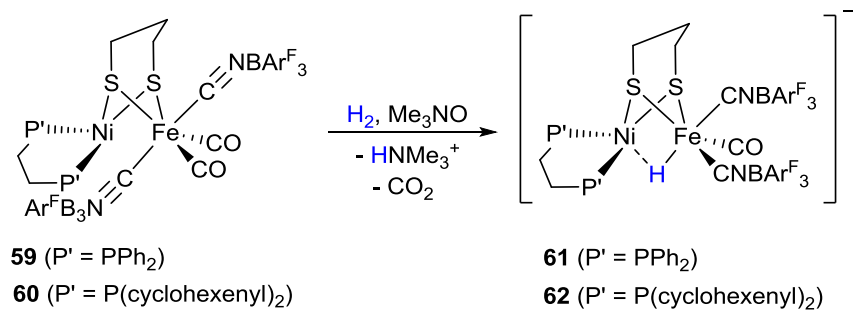


Figure 23. Scheme for the preparation the bridging hydride species [(dppe)Ni( $\mu$-pdt) $(\mu$ $\left.\mathrm{H}) \mathrm{Fe}(\mathrm{CO})\left(\mathrm{CNBAr}_{3}{ }_{2}\right)_{2}\right](\mathbf{6 1})$, which features a hydride ligand with hydridic character akin to the $\mathrm{Ni}$-C/R states of the natural enzyme.

The hydridic character of the bridging hydride in $\mathbf{6 1}$ and $\mathbf{6 2}$, along with the biologically relevant structural features of the Fe centres, make these compounds some of the closest models of the Ni-C and Ni-R states of the natural [NiFe]-hydrogenase to date, with similar systems (50-53) instead bearing hydrides with protic character [150-152]. Formation of 58, 61 and 62 via heterolytic $\mathrm{H}_{2}$ splitting is analogous to the conversion of Ni-SI to Ni-R in the enzyme. The oxidation states of the $\mathrm{Ni}$ and $\mathrm{Fe}$ centres in all three complexes also mirror the electronic structure of the Ni-R state. However, comparisons to the natural system must again be made with caution as these biomimetic systems would appear to function via the Fe centre as opposed to the Ni centre of the active site of the [NiFe]-hydrogenase enzyme. This is concluded from the small difference between the oxidation potentials of $\mathbf{6 1}$ and $\mathbf{6 2}(20 \mathrm{mV})$, whose Ni centres bear diphosphine ligands with very different basicities.

\subsection{Models of the active site of [Fe]-hydrogenases (Hmd)}

Shortly after the report of the first crystal structure of the active site of [Fe]hydrogenases, the groups of Liu, Pickett and Hu reported simple mononuclear iron(II) models containing N-bound pyridine [167], N,O-bound pyridone [168] or N,S-bound 2mercaptopyridine ligands [169]. Spectroscopic comparisons between these models and the active site of the enzyme suggested a $+\mathrm{II}$ oxidation state for the Fe atom in $[\mathrm{Fe}]$-hydrogenases, as further confirmed by Rauchfuss and coworkers with X-ray absorption measurements [170]. These early mimics were devoid of catalytic activity, which was ascribed to the saturation of their coordination sphere. Taking inspiration from the work from Liaw [171], Darensbourg reported the preparation of a penta-coordinate iron dicarbonyl complex containing 2aminothiophenolate ligands. However this [Fe]-mimic still suffered from a lack of relevant activity [172].

The second generation of mimics surfaced soon after the crystal structure of the C176A mutated [Fe]-hydrogenase was reported (Figure 6), which revealed coordination of an acyl 
ligand at the active site. The first coordinatively unsaturated dicarbonyl-acyl-iron complex was reported in another context by Holland [173], followed by reports of several other mononuclear iron carbonyl complexes with acyl ligands by the groups of $\mathrm{Hu}$ [174] and Rauchfuss $[175,176]$. More relevant mimics of the active site of [Fe]-hydrogenase were reported more recently, in which the acyl functionality is part of either an acylmethylpyridine ligand [177], a 2-acylmethyl-6-methoxypyridine ligand [178-180] or 2-acylmethyl-6hydroxymethylpyridine ligand [181]. In this context, the approach taken by Pickett and coworkers, in which the construction of an [Fe]-mimic is achieved using a pyridinecarbamoyl ligand (63), is of particular interest as it results in a mono iron complex whose metrical data is remarkably close to that of the active site found in the enzyme (Figure 24) $[182,183]$. To date however the closest model of this active site, which reproduces the exact square-pyramidal iron coordination sphere of the natural system (64), was reported by the group of $\mathrm{Hu}$ [184], although their model lacked the naturally occurring acylmethylpyridone ligand.

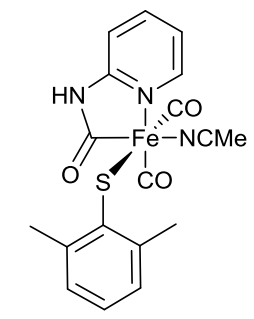

63

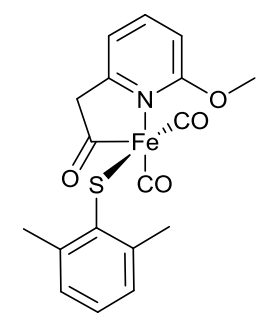

64

Figure 24. Schematic representation of the closest structural mimics to date, of the [Fe]hydrogenase active site.

This issue was somewhat remedied by recent work of the Song group (Figure 25) [185], though following deprotection of the pyridinol with TFA, a bi-metallic species spontaneously forms (65). Unfortunately, despite the continued efforts of multiple research groups, none of 
the synthetic mimics of the active site of [Fe]-hydrogenase have so far shown any relevant activity for hydrogen activation or hydride transfer functionality.
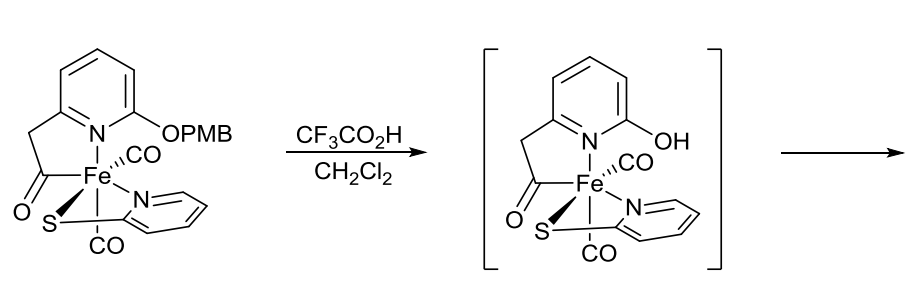

$\mathrm{PMB}=4-\mathrm{MeOC}_{6} \mathrm{H}_{4} \mathrm{CH}_{2}$

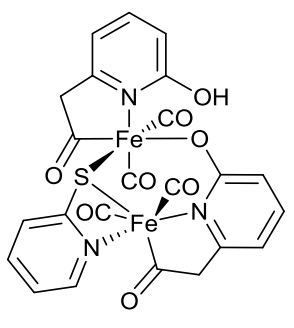

65

Figure 25. Scheme for the preparation of the unstable intermediate shown in brackets, which represents one of the closest [Fe]-hydrogenase structural models, and it's thermodynamically stable compound 65.

\section{Supramolecular control}

As outlined above, biomimetic systems inspired by the $[\mathrm{FeFe}]$ and $[\mathrm{NiFe}]$ catalytic cofactors found in the active site of hydrogenases (Figures 1 and 3), have struggled to live up to the expectations arising from the extreme efficiency observed for these enzymes. The discrepancy between the reactivity of the enzymatic system and these synthetic small molecule models, can be attributed to two important factors; i) the need of the latter to operate in non-aqueous solvents, ii) the absence of a protein environment, important for the modulation of the catalytic activity via outer coordination sphere interactions (Figure 26) [186]. 


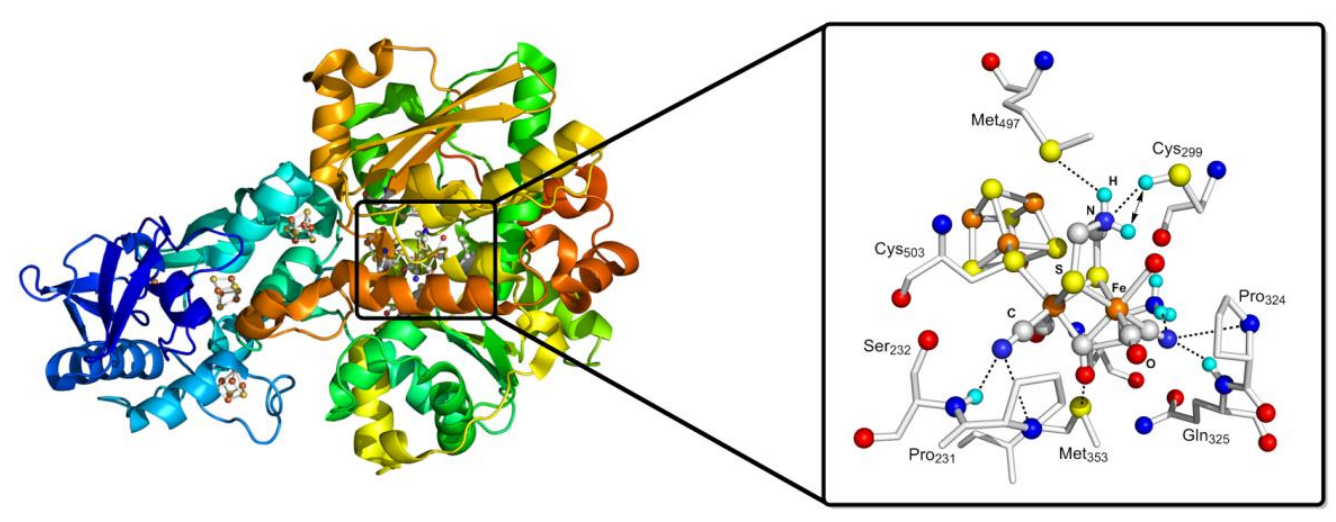

Figure 26. X-ray crystal structure of the CpI [FeFe]-hydrogenase (left, PDB code 3C8Y with a modified active site to display an $\mathrm{NH}$ bridgehead) with the active site (right) and the with the surrounding amino-acid residues important for catalytic activity and active site stability.

Indeed this point has recently been exquisitely illustrated by our recent work, where upon insertion of complex 6 into apo-[FeFe]-hydrogenase, either directly [11] or via the HydF maturase [10] (see section 4.6), a fully active [FeFe]-hydrogenase enzyme is generated, demonstrating that the protein cavity transforms this otherwise inactive and fragile complex in aqueous medium, into a highly efficient and robust catalyst [10].

Consequently, numerous approaches are currently being developed in attempts to mimic the influence of the proteic environment, such as the incorporation of these molecular complexes into supramolecular structures including polymers, micelles, gels and peptidic scaffolds.

\subsection{Incorporation of biomimetic catalysts in gels and resins}


Incorporation of molecular catalysts into a gel or resin support offers a number of potential advantages, as it provides the possibility to tailor the binding environment as well as facilitating the incorporation of such systems into technological devices.

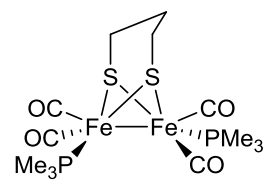

$[\mathrm{A}]$

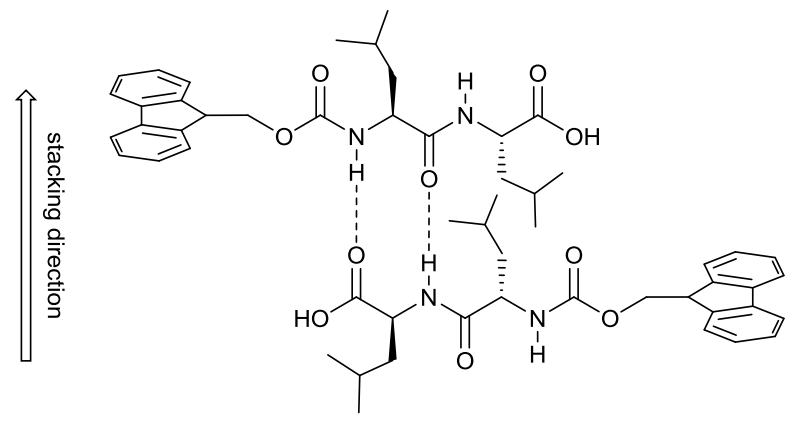

$[B]$

Figure 27. The diiron complex employed for incorporation, [( $\mu$-pdt)Fe $\left.2(\mathrm{CO})_{4}\left(\mathrm{PMe}_{3}\right)_{2}\right][A]$, and the stacking of the Fmoc-LL hydrogel [B].

Frederix et al. have studied the incorporation of $\left[(\mu\right.$-pdt $\left.) \mathrm{Fe}_{2}(\mathrm{CO})_{4}\left(\mathrm{PMe}_{3}\right)_{2}\right]$ into an Fmoc-LL hydrogel (Fmoc-LL = N-(fluorenyl-9-methoxycarbonyl) protected Leu-Leu), a low molecular weight hydrogelator that forms three dimensional networks in water at low concentrations (Figure 27). The organometallic complex was introduced, and stabilized, in the translucent gel via non-covalent interactions. FTIR spectroscopy indicated an environment intermediate between strictly non-polar (heptane) and polar $(\mathrm{MeOH})$. Interestingly, while $[(\mu-$ pdt) $\left.\mathrm{Fe}_{2}(\mathrm{CO})_{4}\left(\mathrm{PMe}_{3}\right)_{2}\right]$ has been reported to be unstable in aqueous solution, it was found to be stable for up to two weeks in the gel environment. However no data on the catalytic activity of this system was reported [187].

Two systems in which Tentagel ${ }^{\mathrm{TM}}$ resin beads are used to anchor Ni [188] and FeFe [189] complexes respectively have been reported by the group of Darensbourg. A CGC (CysGlyCys) peptide fragment was covalently attached to the resin via an amide linkage to provide a binding site for $\mathrm{Ni}$ ions, and indeed the tripeptide was found to be capable of coordinating $\mathrm{Ni}$ ions in a $\mathrm{NiN}_{2} \mathrm{~S}_{2}$ fashion. $\mathrm{NiRh}$ and $\mathrm{NiW}(\mathbf{6 6})$ heterobimetallic centers could 
also be obtained by binding $\mathrm{W}(\mathrm{CO})_{5}$ or $\mathrm{Rh}(\mathrm{CO})_{2}$ via the thiolate ligands of the $\mathrm{Ni}(\mathrm{CGC})$ complex (Figure 28) [188]. These results hint at the intriguing possibility of generating $[\mathrm{NiFe}]$ mimics by reaction of appropriate organometallic iron species with the resin bound $\mathrm{NiN}_{2} \mathrm{~S}_{2}$ moiety.

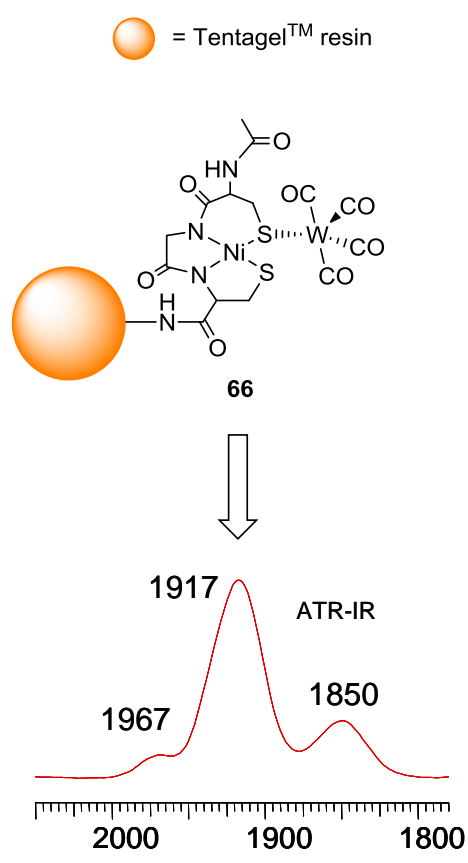

Figure 28. The resin bound $\left.[\mathrm{Ni}(\mathrm{CGC})] \mathrm{W}(\mathrm{CO})_{5}\right]^{2-}$ system $\mathbf{6 6}$ and its ATR-FTIR spectrum.

A study on the covalent attachment of carboxy-functionalized [FeFe]-hydrogenase mimics to the same type of resin was reported in 2009 [189]. Three different linkers were used, in which the carboxylate-group was introduced either on the bridgehead of the dithiolate motif (67), by replacement of a $\mathrm{CO}$ ligand with the phosphine ligand $\mathrm{P}\left(\mathrm{C}_{2} \mathrm{H}_{4} \mathrm{COOH}\right)_{3}(\mathbf{6 8})$, or as two separate thiolate bridging groups (69) (Figure 29). Once attached to the resin (70-72) the complexes could be further modified analogously to their solution state complexes, by introduction of electron rich ligands such as $\mathrm{PMe}_{3}$ and $\mathrm{CN}^{-}$. Surprisingly, attaching the complexes to the Tentagel resin was found to have a negative effect on their stability, both with regards to acidic conditions as well as photo-induced loss of the CO ligands, making this specific resin-complex combination an unlikely candidate for further catalytic studies. 


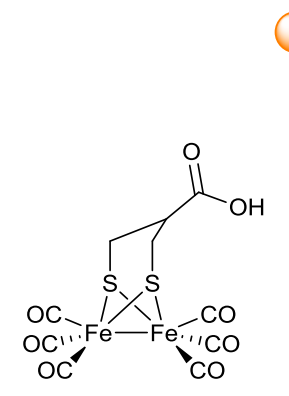

67

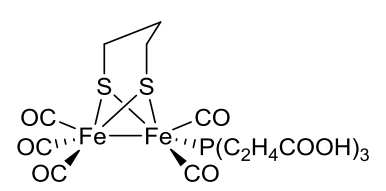

68

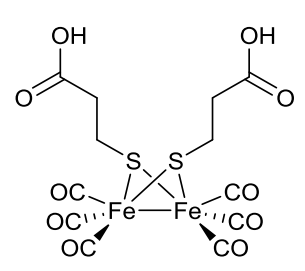

69

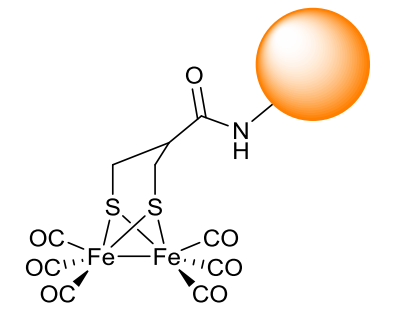

70

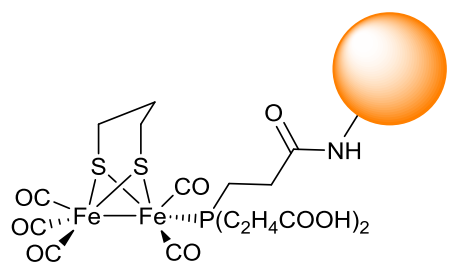

71

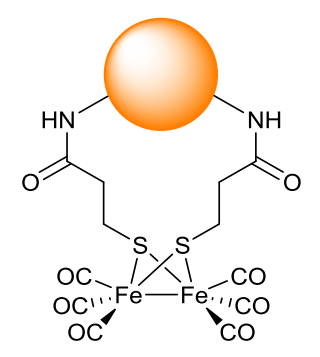

72

Figure 29. Schematic representation of three carboxy-functionalized [FeFe]-hydrogenase model complexes, before (67-69) and after (70-72) covalent attachment to the Tentagel ${ }^{T M}$ resin beads.

\subsection{Cyclodextrines}

A series of dinuclear iron complexes in which the bridgehead nitrogen atom has been functionalized to incorporate an aryl sulfonate group has been reported by the group of Darensbourg [190, 191]. To a certain degree, the presence of the anionic sulfonate group alone increases the solubility of the complex in water but, more importantly, allows for inclusion of the complex into $\beta$-cyclodextrins. Cyclodextrins are cyclic oligosaccharides, consisting of 6-8 glucose units (denoted $\alpha-, \beta$ - and $\gamma$-cyclodextrins respectively), generating a 
hydrophobic cavity with a hydrophilic rim (Figure 30). The adducts formed between $\beta$ cyclodextrins and five [FeFe]-hydrogenase mimics $\left[\left(\mu-\left(\mathrm{SCH}_{2}\right)_{2} \mathrm{NC}_{6} \mathrm{H}_{4} \mathrm{SO}_{3}\right) \mathrm{Fe}_{2}(\mathrm{CO})_{6}\right]^{-}(\mathbf{7 3})$, $\left[\left(\mu-\left(\mathrm{SCH}_{2}\right)_{2} \mathrm{NC}_{6} \mathrm{H}_{4} \mathrm{SO}_{3}\right) \mathrm{Fe}_{2}(\mathrm{CO})_{5}\left(\mathrm{P}(\mathrm{OMe})_{3}\right)\right]^{-},\left[\left(\mu-\left(\mathrm{SCH}_{2}\right)_{2} \mathrm{NC}_{6} \mathrm{H}_{4} \mathrm{SO}_{3}\right) \mathrm{Fe}_{2}(\mathrm{CO})_{5}(\mathrm{PTA})\right]^{-}(\mathrm{PTA}$ $=$ 1,3,5-Triaza-7-phosphaadamantane), $\left[\left(\mu-\left(\mathrm{SCH}_{2}\right)_{2} \mathrm{NC}_{6} \mathrm{H}_{4} \mathrm{SO}_{3}\right) \mathrm{Fe}_{2}(\mathrm{CO})_{5}\left(\mathrm{PPh}_{3}\right)\right]^{-}$and $[(\mu-$ $\left.\left.\left(\mathrm{SCH}_{2}\right)_{2} \mathrm{NC}_{6} \mathrm{H}_{4} \mathrm{SO}_{3}\right) \mathrm{Fe}_{2}(\mathrm{CO})_{4}\left(\mathrm{PMe}_{3}\right)_{2}\right]^{-}$were investigated. The structure of the supramolecular assemblies were studied in solution by NMR but also in the solid state by X-ray crystallography, making this class of guest-host complexes one of the few discussed herein for which crystal structures have been reported. It was found that whilst these cyclodextrins improved the stability of the complexes in aqueous buffer, it impaired their electrocatalytic performance with regards to proton reduction, requiring relatively large cathodic potentials compared to the free complexes [190, 191].

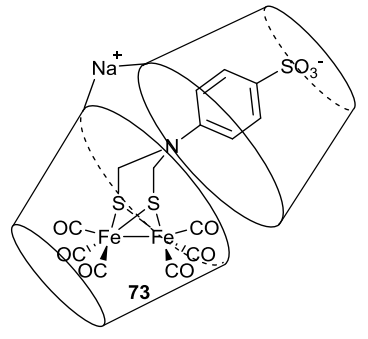

$[\mathrm{A}]$

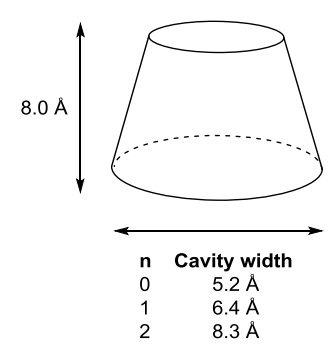

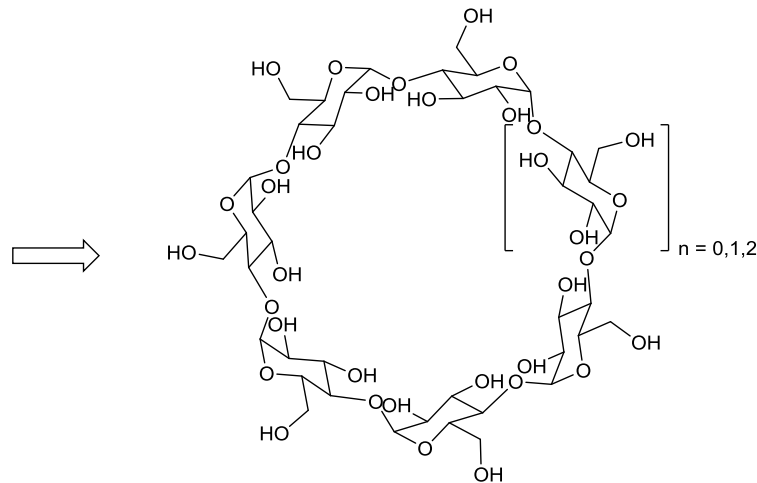

[B]

Figure 30. Schematic representation of 73 encapsulated in a cyclodextrin unit [A], and the structure of the $\alpha$ - $(n=0), \beta$ - $(n=1)$ and $\gamma$ - $(n=2)$ cyclodextrin units. Adapted from [190].

This class of guest-host complexes has been further studied by Sun and co-workers under photocatalytic conditions. Using the organic dyes Eosin Y (EY) or Rose Bengal (RB) as photosensitizers, the photocatalytic properties of $\mathbf{7 3}$ were studied at $\mathrm{pH} 10$ in the presence of TEA (triethylamine) as an electron donor. Indeed the addition of either $\beta$ - or $\gamma$-cyclodextrins was found to have a positive effect on both quantum efficiency as well as catalyst stability, resulting in a nine fold increase in TON $\left(\mathrm{mol} \mathrm{H}_{2} \cdot \mathrm{mol} \mathrm{catalyst}^{-1}\right)$ from 8 to 75 when combining the above mentioned diiron catalyst with EY in the presence of a tenfold excess of $\gamma$ cyclodextrins [192]. 


\subsection{Micelles}

Sodium dodecyl sulfate (SDS) micelles are used to simulate cell membranes, in the sense that they form lipid layers. They are, however, single layer systems featuring a negatively charged surface and a hydrophobic interior. The effect of incorporating water insoluble [FeFe]-hydrogenase mimics into the hydrophobic pocket of aqueous SDS micelles has been studied by the groups of $\mathrm{Wu}[193,194]$ and Gloaguen $[195,196]$. The complexes $[(\mu-$ $\left.\left.\left(\mathrm{SCH}_{2}\right)_{2} \mathrm{NPh}\right) \mathrm{Fe}_{2}(\mathrm{CO})_{6}\right]$ and $\left[\left(\mu-\left(\mathrm{SCH}_{2}\right)_{2} \mathrm{NBn}\right) \mathrm{Fe}_{2}(\mathrm{CO})_{6}\right]$ were studied in combination with Re-based photosensitizers by photo-physical/-catalytic methods. Although the micelle does indeed promote water solubility for both diiron complexes, only traces of $\mathrm{H}_{2}$ are evolved upon visible light irradiation, in the presence of ascorbic acid as a sacrificial electron donor. The complex $\left[\left(\mu-\left(\mathrm{SCH}_{2}\right)_{2} \mathrm{NBn}\right) \mathrm{Fe}_{2}(\mathrm{CO})_{6}\right]$ gives the largest maximum TON of only 0.13 , and as such neither system can be considered truly catalytic [193, 194]. Gloaguen and co-workers have studied the effects of SDS on $\left[(\mu\right.$-bdt $\left.) \mathrm{Fe}_{2}(\mathrm{CO})_{6}\right]$ and its $\mathrm{P}(\mathrm{OMe})_{3}$ substituted analogue $\left[(\mu\right.$-bdt $\left.\left.) \mathrm{Fe}_{2}(\mathrm{CO})_{4}\left(\mathrm{P}(\mathrm{OMe})_{3}\right)_{2}\right]\right)$ using electrochemical techniques. $\left[(\mu\right.$-bdt $\left.) \mathrm{Fe}_{2}(\mathrm{CO})_{6}\right]$ is a slow but robust catalyst for $\mathrm{H}_{2}$ evolution in organic solvents [197, 198]. In the presence of SDS, the complexes not only become water soluble, but also highly efficient catalysts. Electrocatalytic $\mathrm{H}_{2}$ evolution was observed at $-0.7 \mathrm{~V}$ vs. NHE in a $\mathrm{pH} 3.3$ aqueous solution; corresponding to a $0.5 \mathrm{~V}$ overpotential. The catalytic capacity of the system was also verified using bulk electrochemistry, with 52 turnovers achieved during the first hour of electrolysis performed at $-0.66 \mathrm{~V}$ vs. NHE at $\mathrm{pH} \mathrm{3,} \mathrm{and} \mathrm{with} \mathrm{no} \mathrm{noticeable} \mathrm{degradation} \mathrm{of} \mathrm{the} \mathrm{catalyst} \mathrm{[196].} \mathrm{The}$ trimethylphosphite-substituted complex $\left[(\mu\right.$-bdt $\left.) \mathrm{Fe}_{2}(\mathrm{CO})_{4}\left(\mathrm{P}(\mathrm{OMe})_{3}\right)_{2}\right]$ was found to have similar electrochemical properties. Analytical electrochemistry indicated relatively fast $\mathrm{H}_{2}$ production, with an overpotential requirement of $\sim 300 \mathrm{mV}$, although the compound degrades within minutes under bulk electrolysis conditions in the presence of acetic acid [195]. In a follow-up study, micellar solutions of $\left[(\mu\right.$-bdt $\left.) \mathrm{Fe}_{2}(\mathrm{CO})_{6}\right]$ were evaluated for $\mathrm{H}_{2}$ evolution in fully aqueous solution under photocatalytic conditions with Eosin $\mathrm{Y}$ and rose bengal as photosensitizers and triethylamine as the sacrificial donor, with significant stability enhancement due to the inclusion into SDS micelles [199]. 


\subsection{Dendrimers}

An alternative approach to the stabilization of a $\left[(\mu-\mathrm{S})_{2} \mathrm{Fe}_{2}(\mathrm{CO})_{6}\right]$ core $(4$, Figure 8$)$ in a hydrophobic environment has been reported by Yang and Li and co-workers [200]. By covalent attachment of the sulfide ligands of the organometallic core to a Fréchet-type dendritic moiety, consisting of aryl-benzyl ethers, $\mathbf{4}$ was encapsulated in a hydrophobic pocket inside the dendrimer to yield Hy-G4 (74) (Figure 31).

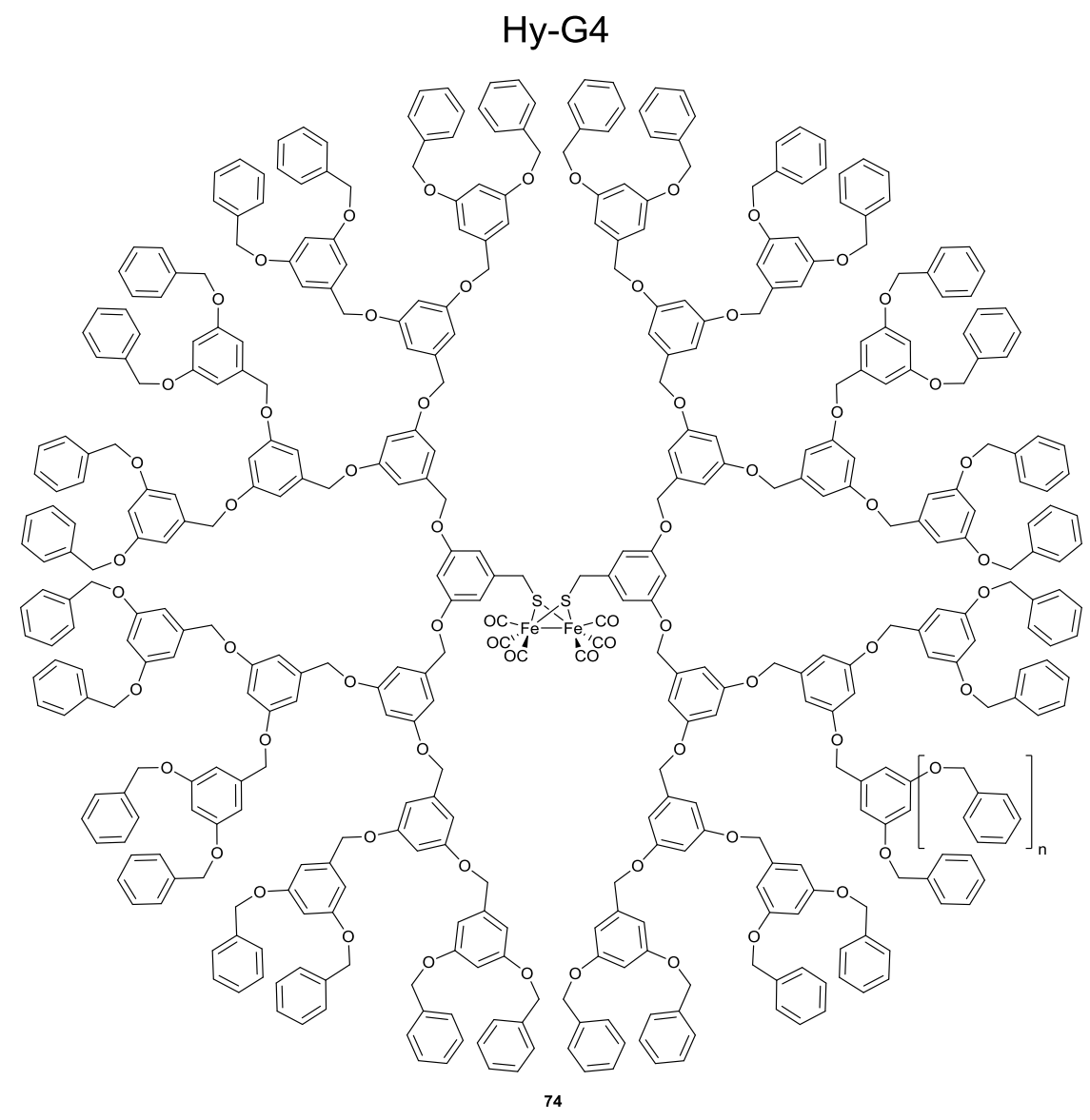

Figure 31. Structure of the dendritic hydrogenase mimic Hy-G4 (74), featuring a [( $\mu$ $\left.\mathrm{S}_{2} \mathrm{Fe}_{2}(\mathrm{CO})_{6}\right]$ core.

Photocatalytic hydrogen production was performed in an acetone/water mixture (9:1) in the presence of TEA as sacrificial electron donor with $\left[\operatorname{Ir}(\mathrm{ppy})_{2}(\mathrm{bpy})\right]^{+}$as the photosensitizer. The TOF and total TON of the system was found to improve with the size of the dendritic structure and for the largest structure $(n=4$, where $n$ denotes the number of benzyl ethers in one branch, Figure 31) the system had a relatively impressive TON of 22200, with an initial TOF of $7240 \mathrm{~h}^{-1}$ (TOF $=\mathrm{mol} \mathrm{H}_{2} \cdot \mathrm{mol}$ catalyst ${ }^{-1} \cdot \mathrm{h}^{-1}$ ) during the first hour of the reaction. 


\subsection{Poly acrylic acid}

$\mathrm{Wu}$ and co-workers have exchanged a CO ligand of $\mathbf{2}$ for an isocyanide ligand, to introduce further functionality to the system. In the original study an isocyanide oligoether ligand (CNR', Figure 32) was introduced to 2 [201] to yield [( $\mu$-pdt) $\left.\mathrm{Fe}_{2}(\mathrm{CO})_{5}\left(\mathrm{CNR}^{\prime}\right)\right]$ (75). The oligoether ligand allowed for photocatalytic studies under strictly aqueous conditions and hydrogen evolution was observed using nanocrystal quantum dots, CdTe, stabilized by 3mercapto-propionic acid (MPA-CdTe), as a photosensitizer and ascorbic acid as an electron and proton donor. The system was found to be stable during 10 hours of continuous irradiation of visible light, during which time it yielded a TON of up to 500 with a constant TOF of 50.

The group of $\mathrm{Wu}$ has continued to explore this type of systems and recently reported a remarkable photocatalytic system in which an alternative di-phenyl isocyanide linker ( $\mathrm{R}$, Figure 32) was employed to graft the di-iron complex to the anionic polymer poly acrylic acid (PAA) via an amide linkage (76) [202]. The successful incorporation of the complex was verified using NMR, FTIR, UV/Vis and inductively coupled plasma-atomic emission spectrometry (ICP-AES). As expected, the PAA framework provided improved water solubility and allowed for photocatalytic studies in aqueous solution. In the presence of $0.1 \mathrm{M}$ ascorbic acid (at an initial $\mathrm{pH}$ of 4.0) and CdSe quantum dots, employed as photosensitizers, 76 was found to produce $\mathrm{H}_{2}$ under irradiation of $430 \mathrm{~nm}$ light for $8 \mathrm{~h}$, during which time it produced a total of 27,000 turn-overs with an initial TOF of $3.6 \mathrm{~s}^{-1}$. It should be noted that the observed efficiency is likely attributable not only to improved catalytic efficiency of the di-iron unit, but also to some extent the interaction between the PAA and the CdSe photosensitizer. As the latter interaction prevents aggregation of the nanoparticles as well as ensuring close contact between the sensitizer and the catalyst. A similar improvement of the photophysical properties of the system is also observed in the case of photocatalytic systems employing dendritic moieties (vide supra). 


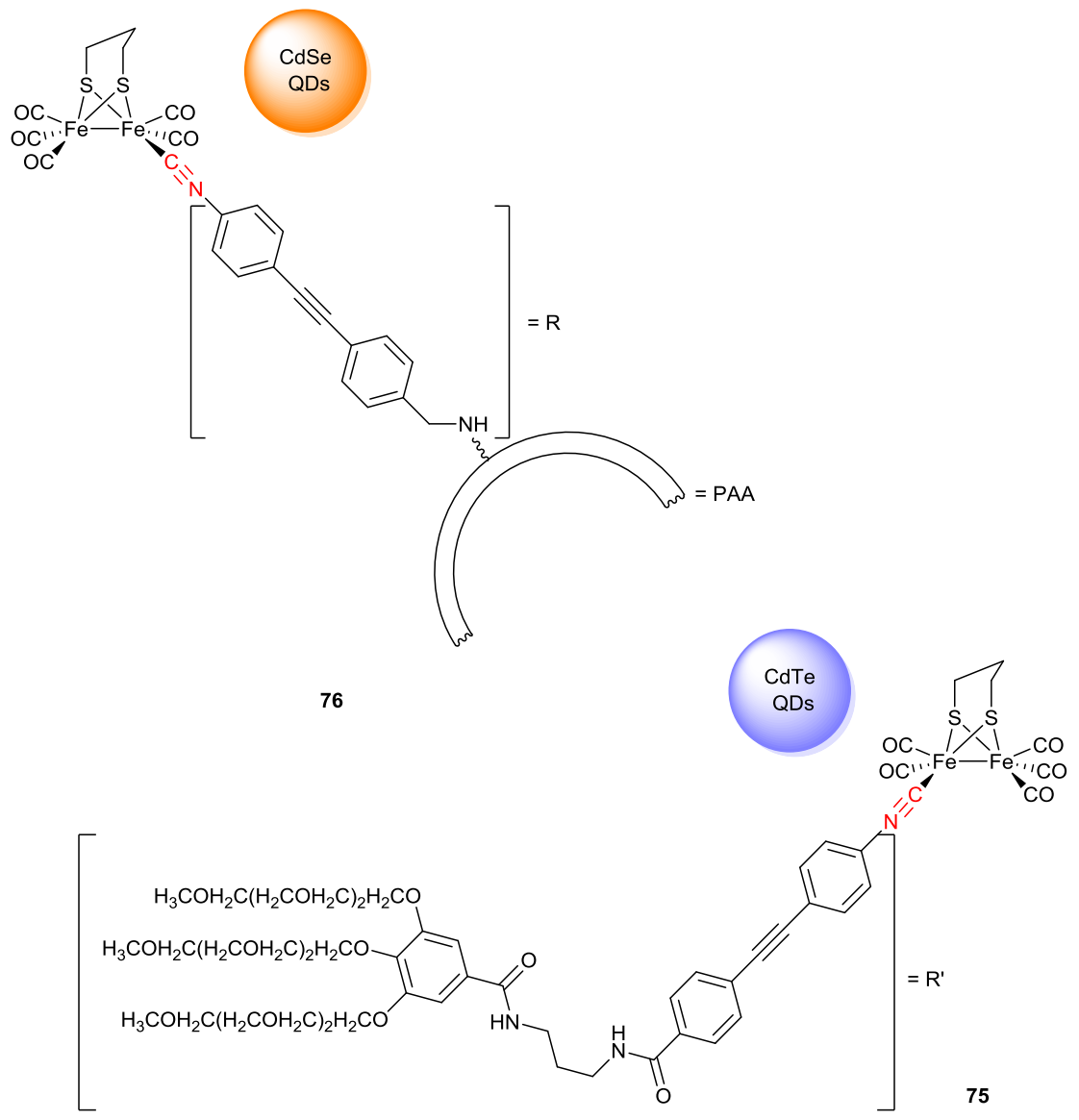

Figure 32. [( $\left.\mu-p d t) \mathrm{Fe}_{2}(\mathrm{CO})_{5}\left(\mathrm{CNR} / \mathrm{R}^{\prime}\right)\right]$ isocyanide complexes employed by $W u$ and coworkers, linked to a water soluble oligoether ligand $(R)(75)$, and a PAA polymer $\left(R^{\prime}\right)(76)$.

\subsection{Artificial maturation of [FeFe]-hydrogenase: the crucial role of the outer coordination sphere.}

During the biosynthesis, or maturation of $[\mathrm{FeFe}]$-hydrogenases, a pre-catalyst is first assembled onto the HydF protein, and from there delivered to the apo-form of HydA [203] for final maturation of the latter [204-207]. As a consequence it is anticipated that HydF contains a well-designed cavity for binding an $\left\{\mathrm{Fe}_{2}(\mathrm{CO})_{\mathrm{x}}(\mathrm{CN})_{\mathrm{y}}\right\}$ type complex. HydF actually contains a $[4 \mathrm{Fe}-4 \mathrm{~S}]$ cluster in which only three $\mathrm{Fe}$ atoms are ligated by a cysteine residue while the fourth one features a free coordination site, which has been shown to be accessible by nitrogen-based ligands such as imidazole [208].- Our group recently explored the possibility of exploiting this property of HydF to introduce synthetic complexes into the assembly line of the enzyme maturation machinery. The synthetic complexes chosen are some of the closest 
mimics of the catalytic subunit of [FeFe]-hydrogenases reported to date, all featuring $\mathrm{CN}^{-}$and CO ligands as well as a bridging dithiolate ligand, differing only in the nature of the bridgehead atom (3, 6 and 8) (Figure 8).

A novel coordination mode was observed in the 3/6/8-HydF hybrid proteins facilitated by the presence of a $[4 \mathrm{Fe}-4 \mathrm{~S}]$ cluster, in which only three Fe atoms are ligated by a cysteine residue whilst the fourth one features a free coordination site, shown to be accessible by nitrogenbased ligands such as imidazole [208]. This 'free' site allowed for the direct association between the dinuclear synthetic complex and the $[4 \mathrm{Fe}-4 \mathrm{~S}]$ cluster as observed in the active site of $[\mathrm{FeFe}]$ hydrogenases, albeit via a bridging cyanide ligand instead of a cysteine derived thiolate ligand (Figure 33). This was demonstrated through a set of spectroscopic (UVvisible, FTIR, EPR) techniques and related DFT computations for 3-HydF. Indeed, these synthetically constructed hybrids of $\mathrm{HydF}$ were found to be capable of mimicking the reactivity of native $\mathrm{HydF}$, i.e. transferring their di-iron complexes into apo-HydA, as shown by protein FTIR. Remarkably, the complex featuring a nitrogen bridgehead (6-HydF) generated a fully active enzyme [10], and more remarkable still, is that subsequent experiments illustrated that such a biomimetic activation pathway also occurs in the absence of the HydF maturase, albeit under different conditions [11]. These results finally settle the debate on the bridgehead atom's true identity [209, 210]. Furthermore, they illustrate the crucial importance of the protein environment in transforming this class of complexes into active catalysts. 

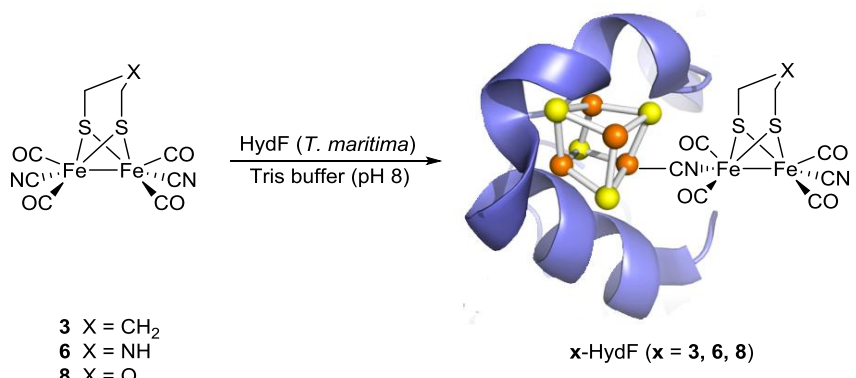

apo-HydA1 (C. reinhardtii) Phosphate buffer $(\mathrm{pH} \mathrm{6.8)}$

$3 \times=\mathrm{CH}_{2}$

$6 \mathrm{X}=\mathrm{NH}$

$x-\operatorname{HydF}(x=3,6,8)$

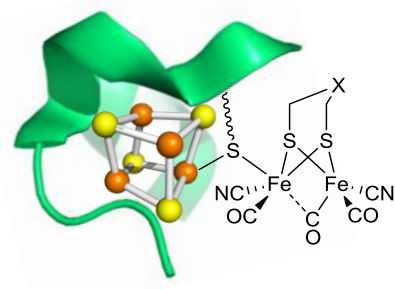

$x-\operatorname{HydA}(x=3,6,8)$

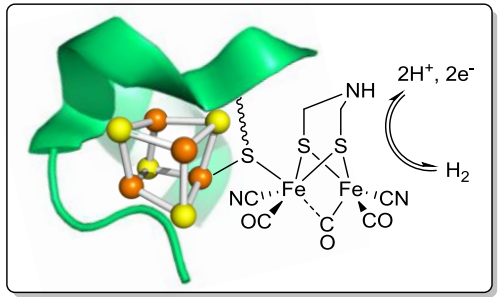

6-HydA

Figure 33. Scheme for the incorporation of 3, 6 and 8 into $\mathrm{HydF}$, bound to the [4Fe-4S]cluster via an isomerised CN ligand, and subsequent delivery of the diiron unit 6 into apoHydAl to produce the reactivated enzyme 6-HydA.

\section{Artificial hydrogenases}

Artificial metalloenzymes result from the association of a catalytically active synthetic organometallic or coordination compound with a bio-macromolecular host, protein or DNA [211-213]. A minimum of three effects contribute to the generally superior catalytic properties observed for (inorganic) catalytic co-factors when embedded inside a protein: i) site isolation, preventing aggregation; ii) substrate control - channels regulate the amount of substrate present around the catalyst, as well as protecting the latter from unwanted substrates; iii) specific protein-complex interactions, resulting in the stabilization of a specific geometry of the complex with enhanced catalytic properties (entatic states), via, for example, hydrogen bonding. The field of artificial metalloenzymes has enjoyed significant advances in a variety of catalytic applications during the last decade. In the following section their use for catalytic $\mathrm{H}_{2}$ evolution will be discussed. 


\subsection{Ni-based artificial hydrogenases}

Mononuclear Ni complexes based on diphosphine $\mathrm{P}_{2}^{\mathrm{R}} \mathrm{N}^{\mathrm{R}}{ }_{2}$ ligands, developed by $\mathrm{D}$. Dubois [163], are among the most efficient bioinspired catalysts for $\mathrm{H}_{2}$ production and uptake. The synthetic versatility of this class of compounds has allowed Shaw and coworkers to prepare a series of complexes (77-79) using diphosphine ligands functionalised through peptidic bonds with amino acids and amino acid esters in order to provide the Ni centre with a protein-like outer-coordination sphere and evaluate the impact of that environment, particularly with regards to the catalytic performances [214-216] (Figure 34). Interestingly these new complexes display excellent catalytic activities for the reduction of protons to $\mathrm{H}_{2}$ with high catalytic rates and moderate overpotentials. Significant variations of the catalytic activities as the result of varying the amino acid in the dipeptide, and thus the size and the charge of the side chains, were observed. Bulky ligands increase the overpotential requirement for $\mathrm{H}_{2}$ evolution. The catalytic performances were found superior when charged (basic > acidic) amino-acids are introduced with regards to those with neutral side chains. Catalysts bearing ester-protected ligands also proved less efficient. This is interpretated in terms of the capability of the functional groups of the ligands to concentrate water and protons near the active site and to facilitate proton transfer. This approach thus provides a unique opportunity to understand the contribution that the outer-coordination sphere can have in tuning the catalytic activity of this important class of hydrogenase mimics and opens the possibility to develop closer structural enzyme mimics with larger peptides. Recently a new amino-acid derivative (79) with glycine residues directly attached on the amine function of the ligand was reported. Upon aging in water, auto-reduction of the $\mathrm{Ni}(\mathrm{II})$ into a $\mathrm{Ni}(0)$ complex (80) occurs. A potential mechanism via decarboxylation of one glycine moiety is proposed to account for this reaction. Importantly, these compounds proved as very efficient catalysts for both hydrogen evolution in water over a wide range of pHs. A maximum turnovers frequencies of $33 \mathrm{~s}^{-1}$ and minimum overpotential requirement of $40 \mathrm{mV}$ is observed for hydrogen oxidation at $\mathrm{pH} 0.5$ [217]. 


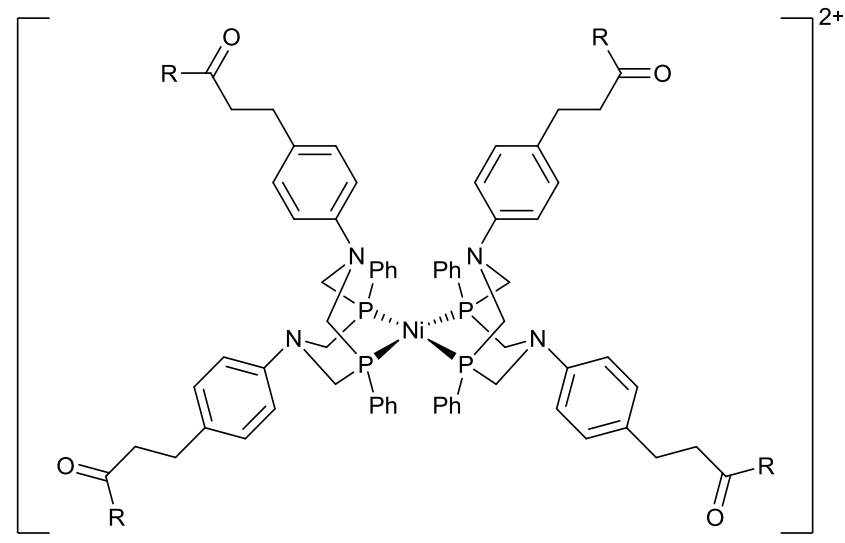

77. $\mathrm{R}=\mathrm{NH}_{2} \mathrm{CH}(\mathrm{Me}) \mathrm{COOH}$ or $\mathrm{NH}_{2} \mathrm{CH}(\mathrm{Me}) \mathrm{COOEt}$ 78. $\mathrm{R}=\mathrm{NH}_{2} \mathrm{CH}_{2} \mathrm{COOH}$ or $\mathrm{NHCH}_{2} \mathrm{COOEt}$

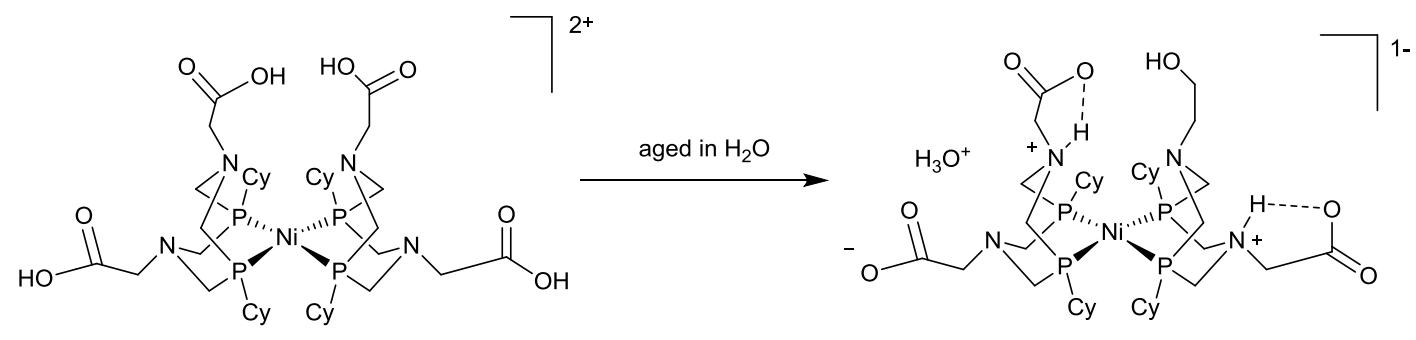

79

80

Figure 34. Schematic of a selected of highly active mono-nuclear Ni complexes bearing $P^{R}{ }_{2} N_{2}{ }_{2}$ type ligands, in which $R^{\prime}$ has been modified to feature amino acid or peptide functionalities (77-80).

Jones showed that it was possible to synthesize hetero-bimetallic Ni-M $\left(M_{n}=R u, F_{2}, M_{2}\right.$ and $\mathrm{W}_{2}$ ) complexes starting from the peptide-Ni complex 81, made with the heptapeptide AlaCys-Asp-Leu-Pro-Cys-Gly, a sequence present in nickel-superoxide dismutase containing the two cysteines that chelate the $\mathrm{Ni}$ ion in the active site of the enzyme (Figure 35) [218]. It has been demonstrated that the cysteinyl thiolates of that metallopeptide were indeed able to exchange labile ligands of organometallic complexes. The reaction thus generates polynuclear species with two cysteinyl thiolate bridges between $\mathrm{Ni}$ and either a single $\mathrm{Ru}(\mathbf{8 2})$, two $\mathrm{Fe}$ (83), two Mo or two W (84) organometallic units. However, these new and rather interesting hetero-bimetallic compounds have not been evaluated for their catalytic activity thus far. 

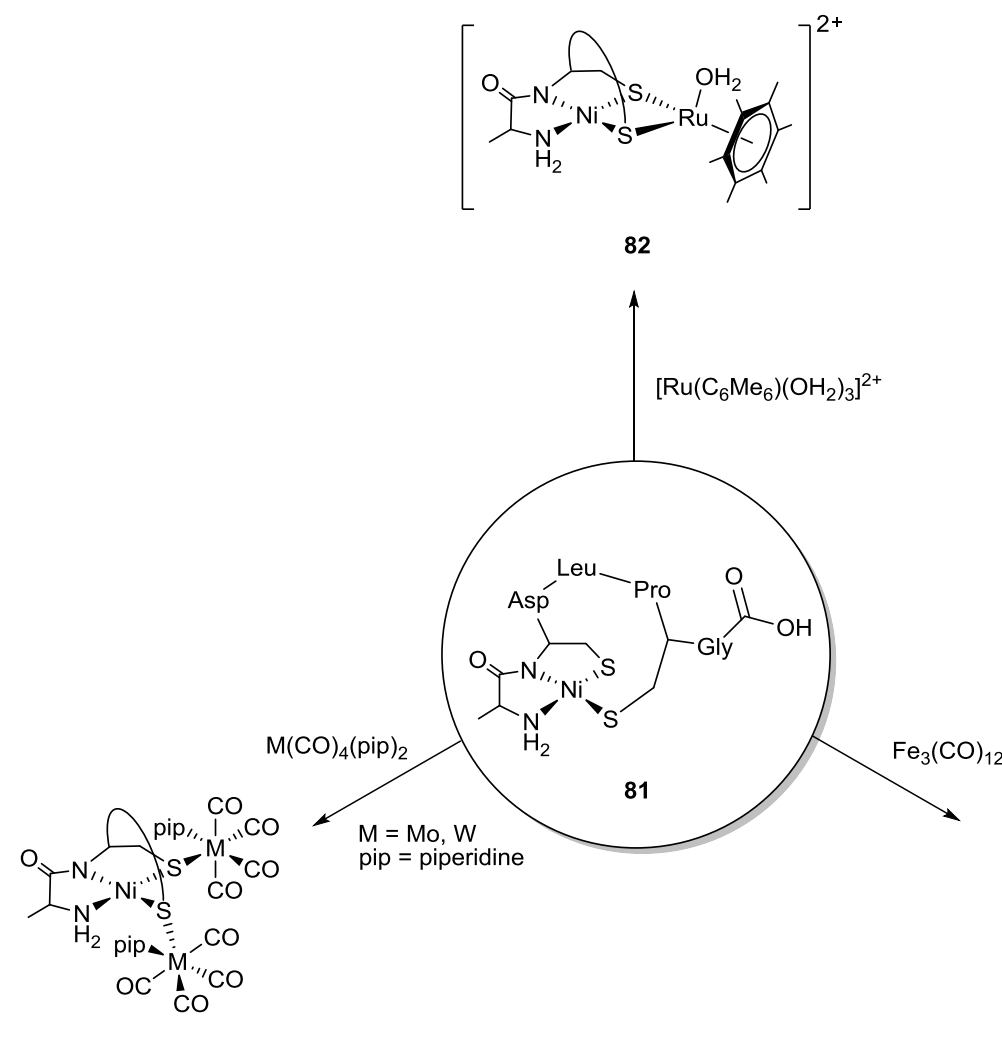

84

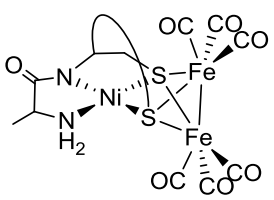

83

Figure 35. The four [NiM] systems prepared by Jones and co-workers [170], from the Ni complex in which the Ni ion is chelated by the two sulphurs of the heptapeptide Ala-Cys-AspLeu-Pro-Cys-Gly (81).

\subsection{Artificial hydrogenases based on synthetic diiron complexes}

Synthetic di-iron complexes mimicking the active site of [FeFe]-hydrogenases have also been incorporated into peptides and proteins. The general concept of this approach is to covalently attach the complexes to a polypeptide backbone via the bridging dithiolate moiety. This can be done by either taking advantage of two appropriately placed cysteine derived thiolate ligands, or by introducing synthetic amino acids containing a propyl bridged dithiolate ligand (Figure 36). 


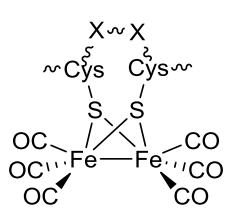

85

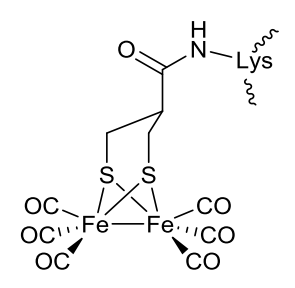

86

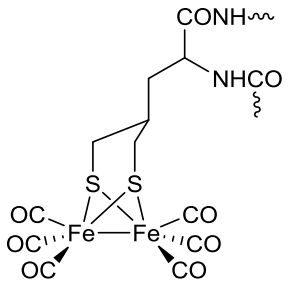

87

Figure 36. Representation of the different way used to covalently attach diiron cores to a peptide backbone (wiggly lines indicate peptidic linkages).

Two representative examples have been reported by Jones and co-workers using de novo designed oligo peptides. By reacting $\mathrm{Fe}_{3}(\mathrm{CO})_{12}$ with an alanine rich, 36 amino-acids long, peptide featuring a CXXC sequence, in which the two cysteine residues are correctly positioned to establish a dithiolate bridge, a new species was obtained [219]. Based on a combination of mass spectrometry, FTIR, circular dichroism (CD) and UV/Visible spectroscopy measurements, the formation of a $\left[\left(\mu-\mathrm{S}_{\mathrm{cys}}\right)_{2} \mathrm{Fe}_{2}(\mathrm{CO})_{6}\right](\mathbf{8 5})$ complex, bound to one face of the $\alpha$-helical peptide and structurally analogous with the active site of [FeFe]hydrogenases was suggested (Figure 36). An alternative synthetic route employing an artificial amino acid was reported in 2011. An oligopeptide incorporating a lysine (Trp-AlaSer-Lys-Leu-Pro-Ser-Gly) was synthesized, to which a propane dithiolate ligand was linked via the lysine moiety by means of amide coupling. The formation of the corresponding $[(\mu-$ $\left.\left.\left\{\mathrm{SCH}_{2}\right\}_{2} \mathrm{CCONHR}\right) \mathrm{Fe}_{2}(\mathrm{CO})_{6}\right]$ complex (86, R = Trp-Ala-Ser-Lys-Leu-Pro-Ser-Gly) (Figure 36) and its subsequent modification to form the di-phosphine analogue, $(\mu$ $\left.\left.\left\{\mathrm{SCH}_{2}\right\}_{2} \mathrm{CHCONHR}\right) \mathrm{Fe}_{2}(\mathrm{CO})_{4}\left(\mathrm{PMe}_{3}\right)_{2}\right]$, was confirmed by FTIR [220].

Such a synthetic artificial amino acid containing a 1,3-dithiol side chain, was incorporated into an alanine-rich 19-mer peptide, known to provide a helical structure. The dithiolate served as double bridge to anchor the di-iron unit of $\mathbf{8 7}$ in the helical peptide (Figure 36). The resulting hybrid system features a $\mathrm{pH}$ dependent irreversible reduction process at $-1.1 \mathrm{~V}$ vs. RHE and was shown to catalyse light-driven $\mathrm{H}_{2}$ evolution at $\mathrm{pH} 4.5$ in aqueous conditions and in the presence of $\left[\mathrm{Ru}(\mathrm{bpy})_{3}\right]^{2+}$ as the photosensitizer and ascorbate as the sacrificial electron donor, resulting in a total TON of 84 (with regards to the catalyst) in $2.3 \mathrm{~h}$ [221]. 
Hayashi and coworkers demonstrated that hybrid systems could be prepared simply by treating apo-cytochrome c (cytc) with $\mathrm{Fe}_{2}(\mathrm{CO})_{9}$ [222]. Mass spectrometry and FTIR spectroscopy indicated a $\left[\left(\mu-\mathrm{S}_{\mathrm{cys}}\right)_{2} \mathrm{Fe}_{2}(\mathrm{CO})_{6}\right]$ structure $(\mathbf{8 5})$ similar to the one obtained by $\mathrm{A}$. K. Jones $[219,220]$ ENREF 36 . This biohybrid displayed catalytic activity for hydrogen production from water ( 82 turnovers in $2 \mathrm{~h}$ at $\mathrm{pH} 4.7$ ) when irradiated in the presence of $\left[\mathrm{Ru}(\text { bipy })_{3}\right]^{2+}$ and ascorbate. Much lower activity was obtained when cytochrome c was replaced by a cytc-derived heptapeptide fragment containing the Cys-X-X-Cys sequence, illustrating the importance of a complete protein environment.

In another study, an octadecapeptide fragment derived from cytochrome c556 and containing a Cys-X-X-Cys-His sequence was used to attach both the di-iron carbonyl cluster to cysteines and a Ru-based photosensitizer, $[\mathrm{Ru}(\mathrm{tpy})(\mathrm{bpy})(\mathrm{His})]^{2+}$, to histidine [223]. In fact, direct coordination of the $\mathrm{Ru}$ complex within the protein cavity was found to be crucial for photocatalysis. Visible light irradiation of the $[\mathrm{FeFe}][\mathrm{Ru}]$-peptide in the presence of ascorbate resulted in catalytic $\mathrm{H}_{2}$ evolution with a total TON of 8 in $2 \mathrm{~h}$, at which point $\mathrm{H}_{2}$ production reached a plateau. However, when the reaction was performed under similar conditions using the $[\mathrm{FeFe}]$-peptide and free $[\mathrm{Ru}(\mathrm{tpy})(\mathrm{bpy})(\mathrm{Im})]^{2+}$ as the photosensitizer, no $\mathrm{H}_{2}$ production was observed.

\section{Conclusion}

During the last decade, biomimetic chemistry has proven very effective for the development of models of the structure of the active sites of hydrogenase enzymes, and the current synthetic capabilities allow for the replication of almost all the key features of the natural active subsites. Noticeable advances in the recent years include isolation of a terminal hydrides by Rauchfuss and co-workers in 2012 [87, 88] and the preparation of the first [FeFe] hydrogenase mimic capable of catalytic $\mathrm{H}_{2}$ oxidation. Remarkably this latter complex, [ $\mu$ $\left.\left\{\left(\mathrm{SCH}_{2}\right)_{2} \mathrm{NBn}\right\} \mathrm{Fe}_{2}(\mathrm{CO})_{3}\left(\mathrm{FcP}^{*}\right)(\mathrm{dppv})\right]$, is also the only system containing a functional electron transfer relay [133]. Two Ni-Fe mimics capable of non-catalytic bidirectional $\mathrm{H}_{2}$ oxidation have also recently reported by Ogo [158] and Rauchfuss [166]. Unfortunately, whilst these sophisticated models can provide valuable insights into the intimate mechanisms of the natural active sites, there remains a notable absence of model systems that are capable 
of achieving similar levels of catalytic activity as the hydrogenase enzymes, with most operating at rates several orders of magnitude lower.

By contrast, controlling the outer sphere environment of these mimics, through incorporation into micelles or dendrimers, has allowed for a significant improvement of the activity and stability of model systems in more naturally relevant media. Indeed, such elegant guest-host systems are capable of several thousand turn-overs by photolysis, conditions traditionally too harsh for homogenous catalytic systems to withstand. It is important to note that direct comparison of these catalytic systems is somewhat hampered by the wide and varied photocatalytic conditions employed, nevertheless, these results clearly demonstrate the relative strength of the guest-host approach [200, 202].

This strategy has been successfully extended to produce elegantly designed artificial hydrogenases based on synthetic biomimics, incorporated into peptidic or proteic frameworks. In general, these artificial hydrogenases are more stable and active for $\mathrm{H}_{2}$ evolution in water than the parent biomimetic complexes.

Finally artificial activation of a hydrogenase enzyme has been achieved through the introduction of a synthetic organometallic moiety into an apo-[FeFe]-hydrogenase [10], via the chaperone protein HydF, which yields a fully active enzyme. This work has allowed for final confirmation of the nature of the bridgehead atom of the bridging dithiolate ligand as that of a nitrogen, but more importantly, it rather effortlessly highlights the essential role that the protein cavity plays in transforming the typically fragile (in aqueous media) catalytically inactive complex $\left[(\mu \text {-adt }) \mathrm{Fe}_{2}(\mathrm{CO})_{4}(\mathrm{CN})_{2}\right]^{2-}(\mathbf{6})$ into a robust and highly efficient catalytic machine.

\section{Acknowledgments}

This work was supported by the French National Research Agency (ANR, NiFe-Cat ANR10-BLAN-711 and Labex program ARCANE, ANR-11-LABX-0003-01) and the FCH Joint Undertaking (ArtipHyction project, grant n. 303435 and Nano-Cat project, grant n. 325239) . GB gratefully acknowledges Bengt Lundqvist minnesfond, FORMAS (contract number 2132010-563) and the Swedish royal academy of sciences.

\section{References and notes}


[1] M. Frey, ChemBioChem, 3 (2002) 153.

[2] N. Armaroli and V. Balzani, ChemSusChem, 4 (2011) 21.

[3] A.K. Jones, E. Sillery, S.P.J. Albracht and F.A. Armstrong, Chem. Commun., (2002) 866.

[4] J.A. Cracknell, K.A. Vincent and F.A. Armstrong, Chem. Rev., 108 (2008) 2439.

[5] S.T. Stripp, G. Goldet, C. Brandmayr, O. Sanganas, K.A. Vincent, M. Haumann, F.A.

Armstrong and T. Happe, Proc. Natl. Acad. Sci. USA, 106 (2009) 17331.

[6] A. Abou Hamdan, B. Burlat, O. Gutierrez-Sanz, P.P. Liebgott, C. Baffert, A.L. De Lacey, M. Rousset, B. Guigliarelli, C. Leger and S. Dementin, Nature Chemical Biology, 9 (2013) 15.

[7] J. Fritsch, P. Scheerer, S. Frielingsdorf, S. Kroschinsky, B. Friedrich, O. Lenz and C.M.T. Spahn, Nature, 479 (2011) 249.

[8] Y. Shomura, K.S. Yoon, H. Nishihara and Y. Higuchi, Nature, 479 (2011) 253.

[9] K. Grubel and P.L. Holland, Angew. Chem. Int. Ed., 51 (2012) 3308.

[10] G. Berggren, A. Adamska, C. Lambertz, T.R. Simmons, J. Esselborn, M. Atta, S. Gambarelli, J.M. Mouesca, E. Reijerse, W. Lubitz, T. Happe, V. Artero and M. Fontecave, Nature, 499 (2013) 66. [11] J. Esselborn, C. Lambertz, A. Adamska-Venkatesh, T. Simmons, G. Berggren, J. Noth, J. Siebel, A. Hemschemeier, V. Artero, E. Reijerse, M. Fontecave, W. Lubitz and T. Happe, Nat Chem Biol, advance online publication (2013).

[12] R.K. Thauer, Eur. J. Inorg. Chem., 2011919.

[13] K.A. Vincent, A. Parkin and F.A. Armstrong, Chem. Rev., 107 (2007) 4366.

[14] A. Magnuson, M. Anderlund, O. Johansson, P. Lindblad, R. Lomoth, T. Polivka, S. Ott, K. Stensjö, S. Styring, V. Sundström and L. Hammarström, Acc. Chem. Res., 42 (2009) 1899.

[15] R.K. Thauer, A.R. Klein and G.C. Hartmann, Chem. Rev., 96 (1996) 3031.

[16] J.C. Fontecilla-Camps, A. Volbeda, C. Cavazza and Y. Nicolet, Chem. Rev., 107 (2007) 4273.

[17] R.K. Thauer, A.K. Kaster, M. Goenrich, M. Schick, T. Hiromoto and S. Shima, Annual

Review of Biochemistry, Vol 79, 79 (2010) 507.

[18] the extra energy required for the reaction over that defined by the standard potential of the $\mathrm{H}+\mathrm{H} 2$ redox couple; in other words, the difference between the potential that needs to be applied to the system to allow it to function and the standard potential of the $\mathrm{H}+/ \mathrm{H} 2$ redox couple

[19] H.R. Pershad, J.L.C. Duff, H.A. Heering, E.C. Duin, S.P.J. Albracht and F.A. Armstrong, Biochemistry, 38 (1999) 8992.

[20] C. Madden, M.D. Vaughn, I. Diez-Perez, K.A. Brown, P.W. King, D. Gust, A.L. Moore and T.A. Moore, J. Am. Chem. Soc., 134 (2012) 1577.

[21] J.W. Peters, W.N. Lanzilotta, B.J. Lemon and L.C. Seefeldt, Science, 282 (1998) 1853.

[22] Y. Nicolet, C. Piras, P. Legrand, C.E. Hatchikian and J.C. Fontecilla-Camps, Structure, 7 (1999) 13.

[23] Z.J. Chen, B.J. Lemon, S. Huang, D.J. Swartz, J.W. Peters and K.A. Bagley, Biochemistry, 41 (2002) 2036.

[24] W. Roseboom, A.L. De Lacey, V.M. Fernandez, E.C. Hatchikian and S.P.J. Albracht, J. Biol. Inorg. Chem., 11 (2006) 102.

[25] A.L. De Lacey, C. Stadler, C. Cavazza, E.C. Hatchikian and V.M. Fernandez, J. Am. Chem. Soc., $122(2000) 11232$.

[26] P.E.M. Siegbahn, J.W. Tye and M.B. Hall, Chem. Rev., 107 (2007) 4414.

[27] C.V. Popescu and E. Munck, J. Am. Chem. Soc., 121 (1999) 7877.

[28] Y. Nicolet, A.L. de Lacey, X. Vernede, V.M. Fernandez, E.C. Hatchikian and J.C. FontecillaCamps, J. Am. Chem. Soc., 123 (2001) 1596.

[29] A. Silakov, B. Wenk, E. Reijerse and W. Lubitz, Physical Chemistry Chemical Physics, 11 (2009) 6592.

[30] W. Lubitz, E. Reijerse and M. van Gastel, Chem. Rev., 107 (2007) 4331. 
[31] Ö.F. Erdem, L. Schwartz, M. Stein, A. Silakov, S. Kaur-Ghumaan, P. Huang, S. Ott, E.J. Reijerse and W. Lubitz, Angewandte Chemie International Edition, 50 (2011) 1439.

[32] K.A. Vincent, A. Parkin, O. Lenz, S.P.J. Albracht, J.C. Fontecilla-Camps, R. Cammack, B. Friedrich and F.A. Armstrong, J. Am. Chem. Soc., 127 (2005) 18179.

[33] C. Tard and C.J. Pickett, Chem. Rev., 109 (2009) 2245.

[34] A. Adamska, A. Silakov, C. Lambertz, O. Rüdiger, T. Happe, E. Reijerse and W. Lubitz, Angew. Chem. Int. Ed., 51 (2012) 11458.

[35] D.W. Mulder, M.W. Ratzloff, E.M. Shepard, A.S. Byer, S.M. Noone, J.W. Peters, J.B. Broderick and P.W. King, J. Am. Chem. Soc., 135 (2013) 6921.

[36] A. Volbeda, M.-H. Charon, C. Piras, E.C. Hatchikian, M. Frey and J.C. Fontecilla-Camps, Nature, 373 (1995) 580.

[37] A. Volbeda, E. Garcin, C. Piras, A.L. de Lacey, V.M. Fernandez, E.C. Hatchikian, M. Frey and J.C. Fontecilla-Camps, Journal of the American Chemical Society, 118 (1996) 12989.

[38] A. Volbeda, L. Martin, C. Cavazza, M. Matho, B.W. Faber, W. Roseboom, S.P.J. Albracht, E. Garcin, M. Rousset and J.C. Fontecilla-Camps, J. Biol. Inorg. Chem., 10 (2005) 239.

[39] S. Canaguier, V. Artero and M. Fontecave, Dalton Trans., (2008) 315.

[40] Y. Montet, P. Amara, A. Volbeda, X. Vernede, E.C. Hatchikian, M.J. Field, M. Frey and J.C. FontecillaCamps, Nature Structural Biology, 4 (1997) 523.

[41] C. Leger, S. Dementin, P. Bertrand, M. Rousset and B. Guigliarelli, J. Am. Chem. Soc., 126 (2004) 12162.

[42] F. Leroux, S. Dementin, B. Burlatt, L. Cournac, A. Volbeda, S. Champ, L. Martin, B.

Guigliarelli, P. Bertrand, J. Fontecilla-Camps, M. Rousset and C. Leger, Proc. Natl. Acad. Sci. USA, 105 (2008) 11188.

[43] H. Ogata, Y. Mizoguchi, N. Mizuno, K. Miki, S. Adachi, N. Yasuoka, T. Yagi, O. Yamauchi, S. Hirota and Y. Higuchi, J. Am. Chem. Soc., 124 (2002) 11628.

[44] C. Tsay and J.C. Peters, Chem. Sci., 3 (2012) 1313.

[45] S. Niu and N.B. Hall, Inorg. Chem., 40 (2001) 6201.

[46] T. Krämer, M. Kampa, W. Lubitz, M. van Gastel and F. Neese, ChemBioChem, 14 (2013) 1898.

[47] J.P. Whitehead, R.J. Gurbiel, C. Bagyinka, B.M. Hoffman and M.J. Maroney, J. Am. Chem. Soc., 115 (1993) 5629.

[48] M. Brecht, M. van Gastel, T. Buhrke, B. Friedrich and W. Lubitz, J. Am. Chem. Soc., 125 (2003) 13075.

[49] S. Foerster, M. van Gastel, M. Brecht and W. Lubitz, J. Biol. Inorg. Chem., 10 (2005) 51.

[50] W. Lubitz, M. Brecht, S. Foerster, M. Stein, Y. Higuchi, T. Buhrke and B. Friedrich, Epr in the 21st Century: Basics and Applications to Material, Life and Earth Sciences, (2002) 437.

[51] M.E. Pandelia, P. Infossi, M. Stein, M.T. Giudici-Orticoni and W. Lubitz, Chem. Commun., $48(2012) 823$.

[52] T.R. Simmons and V. Artero, Angew. Chem. Int. Ed., 52 (2013) 6143.

[53] S. Vogt, E.J. Lyon, S. Shima and R.K. Thauer, J. Biol. Inorg. Chem., 13 (2008) 97.

[54] G. Buurman, S. Shima and R.K. Thauer, FEBS Lett., 485 (2000) 200.

[55] S. Shima, E.J. Lyon, M.S. Sordel-Klippert, M. Kauss, J. Kahnt, R.K. Thauer, K. Steinbach, X.L.

Xie, L. Verdier and C. Griesinger, Angew. Chem. Int. Ed., 43 (2004) 2547.

[56] E.J. Lyon, S. Shima, R. Boecher, R.K. Thauer, F.W. Grevels, E. Bill, W. Roseboom and S.P. Albracht, J. Am. Chem. Soc., 126 (2004) 14239.

[57] S. Shima, O. Pilak, S. Vogt, M. Schick, M.S. Stagni, W. Meyer-Klaucke, E. Warkentin, R.K. Thauer and U. Ermler, Science, 321 (2008) 572.

[58] M. Korbas, S. Vogt, W. Meyer-Klaucke, E. Bill, E.J. Lyon, R.K. Thauer and S. Shima, J. Biol. Chem., 281 (2006) 30804.

[59] T. Hiromoto, K. Ataka, O. Pilak, S. Vogt, M.S. Stagni, W. Meyer-Klaucke, E. Warkentin, R.K. Thauer, S. Shima and U. Ermler, FEBS Lett., 583 (2009) 585.

[60] S. Shima and K. Ataka, FEBS Lett., 585 (2011) 353. 
[61] H. Tamura, M. Salomone-Stagni, T. Fujishiro, E. Warkentin, W. Meyer-Klaucke, U. Ermler and S. Shima, Angew. Chem. Int. Ed., 52 (2013) 9656.

[62] T. Hiromoto, E. Warkentin, J. Moll, U. Ermler and S. Shima, Angew. Chem. Int. Ed., 48 (2009) 6457.

[63] X.Z. Yang and M.B. Hall, J. Am. Chem. Soc., 131 (2009) 10901.

[64] H. Reihlen, A. Gruhl and G. Hessling, Liebigs Ann. Chem., 472 (1929) 268.

[65] D. Seyferth, G.B. Womack, M.K. Gallagher, M. Cowie, B.W. Hames, J.P. Fackler and A.M.

Mazany, Organometallics, 6 (1987) 283.

[66] A. Le Cloirec, S.P. Best, S. Borg, S.C. Davies, D.J. Evans, D.L. Hughes and C.J. Pickett, Chem. Commun., (1999) 2285.

[67] M. Schmidt, S.M. Contakes and T.B. Rauchfuss, J. Am. Chem. Soc., 121 (1999) 9736.

[68] E.J. Lyon, I.P. Georgakaki, J.H. Reibenspies and M.Y. Darensbourg, Angew. Chem. Int. Ed., 38 (1999) 3178.

[69] J.D. Lawrence, H.X. Li, T.B. Rauchfuss, M. Benard and M.M. Rohmer, Angew. Chem. Int. Ed., 40 (2001) 1768.

[70] L.C. Song, Z.Y. Yang, H.Z. Bian and Q.M. Hu, Organometallics, 23 (2004) 3082.

[71] L.C. Song, Z.Y. Yang, H.Z. Bian, Y. Liu, H.T. Wang, X.F. Liu and Q.M. Hu, Organometallics, 24 (2005) 6126.

[72] J.F. Capon, F. Gloaguen, F.Y. Petillon, P. Schollhammer and J. Talarmin, Coord. Chem. Rev., 253 (2009) 1476.

[73] M. Razavet, S.C. Davies, D.L. Hughes and C.J. Pickett, Chem. Commun., (2001) 847.

[74] J.I. van der Vlugt, T.B. Rauchfuss and S.R. Wilson, Chem. Eur. J., 12 (2006) 90.

[75] C.A. Boyke, T.B. Rauchfuss, S.R. Wilson, M.M. Rohmer and M. Benard, J. Am. Chem. Soc., 126 (2004) 15151.

[76] C.A. Boyke, J.I. van der Vlugt, T.B. Rauchfuss, S.R. Wilson, G. Zampella and L. De Gioia, J. Am. Chem. Soc., 127 (2005) 11010.

[77] D. Chouffai, G. Zampella, J.F. Capon, L. De Gioia, A. Le Goff, F.Y. Petillon, P. Schollhammer and J. Talarmin, Organometallics, 31 (2012) 1082.

[78] A.K. Justice, M.J. Nilges, T.B. Rauchfuss, S.R. Wilson, L. De Gioia and G. Zampella, J. Am. Chem. Soc., 130 (2008) 5293.

[79] A.K. Justice, L. De Gioia, M.J. Nilges, T.B. Rauchfuss, S.R. Wilson and G. Zampella, Inorg. Chem., 47 (2008) 7405.

[80] A.K. Justice, T.B. Rauchfuss and S.R. Wilson, Angew. Chem. Int. Ed., 46 (2007) 6152.

[81] T.B. Liu and M.Y. Darensbourg, J. Am. Chem. Soc., 129 (2007) 7008.

[82] C.M. Thomas, T.B. Liu, M.B. Hall and M.Y. Darensbourg, Inorg. Chem., 47 (2008) 7009.

[83] M.L. Singleton, N. Bhuvanesh, J.H. Reibenspies and M.Y. Darensbourg, Angew. Chem. Int. Ed., 47 (2008) 9492.

[84] W. Wang, T.B. Rauchfuss, C.E. Moore, A.L. Rheingold, L. De Gioia and G. Zampella, Chemistry - A European Journal, 19 (2013) 15476.

[85] S. Munery, J.-F. Capon, L. De Gioia, C. Elleouet, C. Greco, F.Y. Pétillon, P. Schollhammer, J. Talarmin and G. Zampella, Chemistry - A European Journal, 19 (2013) 15458.

[86] J.I. van der Vlugt, T.B. Rauchfuss, C.M. Whaley and S.R. Wilson, J. Am. Chem. Soc., 127 (2005) 16012.

[87] M.E. Carroll, B.E. Barton, T.B. Rauchfuss and P.J. Carroll, J. Am. Chem. Soc., 134 (2012) 18843.

[88] R. Zaffaroni, T.B. Rauchfuss, D.L. Gray, L. De Gioia and G. Zampella, J. Am. Chem. Soc., 134 (2012) 19260.

[89] C. Tard, X.M. Liu, S.K. Ibrahim, M. Bruschi, L. De Gioia, S.C. Davies, X. Yang, L.S. Wang, G. Sawers and C.J. Pickett, Nature, 433 (2005) 610.

[90] M.K. Harb, T. Niksch, J. Windhager, H. Gorls, R. Holze, L.T. Lockett, N. Okumura, D.H. Evans, R.S. Glass, D.L. Lichtenberger, M. El-Khateeb and W. Weigand, Organometallics, 28 (2009) 1039. 
[91] M.K. Harb, J. Windhager, A. Daraosheh, H. Gorls, L.T. Lockett, N. Okumura, D.H. Evans, R.S. Glass, D.L. Lichtenberger, M. El-Khateeb and W. Weigand, Eur. J. Inorg. Chem., (2009) 3414.

[92] T. Kuckmann, F. Schodel, I. Sanger, M. Bolte, M. Wagner and H.W. Lerner, Eur. J. Inorg. Chem., (2010) 468.

[93] U.P. Apfel, D. Troegel, Y. Halpin, S. Tschierlei, U. Uhlemann, H. Gorls, M. Schmitt, J. Popp, P. Dunne, M. Venkatesan, M. Coey, M. Rudolph, J.G. Vos, R. Tacke and W. Weigand, Inorg. Chem., 49 (2010) 10117.

[94] U.P. Apfel, Y. Halpin, H. Gorls, J.G. Vos and W. Weigand, Eur. J. Inorg. Chem., (2011) 581.

[95] M.K. Harb, U.P. Apfel, J. Kubel, H. Gorls, G.A.N. Felton, T. Sakamoto, D.H. Evans, R.S. Glass, D.L. Lichtenberger, M. El-Khateeb and W. Weigand, Organometallics, 28 (2009) 6666.

[96] U.P. Apfel, H. Gorls, G.A.N. Felton, D.H. Evans, R.S. Glass, D.L. Lichtenberger and W. Weigand, Helv. Chim. Acta, 95 (2012) 2168.

[97] L.C. Song, Q.L. Li, Z.H. Feng, X.J. Sun, Z.J. Xie and H.B. Song, Dalton Trans., 42 (2013) 1612. [98] M.K. Harb, H. Gorls, T. Sakamoto, G.A.N. Felton, D.H. Evans, R.S. Glass, D.L. Lichtenberger, M. El-khateeb and W. Weigand, Eur. J. Inorg. Chem., (2010) 3976.

[99] S. Gao, J. Fan, S. Sun, X. Peng, X. Zhao and J. Hou, Dalton Trans., 0 (2008) 2128.

[100] E.S. Donovan, J.J. McCormick, G.S. Nichol and G.A.N. Felton, Organometallics, 31 (2012)

8067.

[101] L. Schwartz, P.S. Singh, L. Eriksson, R. Lomoth and S. Ott, C. R. Chim., 11 (2008) 875.

[102] F. Gloaguen, J.D. Lawrence and T.B. Rauchfuss, J. Am. Chem. Soc., 123 (2001) 9476.

[103] X. Zhao, I.P. Georgakaki, M.L. Miller, J.C. Yarbrough and M.Y. Darensbourg, J. Am. Chem. Soc., 123 (2001) 9710.

[104] W. Zhong, Y. Tang, G. Zampella, X.F. Wang, X.L. Yang, B. Hu, J.A. Wang, Z.Y. Xiao, Z.H. Wei, H.W. Chen, L. De Gioia and X.M. Liu, Inorg. Chem. Commun., 13 (2010) 1089.

[105] Y. Tang, Z.H. Wei, W. Zhong and X.M. Liu, Eur. J. Inorg. Chem., (2011) 1112.

[106] M. Karnahl, S. Tschierlei, O.F. Erdem, S. Pullen, M.P. Santoni, E.J. Reijerse, W. Lubitz and S. Ott, Dalton Trans., 41 (2012) 12468.

[107] S. Ezzaher, A. Gogoll, C. Bruhn and S. Ott, Chem. Commun., 46 (2010) 5775.

[108] W.B. Dong, M. Wang, X.Y. Liu, K. Jin, G.H. Li, F.J. Wang and L.C. Sun, Chem. Commun., (2006) 305.

[109] C.P. Liu, J.N.T. Peck, J.A. Wright, C.J. Pickett and M.B. Hall, Eur. J. Inorg. Chem., (2011)

1080.

[110] S. Tschierlei, S. Ott and R. Lomoth, Energy Environ. Sci., 4 (2011) 2340.

[111] Y.C. Liu, K.T. Chu, R.L. Jhang, G.H. Lee and M.H. Chiang, Chem. Commun., 49 (2013) 4743.

[112] W.M. Gao, J.L. Sun, T. Akermark, M.R. Li, L. Eriksson, L.C. Sun and B. Akermark, Chem. Eur. J., 16 (2010) 2537.

[113] S. Ezzaher, J.F. Capon, F. Gloaguen, F.Y. Petillon, P. Schollhammer, J. Talarmin and N.

Kervarec, Inorg. Chem., 48 (2009) 2.

[114] Y.W. Wang, Z.M. Li, X.H. Zeng, X.F. Wang, C.X. Zhan, Y.Q. Liu, X.R. Zeng, Q.Y. Luo and X.M. Liu, New J. Chem., 33 (2009) 1780.

[115] P. Li, M. Wang, L. Chen, J.H. Liu, Z.B. Zhaoa and L.C. Sun, Dalton Trans., (2009) 1919.

[116] X. Zhao, I.P. Georgakaki, M.L. Miller, R. Mejia-Rodriguez, C.Y. Chiang and M.Y.

Darensbourg, Inorg. Chem., 41 (2002) 3917.

[117] I.P. Georgakaki, M.L. Miller and M.Y. Darensbourg, Inorg. Chem., 42 (2003) 2489.

[118] N. Wang, M. Wang, J.H. Liu, K. Jin, L. Chen and L.C. Sun, Inorg. Chem., 48 (2009) 11551.

[119] M.T. Olsen, T.B. Rauchfuss and S.R. Wilson, J. Am. Chem. Soc., 132 (2010) 17733.

[120] K. Fauvel, R. Mathieu and R. Poilblanc, Inorg. Chem., 15 (1976) 976.

[121] S. Ezzaher, J.F. Capon, F. Gloaguen, F.Y. Petillon, P. Schollhammer and J. Talarmin, Inorg. Chem., 46 (2007) 3426.

[122] B.E. Barton and T.B. Rauchfuss, Inorg. Chem., 47 (2008) 2261.

[123] F.I. Adam, G. Hogarth, S.E. Kabir and D. Richards, C. R. Chim., 11 (2008) 890.

[124] B.E. Barton, M.T. Olsen and T.B. Rauchfuss, J. Am. Chem. Soc., 130 (2008) 16834.

[125] B.E. Barton, M.T. Olsen and T.B. Rauchfuss, Curr. Opin. Biotechnol., 21 (2010) 292. 
[126] X.H. Zeng, Z.M. Li, Z.Y. Xiao, Y.W. Wang and X.M. Liu, Electrochem. Commun., 12 (2010)

[127] J. Zhao, Z.H. Wei, X.H. Zeng and X.M. Liu, Dalton Trans., 41 (2012) 11125.

[128] C. Gimbert-Surinach, M. Bhadbhade and S.B. Colbran, Organometallics, 31 (2012) 3480.

[129] Y.-C. Liu, C.-H. Lee, G.-H. Lee and M.-H. Chiang, Eur. J. Inorg. Chem., 2011 (2011) 1155.

[130] Y.-C. Liu, T.-H. Yen, Y.-J. Tseng, C.-H. Hu, G.-H. Lee and M.-H. Chiang, Inorg. Chem., 51

(2012) 5997.

[131] Y.T. Si, K. Charreteur, J.F. Capon, F. Gloaguen, F.Y. Petillon, P. Schollhammer and J.

Talarmin, J. Inorg. Biochem., 104 (2010) 1038.

[132] S. Roy, T.L. Groy and A.K. Jones, Dalton Trans., 42 (2013) 3843.

[133] J.M. Camara and T.B. Rauchfuss, Nature Chemistry, 4 (2012) 26.

[134] C. Greco, Inorg. Chem., 52 (2013) 1901.

[135] N. Wang, M. Wang, Y. Wang, D. Zheng, H. Han, M.S.G. Ahlquist and L. Sun, J. Am. Chem. Soc., 135 (2013) 13688.

[136] J.A. Wright and C.J. Pickett, Chemcatchem, 4 (2012) 1723.

[137] C.H. Lai, J.H. Reibenspies and M.Y. Darensbourg, Angew. Chem. Int. Ed., 35 (1996) 2390.

[138] Z.L. Li, Y. Ohki and K. Tatsumi, J. Am. Chem. Soc., 127 (2005) 8950.

[139] T. Naota, H. Takaya and S.I. Murahashi, Chem. Rev., 98 (1998) 2599.

[140] J.A.W. Verhagen, D.D. Ellis, M. Lutz, A.L. Spek and E. Bouwman, Dalton Trans., (2002)

1275.

[141] S. Canaguier, L. Vaccaro, V. Artero, R. Ostermann, J. Pécaut, M.J. Field and M. Fontecave, Chem. Eur. J., 15 (2009) 9350.

[142] Y. Oudart, V. Artero, J. Pécaut and M. Fontecave, Inorg. Chem., 45 (2006) 4334.

[143] Y. Oudart, V. Artero, J. Pécaut, C. Lebrun and M. Fontecave, Eur. J. Inorg. Chem., (2007) 2613.

[144] Y. Oudart, V. Artero, L. Norel, C. Train, J. Pécaut and M. Fontecave, J. Organomet. Chem., 694 (2009) 2866.

[145] S. Canaguier, M. Fontecave and V. Artero, Eur. J. Inorg. Chem., (2011) 1094.

[146] T. Matsumoto, B. Kure and S. Ogo, Chem. Lett., 37 (2008) 970.

[147] S. Ogo, R. Kabe, K. Uehara, B. Kure, T. Nishimura, S.C. Menon, R. Harada, S. Fukuzumi, Y. Higuchi, T. Ohhara, T. Tamada and R. Kuroki, Science, 316 (2007) 585.

[148] L. Vaccaro, V. Artero, S. Canaguier, M. Fontecave and M.J. Field, Dalton Trans., 39 (2010) 3043 .

[149] S. Canaguier, V. Fourmond, C.U. Perotto, J. Fize, J. Pecaut, M. Fontecave, M.J. Field and V. Artero, Chem. Commun., 49 (2013) 5004.

[150] B.E. Barton, C.M. Whaley, T.B. Rauchfuss and D.L. Gray, J. Am. Chem. Soc., 131 (2009) 6942.

[151] B.E. Barton and T.B. Rauchfuss, J. Am. Chem. Soc., 132 (2010) 14877.

[152] S. Canaguier, M. Field, Y. Oudart, J. Pecaut, M. Fontecave and V. Artero, Chem. Commun., $46(2010) 5876$.

[153] K. Weber, T. Krämer, H.S. Shafaat, T. Weyhermüller, E. Bill, M. van Gastel, F. Neese and W. Lubitz, J. Am. Chem. Soc., 134 (2012) 20745.

[154] W.F. Zhu, A.C. Marr, Q. Wang, F. Neese, D.J.E. Spencer, A.J. Blake, P.A. Cooke, C. Wilson and M. Schroder, Proc. Natl. Acad. Sci. USA, 102 (2005) 18280.

[155] V. Fourmond, S. Canaguier, B. Golly, M.J. Field, M. Fontecave and V. Artero, Energy Environ. Sci., 4 (2011) 2417.

[156] V. Fourmond, P.A. Jacques, M. Fontecave and V. Artero, Inorg. Chem., 49 (2010) 10338.

[157] L.-C. Song, J.-P. Li, Z.-J. Xie and H.-B. Song, Inorg. Chem., 52 (2013) 11618.

[158] S. Ogo, K. Ichikawa, T. Kishima, T. Matsumoto, H. Nakai, K. Kusaka and T. Ohhara, Science, 339 (2013) 682.

[159] F.A. Armstrong and J. Hirst, Proc. Natl. Acad. Sci. USA, 108 (2011) 14049.

[160] A.D. Wilson, R.H. Newell, M.J. McNevin, J.T. Muckerman, M.R. DuBois and D.L. DuBois, J. Am. Chem. Soc., 128 (2006) 358. 
[161] S.E. Smith, J.Y. Yang, D.L. DuBois and R.M. Bullock, Angew. Chem. Int. Ed., 51 (2012) 3152. [162] A. Le Goff, V. Artero, B. Jousselme, P.D. Tran, N. Guillet, R. Metaye, A. Fihri, S. Palacin and M. Fontecave, Science, 326 (2009) 1384.

[163] M.R. DuBois and D.L. DuBois, Chem. Soc. Rev., 38 (2009) 62.

[164] T. Liu, D.L. DuBois and R.M. Bullock, Nat Chem, 5 (2013) 228.

[165] V. Fourmond, S. Canaguier, B. Golly, M.J. Field, M. Fontecave and V. Artero, Energy Environ. Sci., 4 (2011) 2417.

[166] B.C. Manor and T.B. Rauchfuss, J. Am. Chem. Soc., 135, (2013) 11895.

[167] X.F. Wang, Z.M. Li, X.R. Zeng, Q.Y. Luo, D.J. Evans, C.J. Pickett and X.M. Liu, Chem.

Commun., (2008) 3555.

[168] B.V. Obrist, D.F. Chen, A. Ahrens, V. Schunemann, R. Scopelliti and X.L. Hu, Inorg. Chem., 48 (2009) 3514.

[169] D.F. Chen, A. Ahrens-Botzong, V. Schuemann, R. Scopelliti and X.L. Hu, Inorg. Chem., 50 (2011) 5249.

[170] M. Salomone-Stagni, F. Stellato, C.M. Whaley, S. Vogt, S. Morante, S. Shima, T.B. Rauchfuss and W. Meyer-Klaucke, Dalton Trans., 39 (2010) 3057.

[171] W.F. Liaw, N.H. Lee, C.H. Chen, C.M. Lee, G.H. Lee and S.M. Peng, J. Am. Chem. Soc., 122 (2000) 488.

[172] T.B. Liu, B. Li, C.V. Popescu, A. Bilko, L.M. Perez, M.B. Hall and M.Y. Darensbourg, Chem. Eur. J., 16 (2010) 3083.

[173] J.M. Smith, R.J. Lachicotte and P.L. Holland, Organometallics, 21 (2002) 4808.

[174] D.F. Chen, R. Scopelliti and X.L. Hu, J. Am. Chem. Soc., 132 (2010) 928.

[175] A.M. Royer, T.B. Rauchfuss and D.L. Gray, Organometallics, 28 (2009) 3618.

[176] A.M. Royer, M. Salomone-Stagni, T.B. Rauchfuss and W. Meyer-Klaucke, J. Am. Chem. Soc., 132 (2010) 16997.

[177] D.F. Chen, R. Scopelliti and X.L. Hu, Angew. Chem. Int. Ed., 49 (2010) 7512.

[178] B.W. Hu, D.F. Chen and X.L. Hu, Chem. Eur. J., 18 (2012) 11528.

[179] B.W. Hu, D.F. Chen and X.L. Hu, Chem. Eur. J., 19 (2013) 6221.

[180] D.F. Chen, R. Scopelliti and X.L. Hu, Angew. Chem. Int. Ed., 50 (2011) 5670.

[181] L.C. Song, Z.J. Xie, M.M. Wang, G.Y. Zhao and H.B. Song, Inorg. Chem., 51 (2012) 7466.

[182] P.J. Turrell, A.D. Hill, S.K. Ibrahim, J.A. Wright and C.J. Pickett, Dalton Trans., 42 (2013)

8140.

[183] P.J. Turrell, J.A. Wright, J.N.T. Peck, V.S. Oganesyan and C.J. Pickett, Angew. Chem. Int. Ed., 49 (2010) 7508.

[184] D.F. Chen, R. Scopelliti and X.L. Hu, Angew. Chem. Int. Ed., 51 (2012) 1919.

[185] L.C. Song, G.Y. Zhao, Z.J. Xie and J.W. Zhang, Organometallics, 32 (2013) 2509.

[186] P. Knorzer, A. Silakov, C.E. Foster, F.A. Armstrong, W. Lubitz and T. Happe, J. Biol. Chem., 287 (2012) 1489.

[187] P.W.J.M. Frederix, R. Kania, J.A. Wright, D.A. Lamprou, R.V. Ulijn, C.J. Pickett and N.T. Hunt, Dalton Transactions, 41 (2012) 13112.

[188] K.N. Green, S.P. Jeffery, J.H. Reibenspies and M.Y. Darensbourg, Journal of the American Chemical Society, 128 (2006) 6493.

[189] K.N. Green, J.L. Hess, C.M. Thomas and M.Y. Darensbourg, Dalton Transactions, 0 (2009) 4344.

[190] M.L. Singleton, D.J. Crouthers, R.P. Duttweiler, J.H. Reibenspies and M.Y. Darensbourg, Inorganic Chemistry, 50 (2011) 5015.

[191] M.L. Singleton, J.H. Reibenspies and M.Y. Darensbourg, Journal of the American Chemical Society, 132 (2010) 8870.

[192] X. Li, M. Wang, D. Zheng, K. Han, J. Dong and L. Sun, Energy Environ. Sci., 5 (2012) 8220.

[193] H.-Y. Wang, W.-G. Wang, G. Si, F. Wang, C.-H. Tung and L.-Z. Wu, Langmuir, 26 (2010)

9766.

[194] F. Wang, W.-G. Wang, H.-Y. Wang, G. Si, C.-H. Tung and L.-Z. Wu, ACS Catalysis, 2 (2012) 407. 
[195] F. Quentel, G. Passard and F. Gloaguen, Chemistry - A European Journal, 18 (2012) 13473.

[196] F. Quentel, G. Passard and F. Gloaguen, Energy \& Environmental Science, 5 (2012) 7757.

[197] J.-F. Capon, F. Gloaguen, P. Schollhammer and J. Talarmin, Journal of Electroanalytical Chemistry, 595 (2006) 47.

[198] J.-F. Capon, F. Gloaguen, P. Schollhammer and J. Talarmin, Journal of Electroanalytical Chemistry, 566 (2004) 241.

[199] C. Orain, F. Quentel and F. Gloaguen, ChemSusChem, (2013) n/a.

[200] T. Yu, Y. Zeng, J. Chen, Y.-Y. Li, G. Yang and Y. Li, Angewandte Chemie International Edition, 52 (2013) 5631.

[201] F. Wang, W.-G. Wang, X.-J. Wang, H.-Y. Wang, C.-H. Tung and L.-Z. Wu, Angew. Chem. Int. Ed., 50 (2011) 3193.

[202] F. Wang, W.-J. Liang, J.-X. Jian, C.-B. Li, B. Chen, C.-H. Tung and L.-Z. Wu, Angew. Chem. Int. Ed., (2013) n/a.

[203] apo-HydA refers to a form the [FeFe] hydrogenase enzyme incorporating its [4Fe4S] cluster but lacking its dinuclear catalytic subunit

[204] David W. Mulder, Eric M. Shepard, Jonathan E. Meuser, N. Joshi, Paul W. King, Matthew C. Posewitz, Joan B. Broderick and John W. Peters, Structure (London, England : 1993), 19 (2011) 1038.

[205] E.M. Shepard, S.E. McGlynn, A.L. Bueling, C.S. Grady-Smith, S.J. George, M.A. Winslow, S.P. Cramer, J.W. Peters and J.B. Broderick, Proceedings of the National Academy of Sciences, 107 (2010) 10448.

[206] D.W. Mulder, E.S. Boyd, R. Sarma, R.K. Lange, J.A. Endrizzi, J.B. Broderick and J.W. Peters, Nature, 465 (2010) 248.

[207] S.E. McGlynn, E.M. Shepard, M.A. Winslow, A.V. Naumov, K.S. Duschene, M.C. Posewitz, W.E. Broderick, J.B. Broderick and J.W. Peters, FEBS Letters, 582 (2008) 2183.

[208] X. Brazzolotto, J.K. Rubach, J. Gaillard, S. Gambarelli, M. Atta and M. Fontecave, Journal of Biological Chemistry, 281 (2006) 769.

[209] D. Schilter and T.B. Rauchfuss, Angew. Chem. Int. Ed., (2013) n/a.

[210] U.-P. Apfel and W. Weigand, ChemBioChem, (2013) n/a.

[211] J. Steinreiber and T.R. Ward, Coordination Chemistry Reviews, 252 (2008) 751.

[212] Y. Lu, N. Yeung, N. Sieracki and N.M. Marshall, Nature, 460 (2009) 855.

[213] F. Rosati and G. Roelfes, ChemCatChem, 2 (2010) 916.

[214] A. Jain, S. Lense, J.C. Linehan, S. Raugei, H. Cho, D.L. DuBois and W.J. Shaw, Inorg. Chem., 50 (2011) 4073.

[215] A. Jain, M.L. Reback, M.L. Lindstrom, C.E. Thogerson, M.L. Helm, A.M. Appel and W.J. Shaw, Inorg. Chem., 51 (2012) 6592.

[216] M.L. Reback, B. Ginovska-Pangovska, M.H. Ho, A. Jain, T.C. Squier, S. Raugei, J.A.S. Roberts and W.J. Shaw, Chem. Eur. J., 19 (2013) 1928.

[217] A. Dutta, S. Lense, J. Hou, M.H. Engelhard, J.A.S. Roberts and W.J. Shaw, J. Am. Chem. Soc., 135 (2013) 18490.

[218] A. Dutta, G.A. Hamilton, H.E. Hartnett and A.K. Jones, Inorganic Chemistry, 51 (2012) 9580.

[219] A.K. Jones, B.R. Lichtenstein, A. Dutta, G. Gordon and P.L. Dutton, Journal of the American Chemical Society, 129 (2007) 14844.

[220] S. Roy, S. Shinde, G.A. Hamilton, H.E. Hartnett and A.K. Jones, European Journal of Inorganic Chemistry, 2011 (2011) 1050.

[221] A. Roy, C. Madden and G. Ghirlanda, Chemical Communications, 48 (2012) 9816.

[222] Y. Sano, A. Onoda and T. Hayashi, Chemical Communications, 47 (2011) 8229.

[223] Y. Sano, A. Onoda and T. Hayashi, Journal of Inorganic Biochemistry, 108 (2012) 159. 
